\title{
Calcium Handling Defects and Cardiac Arrhythmia Syndromes
}

\author{
Kornél Kistamás ${ }^{1,2 *}$, Roland Veress ${ }^{1}$, Balázs Horváth ${ }^{1}$, Tamás Bányász ${ }^{1}$, \\ Péter P. Nánási ${ }^{1,3}$ and David A. Eisner ${ }^{2}$
}

1 Department of Physiology, Faculty of Medicine, University of Debrecen, Debrecen, Hungary, ${ }^{2}$ Division of Cardiovascular Sciences, School of Medical Sciences, University of Manchester, Manchester, United Kingdom, ${ }^{3}$ Department of Dental Physiology, Faculty of Dentistry, University of Debrecen, Debrecen, Hungary

OPEN ACCESS

Edited by:

Ebru Arioglu Inan,

Ankara University, Turkey

Reviewed by:

Sung Joon Kim,

Seoul National University College of

Medicine, South Korea

Murat $\mathrm{Oz}$,

Health Science Center, Kuwait

Sanda Despa,

University of Kentucky,

United States

${ }^{*}$ Correspondence:

Kornél Kistamás

kistamas.korne/@med.unideb.hu

Specialty section: This article was submitted to

Cardiovascular and

Smooth Muscle Pharmacology,

a section of the journal

Frontiers in Pharmacology

Received: 15 November 2019

Accepted: 24 January 2020

Published: 25 February 2020

Citation:

Kistamás $K$, Veress $R$, Horváth $B$, Bányász T, Nánási PP and Eisner DA (2020) Calcium Handling Defects and

Cardiac Arrhythmia Syndromes.

Front. Pharmacol. 11:72.

doi: 10.3389/fphar.2020.00072
Calcium ions $\left(\mathrm{Ca}^{2+}\right)$ play a major role in the cardiac excitation-contraction coupling. Intracellular $\mathrm{Ca}^{2+}$ concentration increases during systole and falls in diastole thereby determining cardiac contraction and relaxation. Normal cardiac function also requires perfect organization of the ion currents at the cellular level to drive action potentials and to maintain action potential propagation and electrical homogeneity at the tissue level. Any imbalance in $\mathrm{Ca}^{2+}$ homeostasis of a cardiac myocyte can lead to electrical disturbances. This review aims to discuss cardiac physiology and pathophysiology from the elementary membrane processes that can cause the electrical instability of the ventricular myocytes through intracellular $\mathrm{Ca}^{2+}$ handling maladies to inherited and acquired arrhythmias. Finally, the paper will discuss the current therapeutic approaches targeting cardiac arrhythmias.

Keywords: calcium signalling, cardiac arrhythmias, catecholaminergic polymorphic ventricular tachycardia, long QT syndrome, atrial fibrillation, reentry, early afterdepolarization, delayed afterdepolarization

\section{INTRODUCTION}

Excitation-contraction coupling (E-C coupling) of the cardiac myocytes is a well studied phenomenon. We know that the calcium ion $\left(\mathrm{Ca}^{2+}\right)$ plays a major role in controlling contraction and force, a feature that was originally described by Sidney Ringer more than a century ago (Ringer, 1883). Since this discovery, it has become clear that changes in intracellular $\mathrm{Ca}^{2+}$ concentration $\left(\left[\mathrm{Ca}^{2+}\right]_{\mathrm{i}}\right)$ have a significant role in virtually all parts of the human body. Of particular importance is the fact, that within cardiac myocytes, $\left[\mathrm{Ca}^{2+}\right]_{\mathrm{i}}$ changes must be tightly regulated, so that the heart can beat rhythmically. This means that during the cardiac systole, $\left[\mathrm{Ca}^{2+}\right]_{\mathrm{i}}$ has to increase to certain levels to make contraction occur and must fall

Abbreviations: AF, atrial fibrillation; AP, action potential; APD, action potential duration; AV, atrioventricular; BrS, Brugada syndrome; CaM, calmodulin; CaMKII, $\mathrm{Ca}^{2+} /$ calmodulin-dependent protein kinase II; CICR, $\mathrm{Ca}^{2+}$-induced $\mathrm{Ca}^{2+}$ release; CPVT, catecholaminergic polymorphic ventricular tachycardia; CSQ2, calsequestrin 2; DAD, delayed afterdepolarization; EAD, early afterdepolarization; EC, excitation-contraction coupling; ERS, early repolarization syndrome; HF, heart failure; ICD, implantable cardiac defibrillator; IVF, idiopathic ventricular fibrillation; LQTS, long QT syndrome; NCX, sodiumcalcium exchange; NFAT, nuclear factor of activated T-cells; PKA, protein kinase A; PLN, phospholamban; PMCA, plasma membrane $\mathrm{Ca}^{2+}$-ATPase; PVC, premature ventricular contraction; RSV, relative short term beat-to-beat variability of action potential duration; RyR, ryanodine receptor; SA, sinoatrial; SERCA, sarco/endoplasmic reticulum $\mathrm{Ca}^{2+}$-ATPase; SOCE, store overload-induced $\mathrm{Ca}^{2+}$ entry; SOICR, store overload-induced $\mathrm{Ca}^{2+}$ release; SQTS, short QT syndrome; SR, sarcoplasmic reticulum; SV, short term beat-to-beat variability of action potential duration; VF, ventricular fibrillation; VT, ventricular tachycardia. 
in diastole, allowing the muscle to relax and prepare for the next cardiac cycle. E-C coupling has been reviewed in detail (Bers, 2002; Eisner et al., 2017), here we consider the elementary steps and the events that can lead to electrical disturbances (Figure 1).

The normal cardiac action potential (AP) originates in the sinoatrial node and propagates through the heart. In the ventricle the initial depolarization opens voltage-gated sodium channels leading to further depolarization which, in turn, opens the L-type $\mathrm{Ca}^{2+}$ channels, causing a large $\mathrm{Ca}^{2+}$ influx (Figure 1A). Some $\mathrm{Ca}^{2+}$ can also enter via T-type $\mathrm{Ca}^{2+}$ channels and reverse mode $\mathrm{Na}^{+} / \mathrm{Ca}^{2+}$ exchange (NCX) (Kohomoto et al., 1994; Sipido et al., 1997). This $\mathrm{Ca}^{2+}$ entry triggers a process known as calcium-induced calcium release (CICR), in which $\mathrm{Ca}^{2+}$ is released from the sarcoplasmic reticulum (SR) into the cytoplasm via ryanodine receptors (RyR), allowing $\mathrm{Ca}^{2+}$ to bind to the myofilament protein troponin $\mathrm{C}$, activating the contractile machinery. Normal cardiac function also requires relaxation to occur; this results from a decrease of free cytoplasmic $\mathrm{Ca}^{2+}$ levels. Several $\mathrm{Ca}^{2+}$ transport pathways are involved in this process, as $\mathrm{Ca}^{2+}$ reuptake into the SR by the $\mathrm{SR} \mathrm{Ca}^{2+}$-ATPase (SERCA), $\mathrm{Ca}^{2+}$ extrusion by the sarcolemmal NCX and plasma membrane $\mathrm{Ca}^{2+}$-ATPase (PMCA) (Figure 1B) (Bers, 2000). This normal cardiac function requires perfect coordination of the ion currents and intracellular processes, as any imbalance in $\mathrm{Ca}^{2+}$ homeostasis of a cardiac myocyte can lead to electrical disturbances (from cellular AP prolongation to complex arrhythmic storms) (Eisner et al., 2017; Eisner, 2018).

Here we review the role of $\mathrm{Ca}^{2+}$ in generating and maintaining cardiac arrhythmias from basic arrhythmia mechanisms to recent progresses in pharmacological challenges and possible future therapies.

\section{CALCIUM IN PATHOPHYSIOLOGY, ARRHYTHMIA MECHANISMS}

Arrhythmia mechanisms have multiscale dynamics in the heart. The lower end is the molecular scale, originating from the stochastic behavior of ion channels, resulting from thermodynamic fluctuations (Qu and Weiss, 2015). Next is the cellular scale, with differences in the shape of the APs originating from distant parts of the myocardium (Figure 2A). Under some diseased conditions, several mechanisms can lead to electrical disturbances at the cellular level, including early or delayed afterdepolarizations (EAD or DAD, respectively) (Figures $\mathbf{3 A - D}$ ). Whole-cell $\mathrm{Ca}^{2+}$ oscillations, developing into propagating $\mathrm{Ca}^{2+}$ waves arise when the molecular and cellular dynamics merge at the tissue and organ level. The lower and higher scales tend to have a bidirectional information flow. A good example is when EADs arising during an AP due to abnormal ion currents and $\mathrm{Ca}^{2+}$ dynamics, can bring an extra amount of $\mathrm{Ca}^{2+}$ into the cell due to $\mathrm{L}$-type $\mathrm{Ca}^{2+}$ channel reopening and potentiate $\mathrm{Ca}^{2+}$ waves. These multiscale dynamics can lead to life threatening complex arrhythmias.

Normal cardiac automaticity originates in the sinoatrial (SA) node. If SA node impulse generation is impaired, atrioventricular node (AV node) and Purkinje fibers can show automatic activity. These secondary pacemakers are also called latent or subsidiary pacemakers (Antzelevitch and Burashnikov, 2011). SA node pacemaker activity depends on interactions of membrane potential and $\left[\mathrm{Ca}^{2+}\right]_{\mathrm{i}}$. This "coupled-clock" pacemaker system

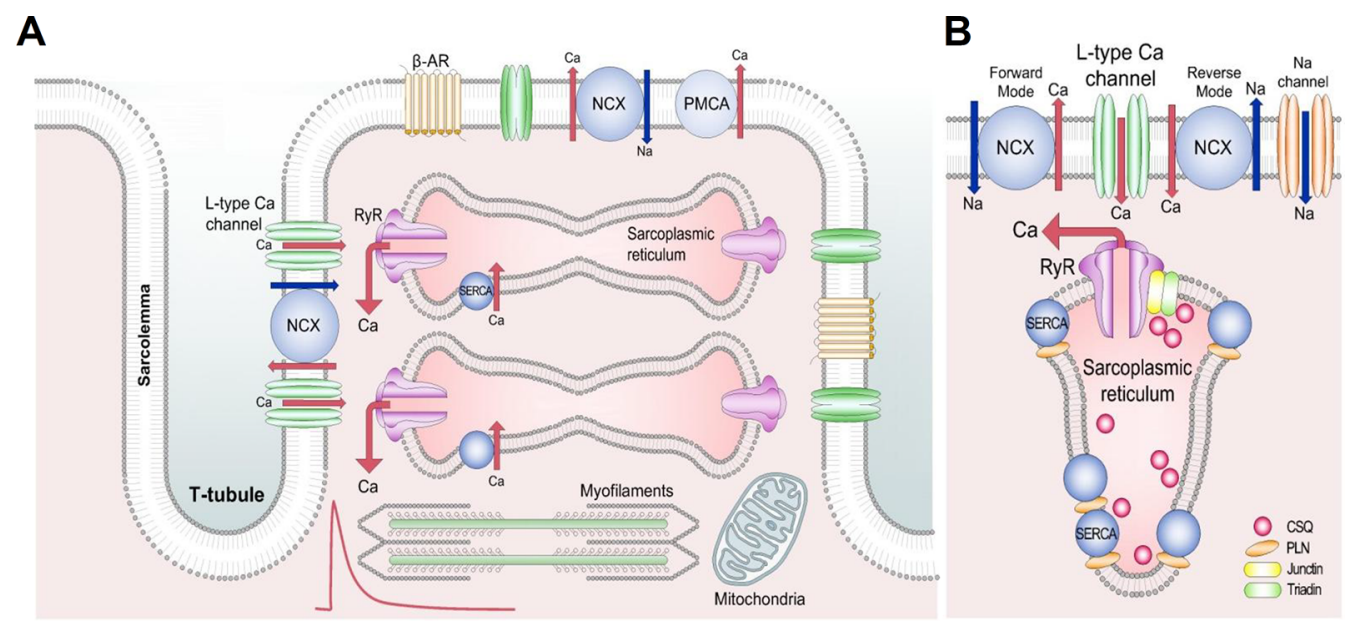

FIGURE 1 | Schematic diagram of the cardiac excitation-contraction coupling. (A) Structures involved in Ca ${ }^{2+}$ transport in cardiac mycocytes. Red trace shows a typical systolic $\mathrm{Ca}^{2+}$ transient. Briefly, during the $\mathrm{Ca}^{2+}$-induced $\mathrm{Ca}^{2+}$ release process, $\mathrm{Ca}^{2+}$ entering the cell via $\mathrm{L}$-type $\mathrm{Ca}{ }^{2+}$ channels releases a larger amount of $\mathrm{Ca}^{2+}$ from the sarcoplasmic reticulum to activate the contractile machinery. Ca ${ }^{2+}$ extrusion requires NCX, PMCA, and SERCA. (B) Detailed section of the dyad showing the major proteins involved in $\mathrm{Ca}^{2+}$ cycling. Reproduced from Eisner et al. used with permission (Eisner et al., 2017). $\beta$-AR, $\beta$ adrenoceptor; NCX, Na ${ }^{+}-\mathrm{Ca}{ }^{2+}$ exchange; PMCA, plasma membrane $\mathrm{Ca}^{2+}$-ATPase; RyR, ryanodine receptor; SERCA, sarco/endoplasmic reticulum Ca ${ }^{2+}-\mathrm{ATPase}$; CSQ, calsequestrin; PLN, phospholamban. 


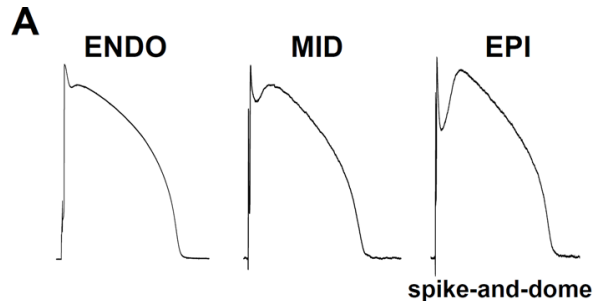

B

\section{Ventricular action potentials}

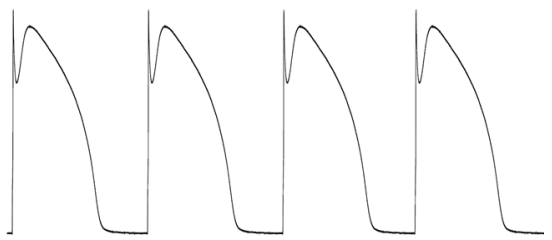

FIGURE 2 | Cellular physiological electrical activities. (A) Transmural heterogeneity in the cardiac ventricular action potential, showing (from left to right) recordings from: subendocardium, midmyocardium, and subepicardium. Note the spike-and-dome action potential configuration in the subepicardium. ENDO, subendocardial mycocyte; MID, midmyocardial "M" myocyte; EPI, subepicardial myocyte. (B) Series of typical subepicardial ventricular action potentials at normal pacing activity. is produced by membrane proteins, driving the $\mathrm{AP}$ and the intracellular $\mathrm{Ca}^{2+}$ cycling molecules (Figure 4) (Maltsev et al., 2006; Lakatta, 2010; Joung et al., 2011).

The "membrane clock" implies sarcolemmal proteins, continuously driving the membrane potential to more positive or more negative values. The most important and well-known participant is the hyperpolarization-activated funny current $\left(\mathrm{I}_{\mathrm{f}}\right)$, working mainly during early diastolic depolarization. The consequent depolarization opens $\mathrm{Ca}^{2+}$ channels $\left(\mathrm{I}_{\mathrm{Ca}, \mathrm{T}}\right.$ and $\mathrm{I}_{\mathrm{Ca}, \mathrm{L}}$ ) and the pacemaker (slow type) action potential occurs. As in the case of the working myocardium, $\mathrm{K}^{+}$currents repolarize the membrane. In the last two decades it has become clear that spontaneous $\mathrm{Ca}^{2+}$ release in a cardiac cell is not always pathological. In the "calcium clock" mechanism, spontaneous SR $\mathrm{Ca}^{2+}$ release events, the $\mathrm{Ca}^{2+}$ sparks activate $\mathrm{I}_{\mathrm{NCX}}$ and cause late diastolic membrane depolarization. Coupled clock pacemaker system comprises functional interactions between the membrane and calcium clock (Figure 4) (Vinogradova et al., 2006; Lakatta and DiFrancesco, 2009; Lakatta et al., 2010).

For physiological contraction and relaxation, not only pacemaker automaticity, but also the impulse conduction system needs to work properly. Spontaneous depolarization from the SA node propagates and depolarizes the distant parts of the cardiac muscle (Figure 2B), via the SA node, AV node, Bundle of His, Bundle branches, and Purkinje fibers pathway.

A

Phase 2 EAD $B$ Phase 3 EAD

C
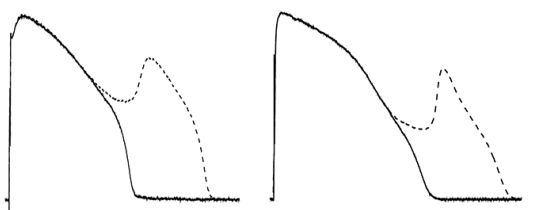

Late-phase 3 EAD

D

DAD

E

Automaticity
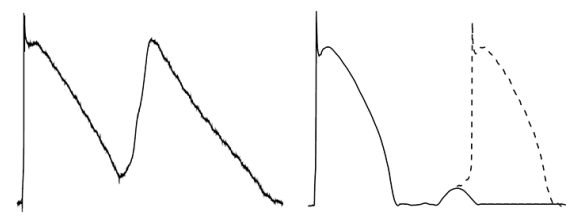

$\mathbf{F}$

Alternans
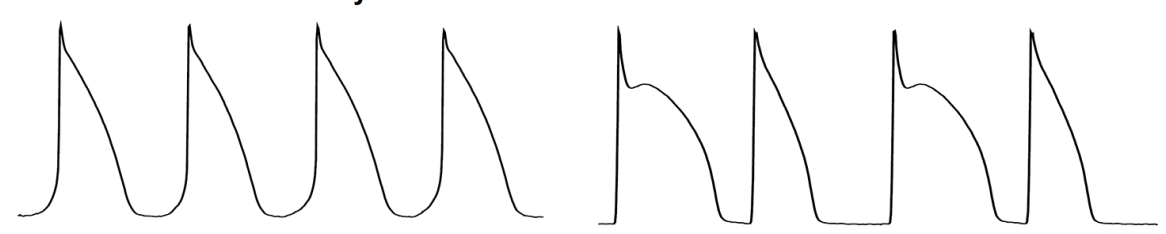

G

Beat-to-beat variability
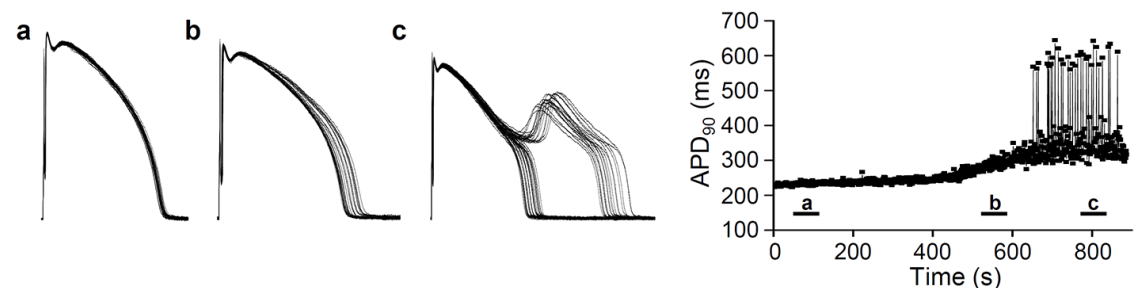

FIGURE 3 | Cellular pathophysiological electrical activities. (A) Phase 2 early afterdepolarization (EAD), (B) Phase 3 EAD, (C) Late-phase 3 EAD, (D) Delayed afterdepolarization (DAD) manifesting triggered activity. $\mathrm{Ca}^{2+}$ has an important role in generating afterdepolarizations. Underlying mechanisms are described in the relevant sections. (E) Automaticity (spontaneous membrane potential oscillations) occurs if the membrane potential of the cells shift to more positive values causing abnormal activity. (F) Cardiac voltage alternans, manifesting a long-short-long-short pattern. (G) Short term beat-to-beat variability of the action potential duration. (a), (b), and (c) show different time points after interventions that increase action potential duration and beat-to-beat variability leading to EAD generation. Right panel of (G) shows action potential duration at $90 \%$ of the repolarization (APD 90 ) as a function of time. 


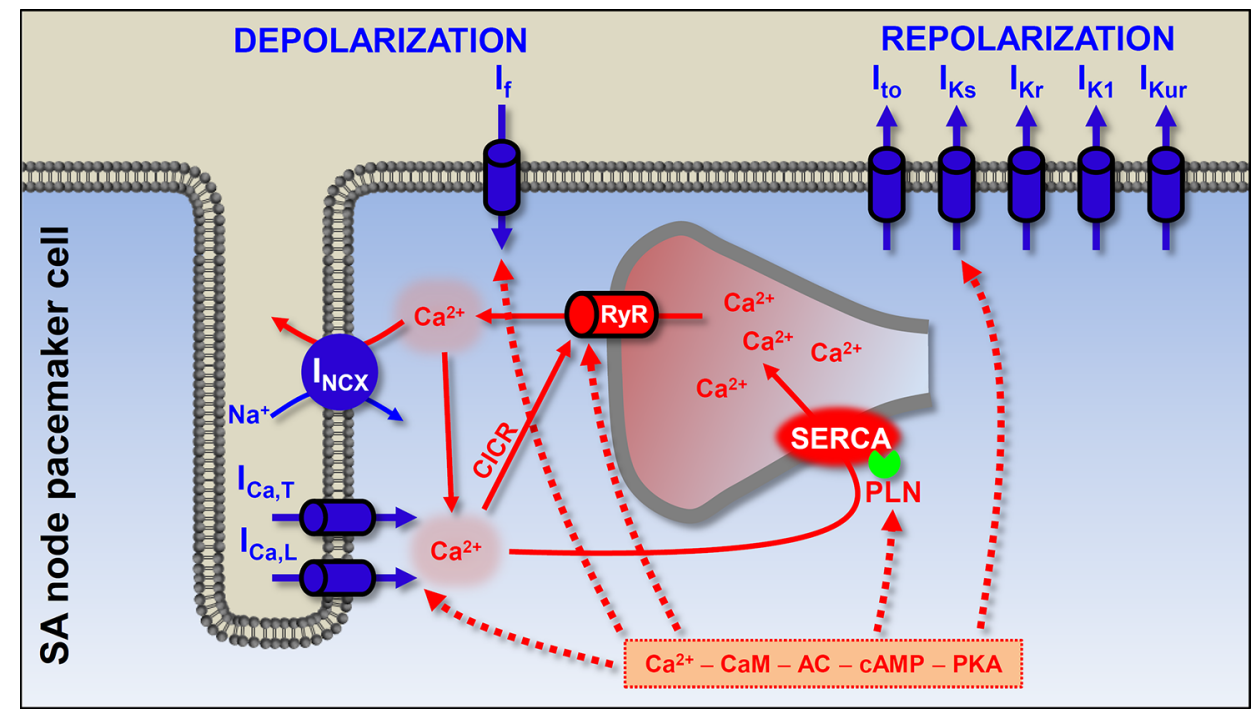

FIGURE 4 | The origin of the heartbeat: coupled-clock pacemaker system in the sinoatrial cells. The pacemaker activity of the SA node originates from the membrane and calcium clock mechanisms. The former is composed of the sarcolemmal channel proteins, and the latter results from sarcoplasmic reticulum and sarcoplasmic $\mathrm{Ca}^{2+}$ turnover. At end of the SA action potential the hyperpolarization-activated $\mathrm{I}_{\mathrm{f}}$ depolarizes the membrane to a level where $\mathrm{Ca}^{2+}$ channels open. In addition, during late diastole, spontaneous SR $\mathrm{Ca}^{2+}$ releases further depolarize the membrane by activating $\mathrm{I}_{\mathrm{NCX}}$. $\mathrm{Ca}^{2+}$ can bind to calmodulin and activate adenylyl cyclase (AC). High constitutive activation of $\mathrm{AC}$ leading to high basal level of CAMP (which is needed for protein kinase A-dependent phosphorylation) in SA node cells has been suggested to contribute to the Ca ${ }^{2+}$ overload state. PKAdependent phosphorylation of phospholamban, $\mathrm{I}_{\mathrm{Ca}, \mathrm{L}}$, and RyR promotes spontaneous $\mathrm{Ca}^{2+}$ release. Blue shows the membrane clock and red shows the calcium clock mechanism. Solid arrows show the $\mathrm{Ca}^{2+}$-induced $\mathrm{Ca}^{2+}$ release process and spontaneous $\mathrm{Ca}^{2+}$ release events via RyR; dashed arrows show the phosphorylation targets of the CAMP-PKA pathway. $I_{\mathrm{Ca}, \mathrm{L}}, \mathrm{L}$-type $\mathrm{Ca}^{2+}$ current; $\mathrm{I}_{\mathrm{Ca}, \mathrm{T}}, \mathrm{T}$-type $\mathrm{Ca}^{2+}$ current; $\mathrm{I}_{\mathrm{NCX}}, \mathrm{Na}^{+}-\mathrm{Ca}^{2+}$ exchange; $\mathrm{I}_{\mathrm{f}}$, funny current; $\mathrm{I}_{\mathrm{to}}$, transient outward $\mathrm{K}^{+}$current; $\mathrm{I}_{\mathrm{Ks}}$, slow component of delayed rectifier $\mathrm{K}^{+}$current; $\mathrm{I}_{\mathrm{K} \text { r, }}$, rapid component of delayed rectifier $\mathrm{K}^{+}$current; $\mathrm{I}_{\mathrm{K} 1}$, inward rectifier $\mathrm{K}^{+}$current; $\mathrm{I}_{\mathrm{Kur}}$, ultra rapid component of delayed rectifier $\mathrm{K}^{+}$current; RyR, yyanodine receptor; SERCA, sarcoplasmic reticulum $\mathrm{Ca}^{2+}$-ATPase; PLN, phospholamban; CaM, calmodulin; AC, adenylyl cyclase; PKA, protein kinase A; CICR, Ca ${ }^{2+}$-induced $\mathrm{Ca}^{2+}$ release; SA, sinoatrial.

Cardiac arrhythmia mechanisms can be divided into two main categories: abnormal impulse formation and abnormal impulse conduction. In general, these arrhythmic events occur when the electrical activity of the heart is slower or faster than normal and/or becomes irregular.

\section{Abnormal Impulse Generation}

Focal activity (enhanced or abnormal impulse generation) is an important arrhythmogenic mechanism and consists of abnormal automaticity and triggered activity.

\section{Automaticity}

In the normal human heart, the SA node generates the propagating APs and determine the heart rate. In the case of parasystole, when the primary pacemaker is bordered by ischemic, infarcted regions the impulse cannot leave the SA node. Under these conditions, parasystolic pacemakers can take over pacemaker activity and fire APs at a lower rate compared to that of the SA node (Gussak et al., 2003). The AV node produces a junctional rhythm of 40 to $60 \mathrm{bpm}$ and Purkinje fibers of about 20 to $40 \mathrm{bpm}$ (Tse, 2016). In diseased hearts (e.g. heart failure, HF) membrane potential of pacemaker cells can shift to more positive values and this depolarization causes abnormal automaticity. Enhanced activity (i.e. tachycardia) increases rate of AP discharge by three mechanisms: threshold potential shifts to more negative, maximum diastolic potential shifts to more positive, and the rate of phase 4 depolarization increases (Figure 3E) (Jalife et al., 2009).

\section{Early Afterdepolarization}

Aside from the abnormal automaticity, the most common causes of focal activity are the early and delayed afterdepolarizations (EAD and DAD, respectively). EADs occur before the terminal repolarization (phase 2 and phase 3 repolarization) of the AP, while DADs occur after the repolarization when membrane potential reaches the resting levels (Figure 5).

EADs usually occur when repolarization reserve is compromised, i.e. reduced outward currents $\left(\mathrm{I}_{\mathrm{K} 1}, \mathrm{I}_{\mathrm{Kr}}, \mathrm{I}_{\mathrm{Ks}}\right)$ and/or increased inward currents $\left(\mathrm{I}_{\mathrm{Na}}\right.$, window $\mathrm{I}_{\mathrm{Ca}, \mathrm{L}}, \mathrm{I}_{\mathrm{NCX}}$ ) (Damiano and Rosen, 1984; Sipido et al., 2007; Benitah et al., 2010; Horvath et al., 2015; Karagueuzian et al., 2017), that is, there is a change in the net membrane current during the plateau (Figure 5A). In most of the cases these conditions cause prolongation of the $\mathrm{AP}$, allowing $\mathrm{I}_{\mathrm{Ca}, \mathrm{L}}$ to recover from inactivation (Chiamvimonvat et al., 2017) and as a positive feedback loop, triggering an AP (January and Riddle, 1989) (Figure 3A). Alternatively, at membrane potentials negative to the activation threshold for $\mathrm{I}_{\mathrm{Ca}, \mathrm{L}}$, spontaneous $\mathrm{Ca}^{2+}$ release from the SR can activate $\mathrm{I}_{\mathrm{NCX}}$, driving a depolarizing current by reactivating $\mathrm{I}_{\mathrm{Na}}$ (Figure 3B) (Szabo et al., 1994). In addition, although EADs usually 

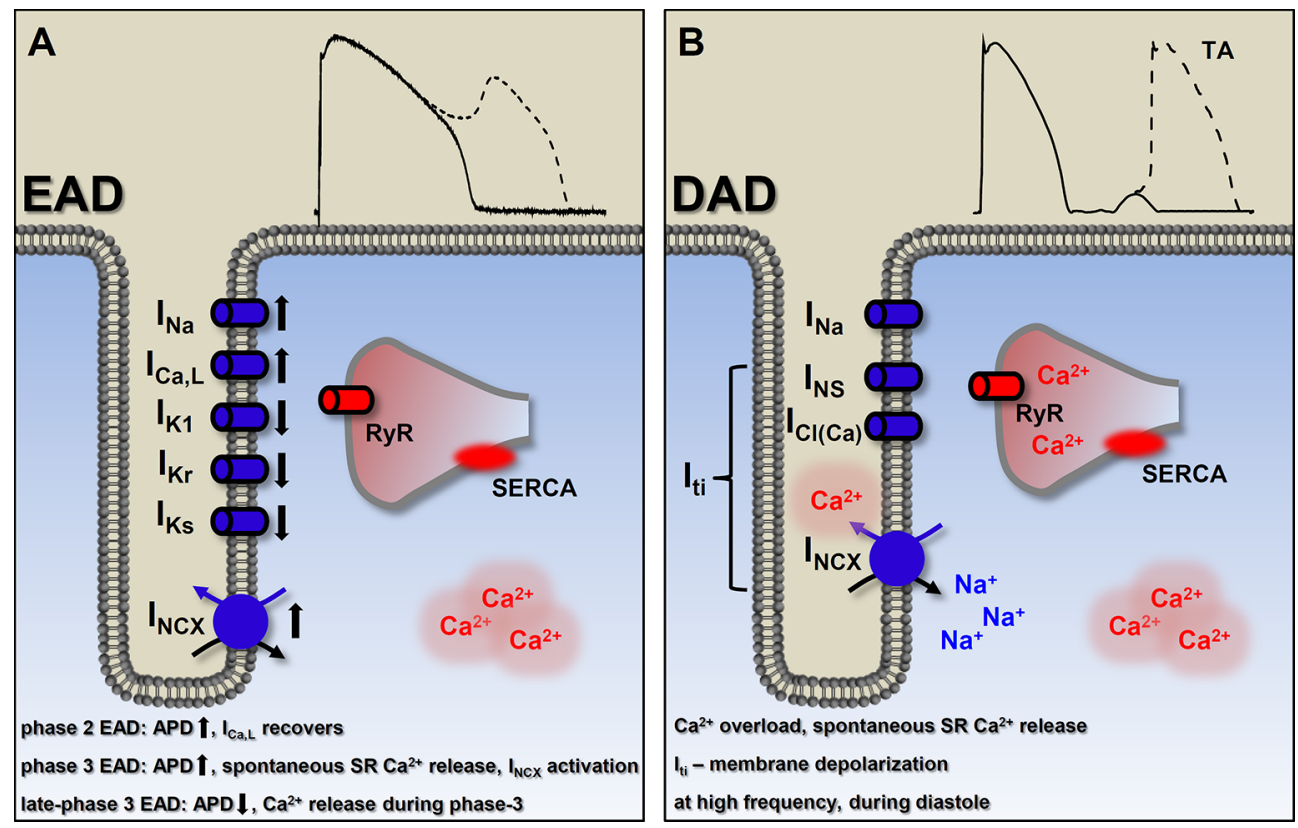

FIGURE 5 | Basic mechanisms of ectopic activity. (A) Factors involved in the generation of early afterdepolarizations (EAD). In general, EADs occur when outward currents are reduced (reduced repolarization reserve) and/or the inward currents are enhanced. The currently known types of EADs are consequencies of different etiologies, indicated on (A). Detailed description in the text. Membrane potential recording shows a typical phase 2 EAD. (B) Delayed afterdepolarizations (DAD) originate from $\mathrm{Ca}^{2+}$ overload and consequently, spontaneous $\mathrm{SR} \mathrm{Ca}^{2+}$ release which, in turn, generates a depolarizing transient inward $\left(\mathrm{I}_{\mathrm{t} i}\right)$ current. Suprathreshold depolarization can elicit triggered activity. Membrane potential recording shows a typical DAD. EAD, early afterdepolarization; DAD, delayed afterdepolarization; Ica,L, L-type $\mathrm{Ca}^{2+}$ current; $I_{\mathrm{Na}}, \mathrm{Na}^{+}$current; $\mathrm{I}_{\mathrm{Ks}}$, slow component of delayed rectifier $\mathrm{K}^{+}$current; $\mathrm{I}_{\mathrm{K}}$, rapid component of delayed rectifier $\mathrm{K}^{+}$current; $\mathrm{I}_{\mathrm{K} 1}$, inward rectifier $\mathrm{K}^{+}$ current; $I_{\mathrm{NCX}}, \mathrm{Na}^{+}-\mathrm{Ca}^{2+}$ exchange; $I_{\mathrm{NS}}$, nonselective $\mathrm{Ca}^{2+}$-sensitive cationic currents; $I_{\mathrm{CI}(\mathrm{Ca})}, \mathrm{Ca}^{2+}$-activated chloride current; $\mathrm{l}_{\mathrm{t}}$, transient outward current; RyR, ryanodine receptor; SR, sarcoplasmic reticulum; SERCA, sarcoplasmic reticulum $\mathrm{Ca}^{2+}$-ATPase; TA, triggered activity.

occur when the AP duration (APD) is prolonged, some data suggests a novel mechanism, where even shortening of APD can be responsible for generation of EADs (late-phase 3 EAD) (Burashnikov and Antzelevitch, 2003). Late-phase 3 EADs occur particularly under elevated intracellular $\mathrm{Ca}^{2+}$ loading (i.e. large $\mathrm{Ca}^{2+}$ transient) and are considered as a hybrid between EAD and DAD (Figure 3C). At normal APD and at membrane potentials negative to the equilibrium of the $\mathrm{I}_{\mathrm{NCX}}$ (and $\mathrm{I}_{\mathrm{Cl}(\mathrm{Ca})}$ ), these $\mathrm{Ca}^{2+}$-mediated currents are weakly inward. However, if APD is abbreviated, they become strongly inward, allowing an $\mathrm{I}_{\mathrm{NCX}}$-driven depolarizing current, when the shorter repolarization allows a stronger (and not spontaneous) $\mathrm{Ca}^{2+}$ release from the SR (Burashnikov and Antzelevitch, 2006). The EAD generated under these circumstances interrupts the final phase of the AP. A key difference compared to the previously described EADs (and DADs) is a non-spontaneous $\mathrm{Ca}^{2+}$ release in generating late-phase 3 EADs (Figure 5). Late-phase $3 \mathrm{EAD}$ also has clinical relevance, as its appearance is immediately following termination of other tachyarrhythmias, such as atrial flutter and fibrillation or ventricular tachycardia and fibrillation (Burashnikov and Antzelevitch, 2006).

The contribution of spontaneous SR $\mathrm{Ca}^{2+}$ release and an inward $\mathrm{I}_{\mathrm{NCX}}$ to the generation of EADs has been described (Priori and Corr, 1990; Volders et al., 1997), furthermore, Volders et al. elegantly demonstrated in isoproterenol induced canine ventricular myocytes that early $\mathrm{Ca}^{2+}$ aftertransients and their aftercontractions precede the upstroke of the subsequent EAD so that they are a primary event inducing EADs (Volders et al., 1997). The time course of the EAD generation is characterized by a conditional phase (in other words, an initial delay in repolarization, defined by net membrane current) and the EAD upstroke. In this regard, a significant role of $\mathrm{I}_{\mathrm{NCX}}$ has been suggested in the initial delay in repolarization, thus in the conditional phase (Volders et al., 2000).

In previous studies, distinct spatial features of afterdepolarizationassociated $\mathrm{Ca}^{2+}$ transients had been shown; i.e. a heterogenous pattern indicating focal, spontaneous $\mathrm{SR} \mathrm{Ca}^{2+}$ release in DADs and a homogenous pattern suggesting $\mathrm{I}_{\mathrm{Ca}, \mathrm{L}}$-induced $\mathrm{Ca}^{2+}$ release in EADs (Miura et al., 1993; Miura et al., 1995; De Ferrari et al., 1995). However, it must be noted, under certain circumstances (adrenergic stimulation mediated sudden $\left[\mathrm{Ca}^{2+}\right]_{\mathrm{i}}$ changes), $\mathrm{Ca}^{2+}$ release during an EAD is not governed by sarcolemmal $\mathrm{Ca}^{2+}$ influx, so that it is spontaneous, which resembles as a heterogenous pattern, just like in the case of DADs (Volders et al., 1997).

In our previous work, EADs were evoked by $\mathrm{I}_{\mathrm{Kr}}$ blockade (dofetilide), activation of $\mathrm{Na}+$ current $\left(\mathrm{I}_{\mathrm{Na}, \mathrm{L}}\right)$ (veratridine), and activation of $\mathrm{I}_{\mathrm{Ca}, \mathrm{L}}(\mathrm{BAY}$ K8644) at slow pacing rates. Additional application of the $\mathrm{Ca}^{2+}$ chelator BAPTA-AM decreased $\left[\mathrm{Ca}^{2+}\right]_{\mathrm{i}}$ as expected, but either reduced EAD frequency in the presence of dofetilide and veratridine or further increased EAD frequency in the presence of BAY K8644 (direct augmentation of the $\mathrm{I}_{\mathrm{Ca}, \mathrm{L}}$ 
brings extra $\mathrm{Ca}^{2+}$ inflow and is a substrate for increased EAD likelihood). Since BAPTA-AM decreased EAD frequency in the presence of veratridine, but failed to shorten APD, these results contradicts the exclusive role of APD in EAD generation and indicate that an increase in $\left[\mathrm{Ca}^{2+}\right]_{\mathrm{i}}$ is a significant factor not only for generating DADs, but for evoking EADs as well (Horvath et al., 2015). Moreover, in another set of experiments of Kistamas et al. $\mathrm{H}_{2} \mathrm{O}_{2}$ significantly increased APD and relative short term beat-tobeat variability (SV) (Kistamas et al., 2015a) and increased the occurrence of EADs on canine ventricular myocytes. Elevation of $\left[\mathrm{Ca}^{2+}\right]_{\mathrm{i}}$ in $\mathrm{H}_{2} \mathrm{O}_{2}$ was shown by others which can account for the increased SV and EAD incidence (Goldhaber, 1996; Xie et al., 2009; Szentandrassy et al., 2015; Kistamas et al., 2015). Furthermore, we also showed in guinea pig cardiomyocytes, that spontaneous $\mathrm{Ca}^{2+}$ release from the SR mediates $\left(\mathrm{I}_{\mathrm{Na}, \mathrm{L}}\right)$ induced EADs (Horvath et al., 2013). The two possible mechanisms proposed by Zaza et al. by which $\mathrm{I}_{\mathrm{Na}, \mathrm{L}}$ promotes EAD genesis are (1) the reactivation of $\mathrm{I}_{\mathrm{Ca}, \mathrm{L}}$ during the plateau phase of $\mathrm{AP}$ and (2) $\mathrm{SR} \mathrm{Ca}^{2+}$ overload (Zaza et al., 2008). In our experiments the first EAD occurred at a membrane potential more positive than the window $\mathrm{Ca}^{2+}$ current voltage range, meaning that not the reactivation of $\mathrm{I}_{\mathrm{Ca}, \mathrm{L}}$ was responsible for the generation of EADs. In fact, several mechanisms were addressed, showing the SR load was key in formation of the EADs: (a) anemone toxin II (ATX-II) facilitates $\mathrm{I}_{\mathrm{Na}, \mathrm{L}}$ that caused elevated systolic $\mathrm{Ca}^{2+}$ transient and SR load, (b) the spontaneous $\mathrm{Ca}^{2+}$ wave precedes the first EAD, and (c) $\mathrm{Ca}^{2+}$ buffering with BAPTA in the patch pipette abolished EADs (Horvath et al., 2013).

Therefore, our recent knowledge about the factors involved in the development of EADs includes changes in $\left[\mathrm{Ca}^{2+}\right]_{\mathrm{i}}$ and the amplitude of $\mathrm{Ca}^{2+}$ transient, along with the APD and beat-tobeat variability of APD, AP morphology and plateau potential, net membrane current, and the actual availability of L-type $\mathrm{Ca}^{2+}$ channels. Regardless of the type of EAD mechanisms, if the depolarizing effect of the EAD on the membrane potential is sufficient to activate $\mathrm{I}_{\mathrm{Na}}$, the result will be an abnormal impulse generation, triggered activity (Hoffman and Rosen, 1981).

EADs are more likely to develop in midmyocardial cells and Purkinje fibers than in subepi- or subendocardial cells. There is a difference in ion current composition (less $\mathrm{I}_{\mathrm{Ks}}$, more $\mathrm{I}_{\mathrm{Na}, \mathrm{L}}$ in midmyocardial cells), consequently these regions are more prone to AP prolongation (Liu and Antzelevitch, 1995; Zygmunt et al., 2001; Szabo et al., 2005). EADs are generally observed under conditions of ventricular hypertrophy and HF, injured cardiac tissue, or when the myocardium is exposed to catecholamines, hypoxia, acidosis, and pharmacologic agents (Roden, 2004; Roden, 2006). The clinical significance of EADs is clear, as they can either serve as the trigger or as the substrate for initiation and perpetuation of torsade de pointes arrhythmia (Volders et al., 2000). Being as a trigger, as EADs can cause new APs which will be reflected on the ECG as ectopic beats. EADs provide a substrate by causing electrical inhomogeneity in the surrounding tissues.

\section{Delayed Afterdepolarization}

DADs are the other common causes of focal activity and were originally described as oscillatory afterpotentials (Ferrier et al., 1973).
They occur in diastole, after complete repolarization of the cell (Figure 5B). DADs can originate from intracellular $\mathrm{Ca}^{2+}$ overload that induces spontaneous $\mathrm{SR} \mathrm{Ca}^{2+}$ release, resulting in a depolarizing current via forward mode $\mathrm{I}_{\mathrm{NCX}}$ (Mechmann and Pott, 1986). Other nonselective $\mathrm{Ca}^{2+}$-sensitive cationic currents $\left(\mathrm{I}_{\mathrm{NS}}\right)$ and chloride current $\left(\mathrm{I}_{\mathrm{Cl}(\mathrm{Ca})}\right)$ may also be involved in DAD generation (Asakura et al., 2014). These three depolarizing currents result in a transient inward current $\left(\mathrm{I}_{\mathrm{ti}}\right)$, which is responsible for the membrane depolarization (Figure 3D). $\mathrm{Ca}^{2+}$ overload of the cardiac myocytes can occur in several diseases and also in several experimental conditions, e.g. toxic levels of digitalis (Ferrier et al., 1973; Saunders et al., 1973; Rosen et al., 1973), catecholamines (Wit and Cranefield, 1977; Rozanski and Lipsius, 1985; Priori and Corr, 1990), hypokalemia and hypercalcemia (Tse, 2016), hypertrophy, HF (Aronson, 1981; Vermeulen et al., 1994), and rapid heart rates. The amplitude of the generated DAD depends on the size of the $\mathrm{Ca}^{2+}$ transient and on the properties of $\mathrm{I}_{\mathrm{NCX}}$ and the inward rectifier $\mathrm{K}^{+}$ current $\left(\mathrm{I}_{\mathrm{K} 1}\right)$ (Pogwizd et al., 2001; Sung et al., 2006; Maruyama et al., 2010). Subthreshold DADs [appearing as the U wave on the electrocardiogram (ECG)] are small voltage deflections, which although unable to trigger a propagating action potential, may still cause dispersion of excitability, thereby promoting regional conduction block (Rosen et al., 1975; Surawicz, 1998; di Bernardo and Murray, 2002). However, if DADs reach the threshold potential for the opening of $\mathrm{Na}^{+}$channels, a spontaneous AP emerges and can result in premature ventricular contraction (PVC). The clinical significance of DAD generation lies in triggered activity that contributes to arrhythmogenesis with catecholaminergic polymorphic ventricular tachycardia (CPVT), atrial fibrillation (AF), and HF. In CPVT and HF, intracellular $\mathrm{Ca}^{2+}$ load combines with RyR dysfunction ("leaky" RyR). Under circumstances when the SR becomes loaded (high $\mathrm{Ca}^{2+}$ load, fast heart rate, and/or increased adrenergic tone) and/or RyR becomes leaky, spontaneous $\mathrm{Ca}^{2+}$ release is favored.

Considering the mechanism of the spontaneous $\mathrm{Ca}^{2+}$ release, there are two main patterns. First, focal $\mathrm{Ca}^{2+}$ release, when $\mathrm{Ca}^{2+}$ signal acts locally (Lipp and Niggli, 1994) and secondly, when the released $\mathrm{Ca}^{2+}$ leaves its focus and propagates as a global $\mathrm{Ca}^{2+}$ wave through the myocyte (Takamatsu and Wier, 1990; Wier et al., 1987; Cheng et al., 1993).

Unlike the EADs, DADs are always generated at relatively rapid rates (Antzelevitch and Burashnikov, 2011). As mentioned earlier, late-phase 3 EADs are considered as a hybrid between $\mathrm{EAD}$ and DAD. A key difference is the time of the SR $\mathrm{Ca}^{2+}$ release during the AP (Figure 5). $\mathrm{Ca}^{2+}$ release occurs during diastole in the case of $\mathrm{DAD}$, while late-phase $3 \mathrm{EAD}$ is generated at the late repolarization of the AP (Fink and Noble, 2010).

\section{Beat-To-Beat Variability of Action Potential Duration}

Variations (physiological or pathological) in AP configuration can cause disturbances in $\mathrm{Ca}^{2+}$ signaling and the electrical properties of cardiac muscle. In our previous experiments, we determined the beat-to-beat variability of AP duration in isolated canine left ventricular myocytes in several experimental settings (Kistamas et al., 2015a; Kistamas et al., 2015b; Szentandrassy et al., 2015; Magyar et al., 2016), as recent studies suggest the short term beatto-beat variability (SV) of APD as a novel method for predicting 
imminent cardiac arrhythmias (Thomsen et al., 2004; Abi-Gerges et al., 2010). Higher variability is considered to be arrhythmic by increasing dispersion of refractoriness (Figure 3G). We established the concept of relative short term beat-to-beat variability of APD (RSV) by normalizing the changes of short term variability of APD to the concomitant changes in APD [see (Nanasi et al., 2017] for review). We summarized that RSV was decreased by ion currents involved in the negative feedback regulation of APD $\left(\mathrm{I}_{\mathrm{Ca}, \mathrm{L}}, \mathrm{I}_{\mathrm{Ks}}\right.$ and $\mathrm{I}_{\mathrm{Kr}}$ ), while it was increased by $\mathrm{I}_{\mathrm{Na}}$ and $\mathrm{I}_{\mathrm{to}}$, and in general, increased if repolarization reserved was compromised. RSV was also increased at faster rates and at increased $\left[\mathrm{Ca}^{2+}\right]_{\mathrm{i}}$. Transient changes of $\left[\mathrm{Ca}^{2+}\right]_{\mathrm{i}}$ due to $\mathrm{Ca}^{2+}$ released from the SR were the dominant contributor to this process (Kistamas et al., 2015b). High RSV at faster rates can also be explained by the elevated $\left[\mathrm{Ca}^{2+}\right]_{\mathrm{i}}$, as faster pacing increases $\mathrm{I}_{\mathrm{Ca}, \mathrm{L}}$, ultimately overloading the cell with $\mathrm{Ca}^{2+}$ which, in turn, increases RSV.

\section{Cardiac Alternans}

A severe form of this beat-to-beat variation is cardiac alternans, where short and long AP duration alternate (Figure 3F). Pulse and T-wave alternans can be clinically observed and are considered to be a precursor for cardiac arrhythmias (Rosenbaum et al., 1994; Verrier et al., 2011). Cardiac alternans originates from instabilities of membrane voltage or of $\mathrm{Ca}^{2+}$ cycling. At the cellular level, alternans is manifested as beat-to-beat alternations in contraction amplitude (mechanical alternans), APD (electrical or APD alternans), and $\mathrm{Ca}^{2+}$ transient amplitude $\left(\mathrm{Ca}^{2+}\right.$ alternans) at constant heart rate. However, because of the bidirectional information flow between membrane voltage and $\mathrm{Ca}^{2+}$ cycling, electrical alternans is always influenced by $\mathrm{Ca}^{2+}$ alternans, and vice versa (Weiss et al., 2006).

Two mechanisms have been described for $\mathrm{Ca}^{2+}$-driven alternans. One depends on the relationship between $\mathrm{SR} \mathrm{Ca}^{2+}$ content and the amount of $\mathrm{Ca}^{2+}$ released from the SR (Eisner et al., 2000). If this relationship is steep then a small increase of $\mathrm{SR} \mathrm{Ca}^{2+}$ content will produce a large increase of the amplitude of the $\mathrm{Ca}^{2+}$ transient resulting in increased $\mathrm{Ca}^{2+}$ efflux via $\mathrm{I}_{\mathrm{NCX}}$ and a decreased influx via $\mathrm{I}_{\mathrm{Ca}, \mathrm{L}}\left(\mathrm{Ca}^{2+}\right.$-dependent inactivation). The net result is a decrease of SR $\mathrm{Ca}^{2+}$ content. The next beat therefore arises from a depleted SR resulting in a smaller $\mathrm{Ca}^{2+}$ transient and decreased $\mathrm{I}_{\mathrm{NCX}}$, so that the cell will gain $\mathrm{Ca}^{2+}$ resulting in a larger SR content and $\mathrm{Ca}^{2+}$ transient for the third beat (Eisner et al., 2006). Later, it was shown that reduced SERCA pump activity is also needed for an alternating pattern to develop (Shiferaw et al., 2003; Qu et al., 2007; Xie et al., 2008; Li et al., 2009). Another mechanism for $\mathrm{Ca}^{2+}$-driven alternans has been proposed, when on every beat, the SR load is unchanged, however the released amount of $\mathrm{Ca}^{2+}$ is alternating beat-to-beat. This kind of alternans results from the refractoriness of the RyRs, without the need for SR Ca ${ }^{2+}$ content alternans (Picht et al., 2006; Shkryl et al., 2012).

Voltage-driven or electrical alternans is determined by APD restitution. Here, the shorter the preceding diastolic interval, the less the APD (Nolasco and Dahlen, 1968). The steeper this relationship, the more likely is alternans to occur. There may be several causes for this APD restitution. The rapid, pacinginduced electrical alternans occurs at fast heart rates (short diastolic intervals, where recovery of $\mathrm{I}_{\mathrm{Ca}, \mathrm{L}}$ is crucial, becoming a key factor in regulating the steepness of APD restitution (Mahajan et al., 2008). Another APD alternating mechanism is driven by $\mathrm{I}_{\text {to }}$ at slow or normal heart rates and possibly accounts for $\mathrm{T}$-wave alternans in patients with Brugada syndrome (Hopenfeld, 2006). The third type of electrical alternans is mediated by non-inactivating $\mathrm{I}_{\mathrm{Ca}, \mathrm{L}}$ with $\mathrm{I}_{\mathrm{Ks}}$ at normal or slow rates and possibly cause T-wave alternans in LQTS patients (Wegener et al., 2008). Electrical, restitution-based alternans has been associated with the breakdown of reentry into ventricular fibrillation (VF). At the tissue level, if cellular alternanses in different regions of the ventricle occur in phase with each other (spatially concordant), T-wave alternanses is observed on the ECG. A more malignant form, the spatially discordant APD alternans, manifesting as QRS alternans on the ECG, causes large dispersion of refractoriness, a substrate for reentry. Spatially discordant alternans is a significant cause of wave break, a phenomenon that is essential to VF (Garfinkel, 2007). It has been shown, that interventions that lower the slope of the APD restitution curve can turn multiwave VF to single-wave monomorphic ventricular tachycardia (VT) (Garfinkel et al., 2000; Wu et al., 2002).

\section{Abnormal Impulse Conduction}

Abnormal impulse conduction, i.e. reentry, occurs when the AP fails to terminate and has the ability to re-excite tissue regions which have already recovered. This mechanism can be divided into two main types, one with an obstacle (circus type with anatomical or functional barrier) and the other without an obstacle (phase-2 reentry and reflection). The key difference is in refractoriness. Circus movement reentry travels around an anatomic or functional obstacle and all cells are recovered from inactivation, while cells involved in reflection or phase- 2 reentry show large differences in recovery from refractoriness with no obstacle in the way of the reentrant wave. In addition, classic nomenclature distinguishes between microreentry and macroreentry, where the reentrant circuit does not or does appear on the surface ECG, respectively.

The myocardium works as a functional syncytium (Figure 6A). The elemental components of this system are the gap junctions. Gap junctions form channels (comprised of two neighboring connexons) between adjacent cardiomyocytes and allow the cardiac AP to propagate from cell to cell and thereby initiate contraction. However, gap junction channels are unevenly distributed within the cells, expressing a larger portion of channel proteins at the longitudinal ends of the cells than at the transversal, lateral sides (De Maziere and Scheuermann, 1990; Oosthoek et al., 1993). This anisotropy allows a much larger longitudinal conduction velocity and effective electrical coupling between the adjacent cells (Figure 6B). Several conditions are reported to reduce or abolish gap junctional conductance, including increased $\left[\mathrm{Ca}^{2+}\right]_{\mathrm{i}}$, reduced $\mathrm{pH}$, or lower ATP levels (Dhein, 1998). Uncoupling of the cells may lead to the formation of unidirectional conduction block and reentry type arrhythmias (Figure 6B). The hypothesis that $\mathrm{Ca}^{2+}$ overload conditions have arrhythmogenic behavior is also supported by experiments in neonatal rat myocytes, where gap junctional conductance was 


\section{A}

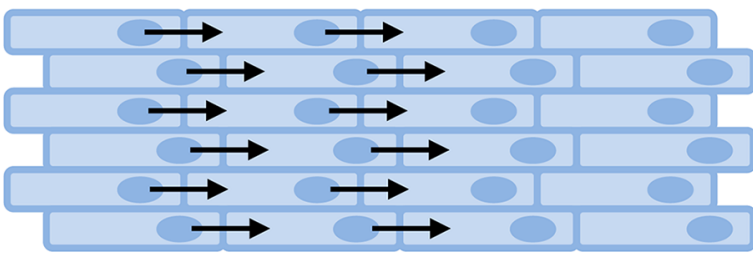

B

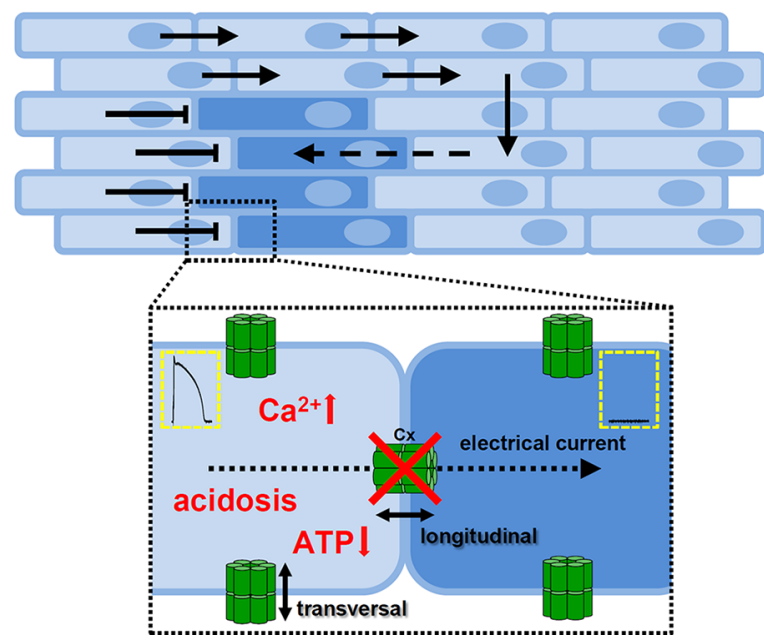

FIGURE 6 | Role of gap junctions in propagating of the cardiac action potential. (A) The cardiac tissue is eletrically homogenous if the adjacent cells are coupled by gap junction channels. The anisotropic nature of gap junction channel distribution favors longitudinal over transversal conduction. (B) Conditions that decrease or abolish coupling between the cells may cause a unidirectional conduction block and as the electrical impulse propagates around the block it can re-excite those tissue regions due to differences in refractoriness. Insert shows cell-cell connections via gap junction channels. The main causes of uncoupling of the cells (showed in red) are elevated intracellular $\mathrm{Ca}^{2+}$ concentration, reduction in $\mathrm{H}^{+}$concentration, or lower levels of ATP. Cx, connexon; ATP, adenosine triphosphate.

decreased by $\mathrm{Ca}^{2+}$ concentrations higher than physiological (Firek and Weingart, 1995), while it was proposed that elevation of $\left[\mathrm{Ca}^{2+}\right]_{\mathrm{i}}$ by $\mathrm{Ca}^{2+}$ entry was more effective in decreasing gap junctional conductance than $\mathrm{Ca}^{2+}$ released from internal stores (Lazrak et al., 1994; Chanson et al., 1999). Furthermore, adequate coupling between the cells in the tissue (i.e. low longitudinal resistance) can suppress differences in APD, eliminate EADs, and reduce beatto-beat variability (Magyar et al., 2015).

In the subsequent sections reentry types are discussed in detail.

\section{Reentry With Anatomical Obstacle (Ring Model)}

Reentry was first described in 1906 by Mayer in rings of tissue cut from jellyfish (ring model) (Mayer, 1906). Later work by Mines showed that circus-type reentry can be initiated by electrical stimulation in cardiac muscle and was the first to define the concept of circus movement reentry around an anatomical obstacle (Figure 7A) (Mines, 1913; Mines, 1914).
The anatomical barrier can be a valve, vessel or scar. The possibility that circus-type reentry can form without an anatomical obstacle was proposed by Garrey (1914).

Initiation of reentry requires a trigger and a substrate. The trigger can be a premature contraction, while tissue substrate is the dispersion of refractoriness. On top of that, fundamental settings are needed for reentry excitation with anatomical obstacle: (1) the impulse initiating the circus movement must propagate in one direction (unidirectional block) and (2) the proportion of absolute and relative refractoriness in the tissue, that is, the reentrant circuit must be long enough to let all areas-within the circuit, distal from the stimulus-recover from refractory (excitable gap), so the circuit can return to its origin and continue as a new cycle (Figure 7A). Consequently, (3) the circulating movement would terminate in case of interruption of the reentrant circuit (Mines, 1913). These criteria proposed by Mines are still in use today. The above mentioned excitation is, in fact, a propagating wave. The length of this wave (wavelength) is determined by the distance between the wavefront (phase 0, AP depolarization) and waveback (phase 3, repolarization), that is, creating an arrhythmogenic excitation needs the special properties of refractoriness and conduction velocity (Weiss et al., 2000). If the above three criteria are not met, i.e. in sinus rhythm if the tissue around the anatomical obstacle is homogenous (and the impulse pathway is wide enough), the wavefront can simultaneously propagate in both pathways around the barrier. However, if the tissue is electrically heterogenous, due to dispersion of refractoriness, unidirectional conduction block can form caused by a PVC, i.e. initiating reentry (Figure 7A).

\section{Reentry Without Anatomical Obstacle (Functional Block)}

In the cases, when there is no anatomical barrier present, functional reentry can still form, maintained only by the electrical properties (dispersion of refractoriness) of the tissue. The best known examples are the leading circle, spiral wave, and figure-of-8 reentry (Figure 7B).

The leading circle model was described by Allessie et al., as "the head of the circulating wavefront is continuously biting in its own tail of refractoriness" (Allessie et al., 1977). The main differences compared to the ring model are (1) the length of the circuit is determined by conduction velocity, stimulating efficacy, and refractory period not by an anatomic obstacle, (2) while the length of the circuit is not fixed, it can be altered by changes in electrophysiological properties of the tissue. (3) There is no excitable gap in the leading circle model and (4) a shortcut of the circuit is possible and finally (5) revolution time is proportional to refractory period, while in the ring model, revolution time is inversely related to conduction velocity (Figure 7B) (Allessie et al., 1977).

Spiral waves and rotors can be induced in small twodimensional pieces of cardiac muscle, without an anatomical barrier, and can drift through the tissue (Pertsov et al., 1993). Scroll waves are the three-dimensional forms of spiral waves. Spiral waves can develop both in homogenous and heterogenous tissues and either in stable or in an unstable form (Ikeda et al., 


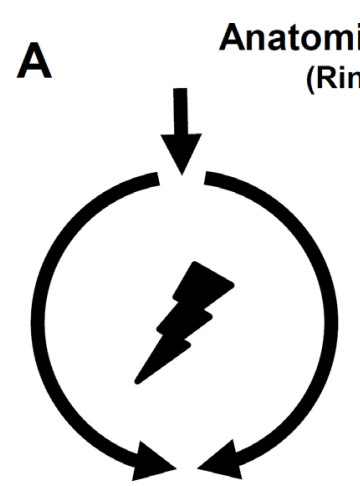

\section{Homogenous tissue} around an obstacle

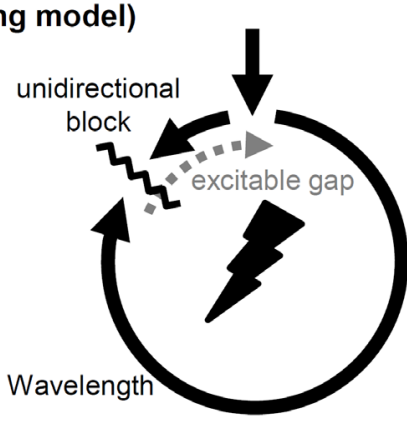

Heterogenous tissue around an obstacle

\section{B No anatomical obstacle (Functional block)}
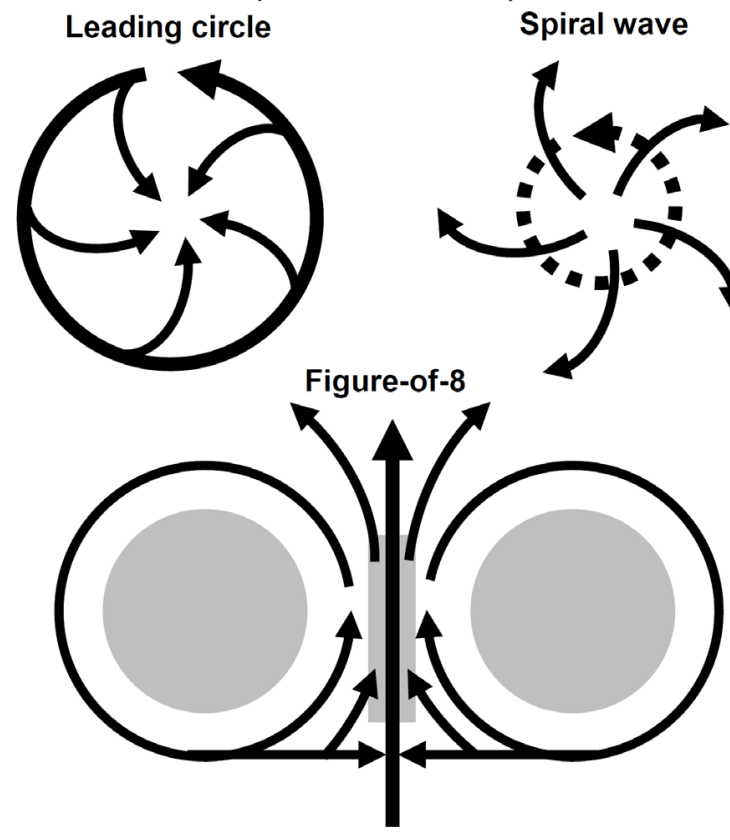

FIGURE 7 | Abnormal impulse conduction. Circus movement reentry types. (A) Reentrant wave travels around an anatomical obstacle. If the cardiac tissue around the obstacle is homogenous the impulse conduction is favored in both directions. However, if the tissue is heterogenous (i.e. dispersion of refractoriness), unidirectional block can form initating a reentry circuit. Excitable gap consists of tissue regions that fully and/or partially recovered from refractory period, therefore excitable. (B) Circuit movement reentry can form in the absence of an anatomical obstacle (functional block). In the leading circle model the length of the circuit is not determined by the pathway around an obstacle, but rather by conduction velocity, refractory period, and stimulating efficacy where (in the absence of an obstacle) a shortcut of the circuit is possible. Spiral waves reentry (or scroll wave if threedimensional) drifts through the tissue without an obstacle and the main wave can break up and radiate waves to the neighboring regions. In the model of figure-of-8 the circulating waves appear in pairs and the wavefront can circulate around the functional blocks clockwise and counterclockwise. If the intermediate area (central gray) can be activated by the colliding separated waves, reentry can form.
1996; Davidenko et al., 1992). The former might result in monomorphic VT, while the latter can cause polymorphic VT or torsade de pointes (Figure 7B) (Gray et al., 1995).

Figure-of- 8 type reentry was first demonstrated by el-Sherif et al. In this case the reentrant wavefront reaches a functional conduction block surrounded by regions of reduced excitability. As conduction is not favored through such tissue, the wavefront drives clockwise and counterclockwise around the two arcs of functional block and beyond the barriers of low excitability the two separated waves can collide. If the conduction is slow enough and the intermediate area can be activated, reentry can form (Figure 7B) (el-Sherif et al., 1985; Lazzara, 1988).

\section{Phase-2 Reentry}

In the previous reentrant mechanisms, the trigger and the substrate originated from different etiologies, while in the case of phase-2 reentry, trigger and substrate are from the same source. Phase-2 reentry occurs in ischemia (Lukas and Antzelevitch, 1996), Brugada syndrome (Brugada and Brugada, 1992) or under conditions of higher pacing rates and higher extracellular $\mathrm{Ca}^{2+}$ concentration (Di Diego and Antzelevitch, 1994). It is caused by severe spatial dispersion of repolarization, that is, spike-and-dome configuration of AP morphology is lost at one site (predominantly at the epicardial region), while preserved at another site and is responsible for the transition to VT and VF. APs without the dome (short APD, early repolarization) can therefore be reexcited and reentry can be initiated (Antzelevitch, 2007). Loss of dome can be explained by a stronger transient outward current $\left(\mathrm{I}_{\mathrm{to}}\right)$ current, and overall by the competitive behavior between $\mathrm{I}_{\mathrm{Na}}$ and $\mathrm{I}_{\text {to }}$ (Greenstein et al. 2000; Szabo et al., 2005; Dong et al., 2010). If the actual membrane potential value is more negative than the activation threshold for the $\mathrm{I}_{\mathrm{Ca}, \mathrm{L}}$ then the AP dome vanishes. Cantalapiedra et al. showed in a simplified ionic and in a realistic cardiac model, that the origin of reexcitation is based on the presence of slow $\mathrm{Ca}^{2+}$ pulse, produced by the slow inward $\mathrm{Ca}^{2+}$ current $\left(\mathrm{I}_{\mathrm{si}}\right)$, so that the slow pulse propagates to the regions of short APs until it triggers a fast pulse (Cantalapiedra et al., 2010). Interestingly, the same research group argued that conditions (e.g. drugs) increasing the $\mathrm{I}_{\mathrm{Ca}, \mathrm{L}}$, to recover the dome or to prevent the loss of dome, decreases dispersion of repolarization, however, also increasing the probability of reexcitation, through the stabilizing effect of the $\mathrm{Ca}^{2+}$ conductance $\left(\mathrm{I}_{\mathrm{Ca}, \mathrm{L}}\right)$ on the slow $\mathrm{Ca}^{2+}$ pulse (Cantalapiedra et al., 2009).

\section{Reflection}

Reflection is another example of non-circus movement reentry, with a one-dimensional behavior and can be the cause of PVCs or even lethal arrhythmias (Wit et al., 1972; Rosenthal, 1988; Van Hemel et al., 1988). Reflection describes reentry in a linear bundle of a conductive tissue. A stimulus from the proximal region travels through an inexcitable gap and elicits an AP at the distal end. Slow electrotonic currents (inexcitable region can only transmit electrotonic currents) generated by this AP can then propagate in the retrograde direction and reenter and reexcite the proximal elements (Antzelevitch et al., 1980). There must be 
an adequate conduction delay to let reflection happen (proximal end can recover from refractoriness), depending on the pacing interval and stimulus strength. It was also shown that neither EADs nor automaticity was required for reflection (Cabo and Barr, 1992; Kandel and Roth, 2015).

\section{Biexcitability}

A novel wave dynamic, termed biexcitability has been described in recent studies (Chang et al., 2012). In pacemaker regions $I_{C a, L}$ causes the activation, while in working muscle cells, the upstroke of the AP is driven by $\mathrm{I}_{\mathrm{Na}}$ and $\mathrm{I}_{\mathrm{Ca}, \mathrm{L}}$. During biexcitability both form of activation can coexist at the same tissue. Under certain conditions, like long QT syndrome, repolarization reserve is compromised, APD prolongs, and EADs can occur. Consequently, there can be a situation where the cells develop two stable membrane potential values $(-80 \mathrm{mV}$ and $-50 \mathrm{mV})$ and switches between them (Gadsby and Cranefield, 1977), resulting in a $\mathrm{Na}^{+}$- and $\mathrm{Ca}^{2+}$-mediated (fast) or a $\mathrm{Ca}^{2+}$-mediated (slow) propagating wavefront. This bi-stable behavior might serve as an explanation for the two different possible outcomes of torsade de pointes. According to Chang et al., in cases where the $\mathrm{Ca}^{2+}$-mediated slow spiral wave is terminated, leads to termination of the torsade de pointes, while if the tissue is sufficiently heterogenous, $\mathrm{Na}^{+}$and $\mathrm{Ca}^{2+}$-mediated fast spiral waves degenerate torsade de pointes to VF (Chang et al., 2012; Chang et al., 2013).

DADs can induce focal VT by DAD-mediated triggered activity or initiate reentry. Moreover, unstable $\mathrm{Ca}^{2+}$ signaling can dynamically serve as a substrate for reentry, by promoting dispersion of excitability or promoting dispersion of refractoriness (Weiss et al., 2015). In those tissue regions, where subthreshold DADs do not trigger a propagating AP, the resultant small membrane depolarization can still be sufficient to depress excitability by inactivating the fast voltage gated $\mathrm{Na}^{+}$channels. This condition can lead to reentry, as the inactivated $\mathrm{Na}^{+}$channels form a regional conduction block for impulses generated by suprathreshold DADs (Rosen et al., 1975; Liu et al., 2015). In the latter case, $\mathrm{DAD}$-mediated triggered activity at fast rates can promote $\mathrm{Ca}^{2+}$ transient alternans, which in turn causes APD alternans, thereby increasing the dispersion of refractoriness (Sato et al., 2006; Weiss et al., 2006). As previously mentioned, subthreshold EADs can also enhance the dispersion of refractoriness, also creating a reentry substrate.

For more detailed reviews on conduction disorders, see $\mathrm{Qu}$ and Weiss (2015) and Antzelevitch and Burashnikov (2011).

The following sections will provide further insights into intracellular $\mathrm{Ca}^{2+}$ handling maladies in the most prevalent inherited and acquired arrhythmia syndromes, caused by channelopathies and defects in $\mathrm{Ca}^{2+}$ handling genes. $\mathrm{Ca}^{2+}$ handling defects also have an arrhythmogenic role in diseases, such as heart failure and cardiomyopathies, however they are beyond the scope of the present review [see recent reviews (Coppini et al., 2018; Johnson and Antoons, 2018; Denham et al., 2018)].

\section{INHERITED SYNDROMES}

\section{Catecholaminergic Polymorphic Ventricular Tachycardia}

Catecholaminergic Polymorphic Ventricular Tachycardia (CPVT) is a severe arrhythmogenic disorder, manifesting as a bidirectional or polymorphic VT, mainly in young patients with structurally healthy hearts after exercise or acute emotional stress (Reid et al., 1975). As heart rate increases as a result of exercise or emotional stress, the ectopic ventricular trigger increases in complexity, such that VT turns into VF and may lead to syncope or sudden cardiac death (Coumel, 1978; Leenhardt et al., 1995).

The main criteria for CPVT diagnosis are as follows: structurally normal heart (and normal coronary arteries in individuals above 40 years of age), normal QT interval, and adrenergic induced bidirectional or polymorphic VT (Venetucci et al., 2012). CPVT is also diagnosed in patients who carry a pathogenic mutation and in family members of a CPVT index case, fulfilling the above mentioned criteria (Priori et al., 2013). There are also nonspecific features, therefore not diagnostic criteria, including a prominent $\mathrm{U}$ wave on the ECG accompanied by sinus bradycardia (Postma et al., 2005).

In CPVT, arrhythmias are induced by $\mathrm{Ca}^{2+}$ release from the SR leading to a DAD. The fundamental feature of this process is the $\mathrm{Ca}^{2+}$ release unit $\left(\mathrm{Ca}^{2+}\right.$ sparks), where the spontaneous $\mathrm{Ca}^{2+}$ release occurs. If sufficient number of release units are activated, a $\mathrm{Ca}^{2+}$ wave is born, which depends on the SR $\mathrm{Ca}^{2+}$ content and the SR Ca ${ }^{2+}$ threshold (Lukyanenko et al., 1999; Venetucci et al., 2007). Interventions that alter RyR opening will affect SR Ca ${ }^{2+}$ threshold. For example, caffeine increases the open probability of $\mathrm{RyR}$, therefore it is easier to elicit spontaneous $\mathrm{Ca}^{2+}$ release (Trafford et al., 2000), on the other hand tetracaine has an opposite effect, by reducing $\mathrm{RyR}$ opening, $\mathrm{SR} \mathrm{Ca}^{2+}$ release threshold is higher (Overend et al., 1997; Venetucci et al., 2006).

In the previous sections we detailed the normal $\mathrm{Ca}^{2+}$ cycling and consequences of elevated $\left[\mathrm{Ca}^{2+}\right]_{i}$. Briefly, the main arrhythmogenic mechanism in CPVT is due to $\mathrm{SR} \mathrm{Ca}^{2+}$ release increasing cytoplasmic $\mathrm{Ca}^{2+}$ levels, NCX exchanges $\mathrm{Ca}^{2+}$ with $\mathrm{Na}^{+}$, thereby generating $\mathrm{I}_{\mathrm{ti}} \cdot \mathrm{I}_{\mathrm{ti}}$ produces DADs and if DADs reach the activation threshold of $\mathrm{Na}^{+}$channels, an elicited AP causes triggered activity, which in turn can lead to an extrasystolic heartbeat. Mutations in CPVT have been shown to alter RyR function and increase the occurrence of spontaneous $\mathrm{Ca}^{2+}$ release events after sympathetic stimulation (Liu et al., 2006). $\beta$-adrenergic activation increases SR $\mathrm{Ca}^{2+}$ content, while the same process enhances RyR phosphorylation by $\mathrm{Ca}^{2+}$ / calmodulin-dependent protein kinase II (CaMKII) and protein kinase A (PKA) (Kashimura et al., 2010; Liu et al., 2011a; Venetucci et al., 2012). In addition to the phosphorylation by PKA, CaMKII-mediated phosphorylation increases the $\mathrm{I}_{\mathrm{Ca}, \mathrm{L}}$ and SERCA (by removing the inhibitory effect of phospholamban on SERCA) and activates RyR. Simultaneous activation of $\mathrm{I}_{\mathrm{Ca}, \mathrm{L}}$, SERCA (increases SR Ca ${ }^{2+}$ content), and RyR therefore increases the possibility of spontaneous $\mathrm{Ca}^{2+}$ release (Maier and Bers, 2007; Hegyi et al., 2019). Experimental data confirmed that higher $\mathrm{RyR} \mathrm{Ca}{ }^{2+}$ sensitivity alone is not sufficient to elicit 
spontaneous $\mathrm{Ca}^{2+}$ release and that inhibition of CaMKII in a CPVT mouse model prevents arrhythmias (Venetucci et al., 2007; Liu et al., 2011a).

Several CPVT subtypes have been described to date, albeit the two most common types are the CPVT-1 and CPVT-2 (Table 1).

CPVT-1 is caused by an autosomal dominant mutation in the RyR2 gene (Swan et al., 1999). This subtype is the most common, accountable for about $60 \%$ of all CPVT cases (Laitinen et al., 2001; Priori et al., 2001). RyR exists as a macromolecular complex with many other molecules, such as calsequestrin 2 (CSQ2), FK506 binding protein 1B (FKBP1B or FKBP12.6), FK506 binding protein 1B (FKBP1B or FKBP12.6), PKA, CaMKII, phosphatase 1 (PP1), phosphatase 1 (PP1), phosphatase 2A (PP2A), histidine-rich $\mathrm{Ca}^{2+}$ binding protein (HRC), junctin and triadin (Wang et al., 1998; George et al., 2007; Yano et al., 2009; Arvanitis et al., 2011; Szabo et al., 2013). Junctin and triadin mediates interaction between RyR and CSQ2 (Eisner et al., 2017). Most RyR mutations in CPVT are gainof-function mutations and thereby leading to increased $\mathrm{Ca}^{2+}$ sensitivity and RyR channels may open during diastole causing $\mathrm{Ca}^{2+}$ leak, particularly during adrenergic stress (Jones et al., 2008). Several hypotheses have been advanced to explain this phenomenon, including the role of FKBP12.6, store overload-induced $\mathrm{Ca}^{2+}$ entry
(SOCE) and a defective mutation in the RyR 3D conformation (Reiken et al., 2003; Lehnart et al., 2004; Jiang et al., 2005; Yamamoto et al., 2008; Liu et al., 2009; Uchinoumi et al., 2010; Suetomi et al., 2011; Venetucci et al., 2012a).

CPVT-2 is an autosomal recessive gene anomaly in CASQ2encoded CSQ2 and responsible for about 3-5\% of CPVT patients (Lahat et al., 2001). The structure of this intra-SR Ca ${ }^{2+}$ buffer changes $\mathrm{Ca}^{2+}$ concentration. At low SR Ca ${ }^{2+}$ concentrations $(<0.6 \mathrm{mmol} / \mathrm{L})$ CSQ2 is a monomer, which is converted to a dimer $(0.6-3 \mathrm{mmol} / \mathrm{L})$ or polymer (>3 mmol/L) at higher $\mathrm{Ca}^{2+}$ concentrations (Mitchell et al., 1988; Wang et al., 1998). It has been shown that, in the absence of functional CSQ2, RyR channels open spontaneously, without the need for L-type $\mathrm{Ca}^{2+}$ current mediated trigger (Knollmann et al., 2006) and that mutation of CSQ2 destabilizes $\mathrm{Ca}^{2+}$ storing capacity of the SR, which in turn alters the $\mathrm{Ca}^{2+}$ sensitivity of $\mathrm{RyR}$ (Viatchenko-Karpinski et al., 2004). In all CSQ2 mutations (missense, deleterious, nonsense), level of CSQ2 protein is reduced or absent, perhaps because it is more susceptible to degradation (Rizzi et al., 2008; Faggioni et al., 2012). Impaired polymerization (Bal et al., 2010), reduced RyR binding and modulation (Houle et al., 2004; Terentyev et al., 2006) are generally associated with lower SR $\mathrm{Ca}^{2+}$ content, higher $\left[\mathrm{Ca}^{2+}\right]_{\mathrm{i}}$ and $\mathrm{Ca}^{2+}$ leak through RyR, these effects

TABLE 1 | $\mathrm{Ca}^{2+}$ handling genes associated with inherited arrhythmogenic syndromes.

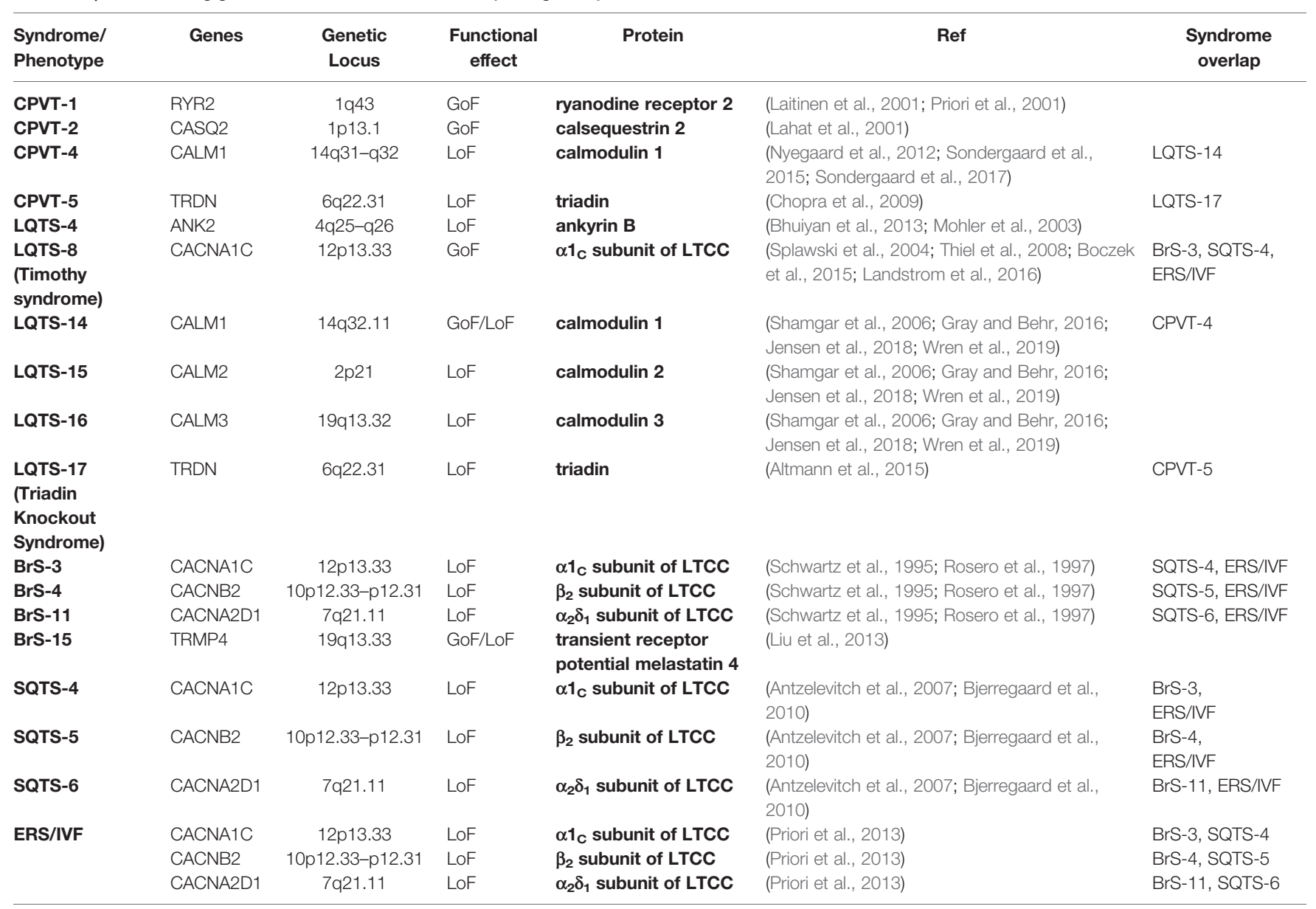

CPVT, catecholaminergic polymorphic ventricular tachycardia; LQTS, long QT syndrome; BrS, Brugada syndrome; SQTS, short QT syndrome; ERS, early repolarization syndrome; IVF, idiopathic ventricular fibrillation; LTCC, L-type $\mathrm{Ca}^{2+}$ channel; GoF, gain-of-function; LoF, loss-of-function. 
can be augmented by $\beta$-stimulation (Song et al., 2007). An interesting feature of CSQ2 protein reduction is a subsequent reduction in triadin and junctin levels. Denegri et al. showed in CSQ2 knock-out animal model that viral gene transfer for in vivo replacement of CSQ2 restored normal CSQ2 levels along with triadin and junctin, and ultimately prevented arrhythmias (Denegri et al., 2012).

Other, less frequent gene mutations have also been described, such as autosomal recessive forms of CPVT, the CPVT-3 and CPVT-5, while CPVT-4 is an autosomal dominant form of the inherited syndrome. CPVT-3 subtype is related to the gene encoding trans-2,3-enoyl-CoA reductase-like protein (TECRL) and is first seen at an early age with high likelihood of infant sudden cardiac death (Bhuiyan et al., 2007). When CPVT-3 is studied in induced pluripotent stem cell-derived cardiomyocytes (iPSC-CM) slower $\mathrm{Ca}^{2+}$ reuptake, slower $\mathrm{Ca}^{2+}$ transient upstroke velocity, and increased APD has been observed, along with norepinephrine-induced DADs, which could be eliminated by flecainide (see below) (Devalla et al., 2016). Mutations in CALM1-encoded calmodulin (CaM) cause the CPVT-4 subtype. In vitro experiments showed that this gene anomaly in the $\mathrm{C}$ domain compromises $\mathrm{Ca}^{2+}$ binding to $\mathrm{CaM}$ and impairs interaction between RyR and its CaM-binding domain, leading to an increased open state of RyR (Nyegaard et al., 2012; Sondergaard et al., 2015; Sondergaard et al., 2017). TRDNencoded triadin mutation results in CPVT-5 subtype, which may cause diastolic $\mathrm{Ca}^{2+}$ leak and $\mathrm{Ca}^{2+}$ overload. Electron microscopy experiments uncovered fragmentation and reduced contact at the dyadic cleft, thus possibly lacking the negative feedback of SR $\mathrm{Ca}^{2+}$ release on the L-type $\mathrm{Ca}^{2+}$ channels, so SR $\mathrm{Ca}^{2+}$ overload may arise from the uncontrolled $\mathrm{Ca}^{2+}$ influx (Chopra et al., 2009).

A possible loss-of-function RyR mutation has also been proposed in a case classified as idiopathic VF, where a reduced SR $\mathrm{Ca}^{2+}$ sensitivity was shown (Jiang et al., 2007). Moreover, exercise induced bidirectional VT has been reported in types of long QT syndromes (LQTS-4 and LQTS-7) (Table 1) (Mohler et al., 2004; Vega et al., 2009).

Because of the hiding nature of the disease, it is difficult to diagnose CPVT, as patients have normal heart structure and show no symptoms before syncope or sudden cardiac death. However, if diagnosed, there are several therapeutic approaches to CPVT.

Generally speaking, life-long administration of $\beta$-blockers is the first choice as treatment. Studies showed that nadolol was clinically effective and a useful prophylactic (Priori et al., 2013). In countries, where nadolol is not available, propranolol was also shown to be effective (Hayashi et al., 2009). Carvedilol has been shown to inhibit store overload-induced $\mathrm{Ca}^{2+}$ release (SOICR) and is the only $\beta$ blocker to have RyR inhibitory action, albeit it is a less potent $\beta$ blocker after all (Zhou et al., 2011). Patients with CPVT are recommended to remove the triggers, in other words to limit or avoid any vigorous physical activities and stressful environments (Priori et al., 2013). In some patients (lacking long-term studies yet) $\beta$-blocker and non-dihydropyridine $\mathrm{Ca}^{2+}$-channel blocker (verapamil) combination therapy was shown to be beneficial (Swan et al., 2005; Rosso et al., 2007).

Flecainide administration has been suggested on top of $\beta$ blockers to prevent arrhythmias, in CPVT patients refractory to $\beta$ blockers alone (Biernacka and Hoffman, 2011; Pott et al., 2011; van der Werf et al., 2011). Flecainide is a $\mathrm{Na}^{+}$-channel blocker drug, specifically a Class Ic antiarrhythmic agent. Several studies, including three retrospective cohorts in human patients with CPVT (Liu et al., 2011; Radwanski et al., 2016; Kannankeril et al., 2017) have shown the effectiveness of flecainide but there is still debate around the mechanism by which it exerts its antiarrhythmic effect. Watanabe et al. concluded that the most important effect of flecainide was blocking the RyR along with the $\mathrm{Na}^{+}$-channel blockade (Watanabe et al., 2009). They hypothesized that blocking RyR reduces the spontaneous $\mathrm{Ca}^{2+}$ release events and therefore DADs, while $\mathrm{Na}^{+}$channel blockade prevents the possibility of triggered activity from any residual DADs (Hilliard et al., 2010). Of the Class Ic antiarrhythmic drugs, only flecainide and propafenone was shown to inhibit RyR activity (Hwang et al., 2011). On the other hand, Liu et al. showed in an animal model of CPVT that although flecainide prevents VT and triggered activity, spontaneous $\mathrm{Ca}^{2+}$ release and DADs were still detectable in single myocytes. They concluded that the antiarrhythmic effect of flecainide results from its $\mathrm{Na}^{+}$-channel blocker effect rather than via RyR inhibition (Liu et al., 2011b; Bannister et al., 2015). These conflicting results raise the question whether the different effects seen in the previous studies are dependent of a specific genetic mutation. In a recent study, isolated myocytes from Casq2 $2^{-/-}$and RyR2R4496C $\mathrm{C}^{+/-}$mice were compared (Hwang et al., 2019). It was found that the former produces a stronger proarrhythmic response upon isoproterenol stimulation, but flecainide prevented arrhythmias in both cases. Also independent from the underlying mutation, effect of flecainide decreased at high $\mathrm{Ca}^{2+}$ load. An additional drug has also been tested both in vitro and in vivo. 1,4-benzothiazepine derivative K201 (JTV519) was shown to prevent arrhythmias in mouse models by reducing RyR opening, SERCA activity and $\mathrm{I}_{\mathrm{Ca}, \mathrm{L}}$ (Lehnart et al., 2004; Loughrey et al., 2007).

The latest guidelines recommend implantable cardiac defibrillator (ICD) implantation in patients with diagnosis of CPVT who experience VT, syncope, or cardiac arrest despite the optimal medical treatment (Priori et al., 2013). However, the use of ICDs without concomitant use of $\beta$-blockers is dangerous because of the possibility of shock-related electrical storms in these patients (Mohamed et al., 2006; Pflaumer and Davis, 2012). Selective left cardiac sympathetic denervation (LCSD) can be a useful therapeutic method and may be considered in patients with uncontrollable arrhythmias (patients with contraindication to $\beta$-blockers; when ICD cannot be implanted; or when recurrent VTs manifest in patients with ICD and $\beta$-blockers treatment) (Priori et al., 2013). Pulmonary vein isolation (catheter ablation) was reported to be efficient in some patients with CPVT and AF (Sumitomo et al., 2010), while the possibility of gene therapy was suggested after successful adenoviral vector infection (CASQ2 gene) in R33Q knock-in mutant mouse with dysfunctional CSQ2 (Denegri et al., 2014). Family screening of first degree relatives 
(clinical evaluation and genetic testing) has been strongly suggested with an optional $\beta$-blocker therapy even in the absence of a positive exercise test (Bauce et al., 2002; Hayashi et al., 2009).

\section{Congenital Long QT Syndrome}

Congenital long QT syndrome (LQTS) is an inherited cardiac ion channelopathy. LQTS is characterized by a prolonged QT interval on the surface ECG, reflecting the ventricular APD prolongation, which gives rise to risk for syncope, seizures, VT or torsade de pointes and finally VF and sudden cardiac death (Schwartz et al., 2012). Prolongation of APD can happen in an inhomogenous pattern, resulting in an enhanced dispersion of repolarization across the tissue. Delay in repolarization can occur e.g. by genetic defects of key ion currents, namely $\mathrm{I}_{\mathrm{Ks}}, \mathrm{I}_{\mathrm{Kr}}$, or $\mathrm{I}_{\mathrm{Na}}$. As mentioned in a previous section, EADs can form if the repolarization reserve is compromised, outward currents are reduced and/or inward currents are increased. In the case of LQTS, inhomogeneity of refractoriness combined with EADs establishes the arrhythmia substrate for VT, torsade de pointes.

The above mentioned conditions are illustrated in the cases of LQTS-1, LQTS-2, and LQTS-3. LQTS-1 is caused by the loss-offunction mutation of KCNQ1 gene $\left(K_{v} 7.1\right)$ that encodes $I_{K s}$ (Sanguinetti et al., 1996; Barhanin et al., 1996) while LQTS-2 is also a loss-of-function mutation, but of the KCNH2 channel gene $\left(\mathrm{K}_{\mathrm{v}} 11.1\right)$, encoding $\mathrm{I}_{\mathrm{Kr}}$ (Sanguinetti et al., 1995). LQTS-3 is an inherited gain-of-function mutation of SCN5 $\mathrm{A} \mathrm{Na}^{+}$channel $\left(\mathrm{Na}_{\mathrm{v}} 1.5\right)$ encoding $\mathrm{I}_{\mathrm{Na}}$ (Wang et al., 1995). All three mutations play key role in determining the length of AP and all of them points towards compromised repolarization reserve with decreased outward currents (LQTS1-2) and increased inward current (LQTS-3). LQTS-1-3 account for $\sim 75-85 \%$ of the congenital LQTS cases (El-Sherif et al., 2017).

Mutations of several other genes have been described in LQTS patients. Mutations of structural and channel interacting proteins result in: LQTS-4, a loss-of-function mutation of ANK2-encoded ankyrin $\mathrm{B}$ and leads to $\mathrm{Ca}^{2+}$ overload, QT prolongation, sinus bradycardia, AF, and CPVT (Bhuiyan et al., 2013; Mohler et al., 2003); LQTS-5, a loss-of-function KCNE1-encoded minK mutation, consequential reduction in $\mathrm{I}_{\mathrm{Ks}}$ (Splawski et al., 1997); LQTS-6, a lossof-function mutation of KCNE2-encoded MiRP1, causing a faster inactivation time course for $\mathrm{I}_{\mathrm{Kr}}$, enhanced $\mathrm{I}_{\mathrm{Ca}, \mathrm{L}}$, and reduced $\mathrm{I}_{\mathrm{f}}$ (Lu et al., 2003; Nawathe et al., 2013; Liu et al., 2014); LQTS-9, CAV3encoded Caveolin 3, causing an enhanced $\mathrm{I}_{\mathrm{Na}, \mathrm{L}}$; and LQTS-11, a mutant A-kinase anchoring protein (AKAP9-Yotiao) results in an abnormal response upon $\beta$-stimulation, as mutation reduces interaction between AKAP9 and $\mathrm{K}_{\mathrm{v}} \mathrm{LQT} 1$ cannel $\alpha$ subunit (KCNQ1, I $\mathrm{K}_{\mathrm{S}}$ ) leading to dysfunctional response to cAMP and a prolonged APD (QT) (Chen et al., 2007).

LQTS-9 and LQTS-10 (gain-of-function mutation in SCN4Bencoded $\mathrm{Na}^{+}$channel $\mathrm{Na}_{\mathrm{v}} \beta 4 \beta$-subunit) together resemble the LQTS-3 phenotype as QT prolongation is achieved by increased $\mathrm{Na}^{+}$current (Medeiros-Domingo et al., 2007). Mutation of SNTA1-encoded $\alpha 1$-syntrophin is a gain-of-function gene anomaly, causing LQTS-12 by enhancing $\mathrm{Na}^{+}$current $\left(\mathrm{Na}_{\mathrm{v}} 1.5\right)$ (Wu et al., 2008). LQTS-7 and LQTS-13 are affecting repolarizing $\mathrm{K}^{+}$currents and channels. LQTS-7 or AndersenTawil type 1 syndrome is caused by the loss-of-function mutation of the KCNJ2-encoded $\mathrm{K}_{\mathrm{ir}} 2.1$ inward rectifier $\mathrm{K}^{+}$ channel, responsible for $\mathrm{I}_{\mathrm{K} 1}$, and as $\mathrm{I}_{\mathrm{K} 1}$ is an important player in terminal repolarization, reduction of $\mathrm{K}_{\mathrm{ir}} 2.1$ function prolongs QT interval (Plaster et al., 2001). In LQTS-13, a loss-of-function mutation on KCNJ5-encoded $\mathrm{K}_{\mathrm{ir}} 3.4$ causes loss of acetylcholine activated, G-protein-gated $\mathrm{K}^{+}\left(\mathrm{I}_{\mathrm{KAch}}\right)$ channel function. $\mathrm{I}_{\mathrm{KAch}}$ is formed by $\mathrm{K}_{\mathrm{ir}} 3.1$ and $\mathrm{K}_{\mathrm{ir}} 3.4$. Mutation in $\mathrm{K}_{\mathrm{ir}} 3.4$ function disrupts membrane targeting and stability, i.e. reduced membrane expression has been suggested as the cause of LQTS-13 (Yang et al., 2010).

Although most of the LQTS mutant genes are related to $\mathrm{K}^{+}$ and $\mathrm{Na}^{+}$channels (i.e. LQTS-1-3 being $\sim 75-85 \%$ of total congenital LQTS), there are several $\mathrm{Ca}^{2+}$-signaling proteins that are linked to the occurrence of long QT intervals, typically causing LQTS-8, LQTS-14, LQTS-15, LQTS-16, and LQTS-17 (Table 1).

LQTS-8 is a gain-of-function mutation of the CACNA1Cencoded $\alpha 1_{\mathrm{C}}$ subunit of L-type $\mathrm{Ca}^{2+}$ channel $\left(\mathrm{Ca}_{\mathrm{v}} 1.2\right)$ and is generally associated with Timothy syndrome. Timothy syndrome is a rare (less than 30 patients reported worldwide), but severe multisystem disorder, involving QT prolongation, syndactyly, congenital heart defects, cardiomyopathies, bradycardia (caused by AV block rather than sinus bradycardia), and autism (Splawski et al., 2004). LQTS-8 mutation of the $\mathrm{Ca}_{\mathrm{v}} 1.2$ leads to (1) a significant reduction in voltage-dependent inactivation of $\mathrm{I}_{\mathrm{Ca}, \mathrm{L}}$, (2) enhanced $\mathrm{I}_{\mathrm{Ca}, \mathrm{L}}$, (3) decreased current density with enhanced window current, and (4) a steeper APD restitution curve (Thiel et al., 2008; Boczek et al., 2015; Landstrom et al., 2016). A lesser inactivation of the steady-state current and/or increased peak current means a higher $\mathrm{Ca}^{2+}$ influx, which can in turn prolong APD, therefore QT interval. A steeper APD restitution curve is proarrhythmic, being a substrate for alternans, as detailed in previous chapters. The mutation can also cause T-wave alternans on the ECG by increasing the dispersion of repolarization (Zhu and Clancy, 2007). In iPSC cells of a Timothy syndrome patient, a cyclindependent kinase inhibitor, roscovitine was found to shorten APD by partially recovering inactivation of the mutant channel (Yarotskyy et al., 2010; Yazawa et al., 2011). If Timothy syndrome/LQTS-8 is diagnosed, because of the high mortality, ICD implantation is the first choice. ICD is often supplemented with $\beta$-blockers, relying on the fact that they are generally effective in LQTS patients. Also, verapamil (Jacobs et al., 2006), mexiletine (Krause et al., 2011), and ranolazine (Shah et al., 2012) have been shown to shorten APD by affecting $I_{C a, L}$ and reducing the risk of arrhythmias.

LQTS-14-16 are newly described subtypes of LQT syndrome, caused by mutations in the genes coding the ubiquitous $\mathrm{Ca}^{2+}$ sensor and binder, calmodulin (CaM). Mutations in CALM1encoding CaM1, CALM2-encoding CaM2, and CALM3encoding CaM3 are responsible for producing LQTS-14, LQTS15, and LQTS-16, respectively. Patients diagnosed with these conditions are usually young and have a high rate of cardiac arrest with severe QT prolongation (Gray and Behr, 2016). CaM 
is important in the inactivation of $\mathrm{Na}^{+}$channels, $\mathrm{Ca}^{2+}$-dependent inactivation of $\mathrm{I}_{\mathrm{Ca}, \mathrm{L}}$ and also important in the trafficking, assembly, and gating of the $\mathrm{I}_{\mathrm{Ks}}$ channel, KCNQ1 (Shamgar et al., 2006). Gene anomalies, affecting $\mathrm{CaM}$, and therefore, $\mathrm{Ca}^{2+}$ binding and/or enhancing $\mathrm{I}_{\mathrm{Ca}, \mathrm{L}}$ can lead to severe APD prolongation. To date, over 20 mutations have been reported in the disease group of calmodulinopathies (Jensen et al., 2018; Wren et al., 2019) associated with LQTS, CPVT, and idiopathic VF. LQTS mutations, e.g. CaM-D130G, CaM-D96V, CaM-N98S, and CaMF142L are all having impaired $\mathrm{Ca}^{2+}$ binding properties at the EF hand domains (Crotti et al., 2013). In CaM-D130G, CaM-D96V, and CaM-N98S mutations impaired CaM-dependent inhibition of RyR was reported, thereby increasing $\mathrm{SR} \mathrm{Ca}^{2+}$ release due to an increased open state of RyR (Sondergaard et al., 2017; Jensen et al., 2018). Unexpectedly, an LQTS-associated CaM mutation, CaMF142L did not diminish, but, increased the CaM-dependent RyR gating inhibition and caused faster RyR closing at high $\left[\mathrm{Ca}^{2+}\right]_{\mathrm{i}}$ (Sondergaard et al., 2017). The authors proposed that the mutation displayed both gain-of-function and loss-of-function properties. In the process of gain-of-function, F142L mutation increases the interactions between the $\mathrm{C}$-domain of $\mathrm{CaM}$ and the $\mathrm{CaM}$ binding domain of RyR, therefore enhancing RyR inhibition. On the other hand, the loss-of-function effect impairs the ability of the $\mathrm{C}$-domain of $\mathrm{CaM}$ to bind free $\mathrm{Ca}^{2+}$, i.e. decreases $\mathrm{RyR}$ inhibition. However, at high $\left[\mathrm{Ca}^{2+}\right]_{\mathrm{i}} \mathrm{C}$-domain of CaM saturates allowing the increased RyR inhibitory effect to be the dominant one (Sondergaard et al., 2017). One might assume an overlap between LQTS and CPVT as diminished inhibitory effect on RyR gating is generally associated with CPVT. In mutant guinea pig cells, it was shown that decreased inhibition of RyR gating with impaired CaM effect on the CaM-dependent inactivation of $\mathrm{I}_{\mathrm{Ca}, \mathrm{L}}$ (i.e. increased $\mathrm{I}_{\mathrm{Ca}, \mathrm{L}}$ ) may contribute to APD prolongation and that LQTS associated CaM mutations can lead to electrical alternans, a pathological feature of LQTS (Limpitikul et al., 2014).

Recently a novel mutation, LQTS-17 has been proposed, however, the nomenclature is still indistinct. Some reviews refer to LQTS-17 as a mutation in TRDN-encoded triadin, which has also been linked to CPVT-5 (Landstrom et al., 2017). However, Altmann et al., originally identified the autosomal recessive homozygous or compound heterozygous frameshift loss-of-function mutations in TRDN, proposed the term Triadin Knockout Syndrome (TKOS) or TRDN-mediated autosomal-recessive LQTS, rather than LQTS-17 (Altmann et al., 2015). As in the previous case, here is also the possibility of an overlap with CPVT, as QT prolongation and disease appearance at young age is accompanied by arrhythmias that occur during exercise. The possible cellular mechanism includes reduced negative feedback on $\mathrm{I}_{\mathrm{Ca}, \mathrm{L}}$ (i.e. increased $\mathrm{I}_{\mathrm{Ca}, \mathrm{L}}$ ), increased spontaneous $\mathrm{Ca}^{2+}$ release via RyR, and promotion of SR Ca ${ }^{2+}$ loading by NCX. It is not clear yet, whether the arrhythmogenic feature is mediated by DAD or EAD, but in a TRDN-null mice model, nifedipine aborted SR $\mathrm{Ca}^{2+}$ overload and spontaneous $\mathrm{Ca}^{2+}$ release (Chopra et al., 2009).

Although most of the LQTSs are inherited in an autosomal dominant form, there is a relatively rare, autosomal recessive inherited form, causing the Jervell and Lange-Nielsen syndrome
(KCNQ1 or KCNE1, leading to reduced $\mathrm{I}_{\mathrm{Ks}}$ ) (Splawski et al., 1997; Duggal et al., 1998). LQTS-related arrhythmias can be triggered by either slow or fast heart rate or by sinus pauses, therefore the relation between the LQTSs and the sinoatrial node is an interesting topic; for details, see the mini-review from Wilders and Verkerk (2018). For a detailed summary chart about LQTSs with the genetic loci, see a recent review of Landstrom et al. (Landstrom et al., 2017).

Pharmacological management of congenital LQTS starts with the administration of $\beta$-blockers, irrespective of the genotype (Moss et al., 2000). In one study, propranolol was shown to be the most effective $\beta$-blocker $\left(\mathrm{Na}^{+}\right.$channel blockade with limited effects on $\mathrm{K}^{+}$channels) (Chockalingam et al., 2012). It should be noted that care is required with the use of $\beta$-blockers at low heart rate in LQTS-3 since bradycardia-dependent arrhythmias occur more often in these patients (El-Sherif et al., 2017). It was shown in LQTS-2 patients that besides $\beta$-blockers, application of mexiletine may also have positive effects (Kim et al., 2010; Ildarova et al., 2012). As an add-on therapy, in the case of LQTS-3 patients mexiletine (Schwartz et al., 1995), lidocaine, tocainide (Rosero et al., 1997), flecainide (Moss et al., 2005), phenytoin (Vukmir and Stein, 1991), or ranolazine (Moss et al., 2008) can be useful (Priori et al., 2013). In LQTS where mutations cause reduction in $\mathrm{K}^{+}$currents, drugs that enhance $\mathrm{K}^{+}$currents, nicorandil (Shimizu et al., 1998) or RPR26043 (Kang et al., 2005) were shown to be effective. ICD implantation is recommended for survivors of cardiac arrest or with recurrent syncope while on $\beta$-blocker (Priori et al., 2013). Left cardiac sympathetic denervation (LCSD) can also be performed on high-risk patients (arrhythmic events even in the presence of $\beta$-blocker/ICD). In addition to drugs or surgical procedures, lifestyle changes, such as avoidance of drugs that lengthen QT interval, identification and correlation of electrolyte abnormalities, avoidance of strenuous exercise (especially swimming in LQTS-1 patients) and abrupt loud noises (LTQS2) are recommended for patients (Priori et al., 2013).

\section{Brugada Syndrome}

Brugada syndrome $(\mathrm{BrS})$ is characterized by ST elevation in V1-V3 ECG leads and is associated with elevated risk of polymorphic VT, VF, and sudden cardiac death (Brugada and Brugada, 1992). Two hypotheses have been proposed to describe the mechanism behind BrS and how ST segment elevation is linked to VT/VF. (Ringer, 1883) In the repolarization hypothesis, the loss of spike-and-dome AP morphology (heterogenous shortening of AP due to predominance of $\mathrm{I}_{\text {to }}$ over $\mathrm{I}_{\mathrm{Na}}$ and $\mathrm{I}_{\mathrm{Ca}, \mathrm{L}}$ ) is suggested in the epicardium of the right ventricular outflow tract, causing an enhanced transmural dispersion of repolarization, i.e. ST elevation (Yan and Antzelevitch, 1999). The arrhythmogenic mechanism is delivered by phase- 2 reentry, when the produced extrasystole can occur on the preceding $\mathrm{T}$ wave (R-on-T phenomenon), finally initiating VT/VF. (Bers, 2002) The depolarization theory proposes a slowed conduction and delayed activation mechanism in the right ventricular outflow tract as a substrate for reentry (Meregalli et al., 2005). 
To date, 23 gene (gain-of-function and also loss-of-function) mutations have been described generating BrS-1-BrS-23 (Gray and Behr, 2016). The most common subtype is BrS-1, mutation affects the SCN5A-encoded $\alpha$-subunit of the $\mathrm{Na}^{+}$channel $\left(\mathrm{Na}_{\mathrm{v}} 1.5\right)$ and is accountable for about one third of all $\mathrm{BrS}$ (Antzelevitch et al., 2005). Genes, governing $\mathrm{Ca}^{2+}$-signaling molecules are also affected in BrS and causing $10-15 \%$ of cases (Burashnikov et al., 2010) (Table 1). Loss-of-function mutation of the CACNA1C-encoded $\alpha_{1 \mathrm{C}}$-subunit $\left(\mathrm{Ca}_{\mathrm{v}} 1.2 \alpha 1\right.$; BrS-3), the CACNB2-encoded $\beta_{2}$-subunit $\left(\mathrm{Ca}_{\mathrm{v}} \beta 2 ; \mathrm{BrS}-4\right)$, and the CACNA2D1-encoded $\alpha_{2} \delta_{1}$-subunit $\left(\mathrm{Ca}_{\mathrm{v}} \alpha 2 \delta 1\right.$; BrS-11) of the L-type $\mathrm{Ca}^{2+}$ channel (governing $\mathrm{I}_{\mathrm{Ca}, \mathrm{L}}$ ) have been described with a concomitant reduction of $\mathrm{I}_{\mathrm{Ca}, \mathrm{L}}$ (Antzelevitch et al., 2007). Patients harboring these $\mathrm{Ca}^{2+}$ related mutations showed $\mathrm{BrS}$ like ECG but with shorter than normal QT intervals. Recently, a new $\mathrm{Ca}^{2+}$-related mutation has been linked to $\mathrm{BrS}$, accounting for about $6 \%$ of the cases. Mutation of the TRPM4-encoded $\mathrm{Ca}^{2+}$ activated non-selective cation channel transient receptor potential melastatin 4 (TRPM4; BrS-15) can either be gain-offunction or loss-of-function (Liu et al., 2013). TRPM4-mediated current increases APD in atrial muscle and isolated myocytes (Simard et al., 2013), possibly by promoting the plateau (as it is more likely to activate when $\mathrm{Ca}^{2+}$ is elevated). Therefore, TRPM4 mutation may change the AP dome and be arrhythmogenic. TRMP4 may also slow down conduction by altering the availability of $\mathrm{Na}^{+}$channels (Liu et al., 2013).

There have been pharmacological attempts to manage BrS (isoproterenol, quinidine, procainamide, propafenone, pilsicainide, flecainide), some of them were effective in preventing recurrent episodes of VF or electrical storms, but did not reduce the overall risk of VF (Brugada et al., 2000; Shimizu et al., 2000; Morita et al., 2003; Belhassen et al., 2004; Ohgo et al., 2007). Guidelines are also recommending lifestyle changes (omit drugs that aggravate ST elevation, avoid alcohol and immediate treatment if fevered) and implantation of ICD (Priori et al., 2013).

\section{Short QT Syndrome}

Short QT syndrome (SQTS) is a rare inherited syndrome characterized by QT intervals essentially shorter than $360 \mathrm{~ms}$ and by an increased incidence of VT/VF mainly in youngsters (Bjerregaard et al., 2010). There are eight different gene mutations, of which three affect $\mathrm{I}_{\mathrm{Ca}, \mathrm{L}}$ (Table 1). Loss-offunction mutation of the CACNA1C-encoded $\alpha_{1 \mathrm{C}}$-subunit $\left(\mathrm{Ca}_{\mathrm{v}} 1.2 \alpha 1\right.$; SQTS-4), the CACNB2-encoded $\beta_{2}$-subunit $\left(\mathrm{Ca}_{\mathrm{v}} \beta 2\right.$; SQTS-5), and the CACNA2D1-encoded $\alpha_{2} \delta_{1}$-subunit $\left(\mathrm{Ca}_{\mathrm{v}} \alpha 2 \delta 1\right.$; SQTS-6) of the L-type $\mathrm{Ca}^{2+}$ channel, similar to the BrS-3, BrS-4, and BrS-11 phenotype. These mutations decrease $\mathrm{I}_{\mathrm{Ca}, \mathrm{L}}$ (alter current density and activation/inactivation kinetics), cause heterogenous shortening of APD and QT interval, therefore increases dispersion of repolarization (Antzelevitch et al., 2007). Transmural dispersion of repolarization (shortening effect is more pronounced in the epicardium compared to endocardium and midmyocardium) finally serves as a substrate for reentry. These mutations combined with the mutation of SCN5A-encoded $\alpha$-subunit of the $\mathrm{Na}^{+}$channel $\left(\mathrm{Na}_{\mathrm{v}} 1.5\right)$ causes an overlapping phenotype of SQTS and BrS.

\section{Early Repolarization Syndrome and Idiopathic Ventricular Fibrillation}

Early repolarization syndrome (ERS) is characterized by J-point and ST segment elevation in two or more contiguous leads on ECG (Boineau, 2007). The early repolarization pattern (in the inferior and/ or lateral precordial leads) had been considered harmless, but it has recently been associated with idiopathic ventricular fibrillation (IVF) (Rosso et al., 2008). ERS now is diagnosed in IVF survival patients, without other causes of cardiac arrest (channelopathies; structural or non-structural heart diseases, e.g. BrS; metabolic; toxicological; respiratory; and infectious) (Haissaguerre et al., 2008). Seven gene mutations were shown, to date, including loss-of-function mutations of CACNA1C, CACNAB2, and CACNA2D1, as seen in BrS or SQTS (Table 1). L-type channel mutations account for $16 \%$ of cases (Burashnikov et al., 2010). CaM-F90L mutation was proposed to be linked to IVF phenotype, where the authors speculated that CaM mutations could be arrhythmogenic by altering $\mathrm{Ca}^{2+}$ binding and/or binding of target proteins, thus generating a rather insensitive CaM and that the gene anomaly is more pronounced in the Purkinje system (Marsman et al., 2014). Recently, a novel single point mutation in RyR2 (RyR2-H29D) has been linked to IVF phenotype (Cheung et al., 2015). RyR2-H29D mutation was shown to be associated with shortcoupled premature ventricular contractions, initiating polymorphic VT. This mutation caused diastolic $\mathrm{Ca}^{2+}$ leak at rest by higher open probability and higher frequency of opening of RyR at low diastolic $\mathrm{Ca}^{2+}$ levels in a non-PKA phosphorylated state, unlike the typical CPVT-related RyR mutations. Therefore, RyR dysfunction caused by RyR2-H29D mutation may play a role in short-coupled polymorphic VT.

J-point elevation associated malignant arrhythmias have recently been proposed with a new classification, as J-wave syndrome (Antzelevitch and Yan, 2010).

\section{ACQUIRED SYNDROMES}

\section{Acquired Long QT Syndrome}

In addition to the congenital form, LQTS can also be acquired. The prevalence of acquired LQTS is greater than that of congenital forms (El-Sherif et al., 2019). It is generally caused by adverse, unwanted drug effects and/or electrolyte abnormalities and may predispose to the prolongation of the APD/QT interval, increase in dispersion of refractoriness and to a higher risk for generating EADs, being the substrates for VTs, especially for torsade de pointes VT (El-Sherif and Turitto, 1999).

The above mentioned effects are often seen for the hERGencoded (human ether-à-go-go-related gene or KCNH2) $\mathrm{K}_{\mathrm{v}} 11.1$ channel, responsible for $\mathrm{I}_{\mathrm{Kr}}$ while effects on enhanced $\mathrm{I}_{\mathrm{Na}, \mathrm{L}}$ has also been reported (Yang et al., 2014). The role of dispersion of repolarization in generating tachyarrhythmias (and the role as a preclinical proarrhythmia marker) is further supported by a series of experiments, where DL-sotalol and amiodarone were compared (Milberg et al., 2004). It was shown, that both hERGblockers increased QT interval, however only DL-sotalol increased transmural dispersion of refractoriness, EADs and 
torsade de pointes (and caused triangulation of the AP), while amiodarone caused phase- 2 prolongation of the AP without triangulation, which is otherwise considered proarrhythmic.

Several other causes of acquired LQTS have been described, including electrolyte disorders (El-Sherif and Turitto, 2011), such as hypokalemia, hypomagnesemia or hypocalcemia, hypothyroidism, hypothermia, but also antidepressant and antipsychotic treatments (Sicouri and Antzelevitch, 2018), female gender, and autoimmune and inflammatory diseases (Lazzerini et al., 2015; Boutjdir et al., 2016). Hypocalcemia causes QT prolongation via phase-2 prolongation of AP (Eryol et al., 2003), also longer and late $\mathrm{Ca}^{2+}$ influx (due to reduced $\mathrm{Ca}^{2+}$-dependent inactivation of $\mathrm{I}_{\mathrm{Ca}, \mathrm{L}}$ ) can favor the formation of EADs.

\section{Atrial Fibrillation}

The most prevalent cardiac arrhythmia is atrial fibrillation (AF) and this can be classified as paroxysmal (spontaneously self-terminates into sinus rhythm in less than 7 days), persistent (lasts for more than 7 days), long-lasting persistent (AF lasts for more than a year) or permanent AF (without active rhythm control) (Kirchhof et al., 2016). AF is multifactorial. Basic arrhythmogenic mechanisms include $\mathrm{Ca}^{2+}$ handling defects such as triggered activity (DAD, latephase $3 \mathrm{EAD}$ ), conduction block (reentry), and $\mathrm{Ca}^{2+}$-driven cardiac alternans and altered $\mathrm{Ca}^{2+}$ buffering (Nattel and Dobrev, 2016). DAD-mediated triggered arrhythmias are underlined by $\mathrm{Ca}^{2+}$ handling instability in AF, namely RyR dysfunction (increased phosphorylation and open probability), increased SERCA function, increased diastolic SR $\mathrm{Ca}^{2+}$ leak and spontaneous SR $\mathrm{Ca}^{2+}$ release, increase in $\mathrm{Ca}^{2+}$ sparks and waves, enhanced CaMKII function (with subsequent RyR hyperphosphorylation), or reduced $\mathrm{I}_{\mathrm{Ca}, \mathrm{L}}$ (Sood et al., 2008; Neef et al., 2010; Shan et al., 2012; Voigt et al., 2012). Involvement of late-phase 3 EAD has also been shown (Burashnikov and Antzelevitch, 2006). As in most of the AF models APD is abbreviated, this observation can be somewhat surprising, since EADs generally occur at a prolonged APD. However, as we previously described, latephase 3 EADs occur at shorter APD and at elevated $\mathrm{Ca}^{2+}$ loading conditions (such as rapid atrial pacing). These ectopic activities can serve as a trigger for reentry which is considered to be the main arrhythmogenic mechanism in AF. Also, $\mathrm{I}_{\mathrm{Ca}, \mathrm{L}}$ reduction in $\mathrm{AF}$ causes $\mathrm{APD}$ shortening and promotes reentrant activity (Heijman et al., 2014). Reduction of $\mathrm{I}_{\mathrm{Ca}, \mathrm{L}}$ might be governed by reduction of protein and mRNA levels of the channel (alpha subunit) after rapid pacing. This transcriptional downregulation of $\mathrm{Ca}^{2+}$ channel has been proposed to be mediated by activation of calcineurin by $\mathrm{Ca}^{2+} / \mathrm{CaM}$, which in turn, regulates nuclear translocation of NFAT (Qi et al., 2008).

A novel, interesting theory has been proposed, namely, $\mathrm{Ca}^{2+}$ signaling silencing, as an antiarrhythmic adaptive mechanism in AF (Greiser et al., 2014). The key observation was, that sustained high atrial pacing may not lead to $\mathrm{Ca}^{2+}$ instability, suggesting a role of accompanying cardiovascular diseases (e.g. HF) rather than "lone AF" itself in those cases when unstable $\mathrm{Ca}^{2+}$ signaling occurs in AF. $\mathrm{Ca}^{2+}$ signaling silencing process includes the failure of centripetal intracellular $\mathrm{Ca}^{2+}$ signal propagation (also unchanged level of $\mathrm{Ca}^{2+}$ sparks and decreased amplitude of the systolic $\mathrm{Ca}^{2+}$ transient), remodeling of the RyR complex (reduced protein expression and CaMKII-mediated phosphorylation), and lower $\mathrm{Na}^{+}$concentration (consequential reduction in $\mathrm{Ca}^{2+}$ load) (Greiser, 2017). The decreased propagation was associated with an increase of cytoplasmic buffer power possibly due to increased $\mathrm{Ca}^{2+}$ sensitivity of myofilaments resulting from decreased phosphorylation of troponin I (Greiser et al., 2014). The authors concluded that the $\mathrm{Ca}^{2+}$ signaling phenotype in AF patients is a net result of factors that stabilize (i.e. $\mathrm{Ca}^{2+}$ signaling silencing) or destabilize it (arrhythmogenic $\mathrm{Ca}^{2+}$ instability). Therefore, future therapeutic approaches should identify the substrate (arrhythmia enhancing abnormalities or arrhythmia suppressing $\mathrm{Ca}^{2+}$ signaling silencing) and tailor therapies for individual AF patients (Kirchhof et al., 2016; Schotten et al., 2016; Greiser, 2017).

For an excess review about the role of $\mathrm{Ca}^{2+}$ in the pathophsiology of AF see the review of Denham et al. (2018).

\section{CONCLUSIONS}

In summary, we have reviewed the roles of $\mathrm{Ca}^{2+}$ in cardiac E-Ccoupling focusing on those defects which lead to cardiac arrhythmias in inherited and acquired syndromes. In the last few decades there have been great advances in the understanding of these arrhythmias, however, there is still a need for more work investigating the physiology and pathophysiology of $\mathrm{Ca}^{2+}$ related events. Designing drugs to treat a specific disease type has never been simple; it is enough to think of the early disappointing attempts to block the $\mathrm{Na}^{+}$or $\mathrm{K}^{+}$channels (CAST and SWORD trials, respectively). Multiple characteristics of novel therapeutic approaches have to be determined and to be considered as a complex, systems problem.

Along with the generally used $\beta$-blockers, newly developed selective drugs without proarrhythmic side effects are necessary. While implantable cardiac defibrillators provide longer life expectancy, they cannot prevent the onset of cardiac events. An additional helpful tool would be reliable and effective risk stratification and clinical guidance for all of the syndromes discussed. It should not be overlooked that in the future other genetic mutations may be discovered requiring novel biological therapies. Because of the diversity of inherited and acquired mutations individually tailored therapeutic approaches (gene-specific or mutation-specific pharmacological and/or gene therapy) will be required.

To gain a better understanding of the role of $\mathrm{Ca}^{2+}$ in the cardiac arrhythmias data from basic science should meet the clinical practice; translational aspects must be key in all fields of science. 


\section{AUTHOR CONTRIBUTIONS}

KK conceived the review and drafted the manuscript. KK, RV, $\mathrm{BH}, \mathrm{TB}, \mathrm{PN}$, and $\mathrm{DE}$ revised the manuscript critically for important intellectual content. DE contributed to the critical review of the literature, editing of the manuscript text and review of the figures. All authors approved the final version of the manuscript submitted.

\section{FUNDING}

This work was funded by the National Research Development and Innovation Office (NKFIH-K115397). Further support was obtained from GINOP-2.3.2.-15-2016-00040 and EFOP3.6.2-16-2017-00006 projects, which are co-financed by the European Union and the European Regional Development

\section{REFERENCES}

Abi-Gerges, N., Valentin, J. P., and Pollard, C. E. (2010). Dog left ventricular midmyocardial myocytes for assessment of drug-induced delayed repolarization: short-term variability and proarrhythmic potential. Br. J. Pharmacol. 159 (1), 77-92. doi: 10.1111/j.1476-5381.2009.00338.x

Allessie, M. A., Bonke, F. I., and Schopman, F. J. (1977). Circus movement in rabbit atrial muscle as a mechanism of tachycardia. III. The "leading circle" concept: a new model of circus movement in cardiac tissue without the involvement of an anatomical obstacle. Circ. Res. 41 (1), 9-18. doi: 10.1161/ 01.res.41.1.9

Altmann, H. M., Tester, D. J., Will, M. L., Middha, S., Evans, J. M., Eckloff, B. W., et al. (2015). Homozygous/compound heterozygous triadin mutations associated with autosomal-recessive long-QT syndrome and pediatric sudden cardiac arrest: elucidation of the triadin knockout syndrome. Circulation 131 (23), 2051-2060. doi: 10.1161/CIRCULATIONAHA.115.015397

Antzelevitch, C., and Burashnikov, A. (2011). Overview of basic mechanisms of cardiac arrhythmia. Cardiac Electrophysiol. Clinics 3 (1), 23-45. doi: 10.1016/ j.ccep.2010.10.012

Antzelevitch, C., and Yan, G. X. (2010). J wave syndromes. Heart Rhythm 7 (4), 549-558. doi: 10.1016/j.hrthm.2009.12.006

Antzelevitch, C., Jalife, J., and Moe, G. K. (1980). Characteristics of reflection as a mechanism of reentrant arrhythmias and its relationship to parasystole. Circulation 61 (1), 182-191. doi: 10.1161/01.cir.61.1.182

Antzelevitch, C., Brugada, P., Borggrefe, M., Brugada, J., Brugada, R., Corrado, D., et al. (2005). Brugada syndrome: report of the second consensus conference: endorsed by the heart rhythm society and the european heart rhythm association. Circulation 111 (5), 659-670. doi: 10.1161/01.CIR.0000152479.54298.51

Antzelevitch, C., Pollevick, G. D., Cordeiro, J. M., Casis, O., Sanguinetti, M. C., Aizawa, Y., et al. (2007). Loss-of-function mutations in the cardiac calcium channel underlie a new clinical entity characterized by ST-segment elevation, short QT intervals, and sudden cardiac death. Circulation 115 (4), 442-449. doi: 10.1161/CIRCULATIONAHA.106.668392

Antzelevitch, C. (2007). Heterogeneity and cardiac arrhythmias: an overview. Heart Rhythm 4 (7), 964-972. doi: 10.1016/j.hrthm.2007.03.036

Aronson, R. S. (1981). Afterpotentials and triggered activity in hypertrophied myocardium from rats with renal hypertension. Circ. Res. 48 (5), 720-727. doi: 10.1161/01.res.48.5.720

Arvanitis, D. A., Vafiadaki, E., Sanoudou, D., and Kranias, E. G. (2011). Histidinerich calcium binding protein: the new regulator of sarcoplasmic reticulum calcium cycling. J. Mol. Cell. Cardiol. 50 (1), 43-49. doi: 10.1016/ j.yjmcc.2010.08.021

Asakura, K., Cha, C. Y., Yamaoka, H., Horikawa, Y., Memida, H., Powell, T., et al. (2014). EAD and DAD mechanisms analyzed by developing a new human
Fund. The research was financed by the Thematic Excellence Programme of the Ministry for Innovation and Technology in Hungary (ED_18-1-2019-0028), within the framework of the Space Sciences thematic program of the University of Debrecen. This work was supported by the British Heart Foundation Chair Award (grant number: $\mathrm{CH} / 200004 / 12801$ ).

\section{ACKNOWLEDGMENTS}

$\mathrm{KK}$ is grateful to his wife Viktoria Csato, $\mathrm{PhD}$ who is expecting their twin daughters Zoe Amira and Liza Jazmin, without whom this review would have been completed much earlier. The authors wish to thank Jessica L. Caldwell for the design of Figure 1. ventricular cell model. Prog. Biophys. Mol. Biol. 116 (1), 11-24. doi: 10.1016/ j.pbiomolbio.2014.08.008

Bal, N. C., Sharon, A., Gupta, S. C., Jena, N., Shaikh, S., Gyorke, S., et al. (2010). The catecholaminergic polymorphic ventricular tachycardia mutation R33Q disrupts the N-terminal structural motif that regulates reversible calsequestrin polymerization. J. Biol. Chem. 285 (22), 17188-17196. doi: 10.1074/ jbc.M109.096354

Bannister, M. L., Thomas, N. L., Sikkel, M. B., Mukherjee, S., Maxwell, C., MacLeod, K. T., et al. (2015). The mechanism of flecainide action in CPVT does not involve a direct effect on RyR2. Circ. Res. 116 (8), 1324-1335. doi: 10.1161/ CIRCRESAHA.116.305347

Barhanin, J., Lesage, F., Guillemare, E., Fink, M., Lazdunski, M., and Romey, G. (1996). K(V)LQT1 and lsK (minK) proteins associate to form the $\mathrm{I}(\mathrm{Ks})$ cardiac potassium current. Nature 384 (6604), 78-80. doi: 10.1038/384078a0

Bauce, B., Rampazzo, A., Basso, C., Bagattin, A., Daliento, L., Tiso, N., et al. (2002). Screening for ryanodine receptor type 2 mutations in families with effortinduced polymorphic ventricular arrhythmias and sudden death: early diagnosis of asymptomatic carriers. J. Am. Coll. Cardiol. 40 (2), 341-349. doi: 10.1016/s0735-1097(02)01946-0

Belhassen, B., Glick, A., and Viskin, S. (2004). Efficacy of quinidine in high-risk patients with Brugada syndrome. Circulation 110 (13), 1731-1737. doi: 10.1161/ 01.CIR.0000143159.30585.90

Benitah, J. P., Alvarez, J. L., and Gomez, A. M. (2010). L-type Ca(2+) current in ventricular cardiomyocytes. J. Mol. Cell. Cardiol. 48 (1), 26-36. doi: 10.1016/ j.yjmcc.2009.07.026

Bers, D. M. (2000). Calcium fluxes involved in control of cardiac myocyte contraction. Circ. Res. 87 (4), 275-281. doi: 10.1161/01.res.87.4.275

Bers, D. M. (2002). Cardiac excitation-contraction coupling. Nature 415 (6868), 198-205. doi: 10.1038/415198a

Bhuiyan, Z. A., Hamdan, M. A., Shamsi, E. T., Postma, A. V., Mannens, M. M., Wilde, A. A., et al. (2007). A novel early onset lethal form of catecholaminergic polymorphic ventricular tachycardia maps to chromosome 7p14-p22. J. Cardiovasc. Electrophysiol. 18 (10), 1060-1066. doi: 10.1111/j.1540-8167.2007.00913.x

Bhuiyan, Z. A., Al-Shahrani, S., Al-Aama, J., Wilde, A. A., and Momenah, T. S. (2013). Congenital long QT syndrome: an update and present perspective in Saudi Arabia. Front. Pediatr. 1, 39. doi: 10.3389/fped.2013.00039

Biernacka, E. K., and Hoffman, P. (2011). Efficacy of flecainide in a patient with catecholaminergic polymorphic ventricular tachycardia. Europace 13 (1), 129-130. doi: 10.1093/europace/euq279

Bjerregaard, P., Nallapaneni, H., and Gussak, I. (2010). Short QT interval in clinical practice. J. Electrocardiol. 43 (5), 390-395. doi: 10.1016/ j.jelectrocard.2010.06.004

Boczek, N. J., Miller, E. M., Ye, D., Nesterenko, V. V., Tester, D. J., Antzelevitch, C. et al. (2015). Novel Timothy syndrome mutation leading to increase in 
CACNA1C window current. Heart Rhythm. 12 (1), 211-219. doi: 10.1016/ j.hrthm.2014.09.051

Boineau, J. P. (2007). The early repolarization variant-normal or a marker of heart disease in certain subjects. J. Electrocardiol. 40 (1), 3.e11-3.e16. doi: 10.1016/ j.jelectrocard.2006.04.002

Boutjdir, M., Lazzerini, P. E., Capecchi, P. L., Laghi-Pasini, F., and El-Sherif, N. (2016). Potassium channel block and novel autoimmune-associated long QT syndrome. Cardiac Electrophysiol. Clinics 8 (2), 373-384. doi: 10.1016/ j.ccep.2016.02.002

Brugada, P., and Brugada, J. (1992). Right bundle branch block, persistent ST segment elevation and sudden cardiac death: a distinct clinical and electrocardiographic syndrome. a multicenter report. J. Am. Coll. Cardiol. 20 (6), 1391-1396. doi: 10.1016/0735-1097(92)90253-j

Brugada, R., Brugada, J., Antzelevitch, C., Kirsch, G. E., Potenza, D., Towbin, J. A., et al. (2000). Sodium channel blockers identify risk for sudden death in patients with ST-segment elevation and right bundle branch block but structurally normal hearts. Circulation 101 (5), 510-515. doi: 10.1161/01.cir.101.5.510

Burashnikov, A., and Antzelevitch, C. (2003). Reinduction of atrial fibrillation immediately after termination of the arrhythmia is mediated by late phase 3 early afterdepolarization-induced triggered activity. Circulation 107 (18), 2355-2360. doi: 10.1161/01.CIR.0000065578.00869.7C

Burashnikov, A., and Antzelevitch, C. (2006). Late-phase 3 EAD. a unique mechanism contributing to initiation of atrial fibrillation. Pacing Clin. Electrophysiol. 29 (3), 290-295. doi: 10.1111/j.1540-8159.2006.00336.x

Burashnikov, E., Pfeiffer, R., Barajas-Martinez, H., Delpon, E., Hu, D., Desai, M., et al. (2010). Mutations in the cardiac L-type calcium channel associated with inherited J-wave syndromes and sudden cardiac death. Heart Rhythm 7 (12), 1872-1882. doi: 10.1016/j.hrthm.2010.08.026

Cabo, C., and Barr, R. C. (1992). Propagation model using the DiFrancesco-Noble equations. Comparison to reported experimental results. Med. Biol. Eng. Comput. 30 (3), 292-302. doi: 10.1007/bf02446967

Cantalapiedra, I. R., Penaranda, A., Mont, L., Brugada, J., and Echebarria, B. (2009). Reexcitation mechanisms in epicardial tissue: role of I(to) density heterogeneities and I(Na) inactivation kinetics. J. Theor. Biol. 259 (4), 850-859. doi: 10.1016/ j.jtbi.2009.04.021

Cantalapiedra, I. R., Penaranda, A., Echebarria, B., and Bragard, J. (2010). Phase-2 reentry in cardiac tissue: role of the slow calcium pulse. Phys. Rev. E Stat. Nonlinear Soft Matter Phys. 82 (1 Pt 1), 011907. doi: 10.1103/ PhysRevE.82.011907

Chang, M. G., Sato, D., de Lange, E., Lee, J. H., Karagueuzian, H. S., Garfinkel, A., et al. (2012). Bi-stable wave propagation and early afterdepolarizationmediated cardiac arrhythmias. Heart Rhythm 9 (1), 115-122. doi: 10.1016/ j.hrthm.2011.08.014

Chang, M. G., de Lange, E., Calmettes, G., Garfinkel, A., Qu, Z., and Weiss, J. N. (2013). Pro- and antiarrhythmic effects of ATP-sensitive potassium current activation on reentry during early afterdepolarization-mediated arrhythmias. Heart Rhythm 10 (4), 575-582. doi: 10.1016/j.hrthm.2012.12.017

Chanson, M., Mollard, P., Meda, P., Suter, S., and Jongsma, H. J. (1999). Modulation of pancreatic acinar cell to cell coupling during ACh-evoked changes in cytosolic Ca2+. J. Biol. Chem. 274 (1), 282-287. doi: 10.1074/ jbc.274.1.282

Chen, L., Marquardt, M. L., Tester, D. J., Sampson, K. J., Ackerman, M. J., and Kass, R. S. (2007). Mutation of an a-kinase-anchoring protein causes long-QT syndrome. Proc. Natl. Acad. Sci. U. S. A. 104 (52), 20990-20995. doi: 10.1073/ pnas. 0710527105

Cheng, H., Lederer, W. J. , and Cannell, M. B. (1993). Calcium sparks: elementary events underlying excitation-contraction coupling in heart muscle. Science 262 (5134), 740-744. doi: 10.1126/science.8235594

Cheung, J. W., Meli, A. C., Xie, W., Mittal, S., Reiken, S., Wronska, A., et al. (2015). Short-coupled polymorphic ventricular tachycardia at rest linked to a novel ryanodine receptor (RyR2) mutation: leaky RyR2 channels under non-stress conditions. Int. J. Cardiol. 180, 228-236. doi: 10.1016/j.ijcard.2014.11.119

Chiamvimonvat, N., Chen-Izu, Y., Clancy, C. E., Deschenes, I., Dobrev, D., Heijman, J., et al. (2017). Potassium currents in the heart: functional roles in repolarization, arrhythmia and therapeutics. J. Physiol. 595 (7), 2229-2252. doi: 10.1113/JP272883

Chockalingam, P., Crotti, L., Girardengo, G., Johnson, J. N., Harris, K. M., van der Heijden, J. F., et al. (2012). Not all beta-blockers are equal in the management of long QT syndrome types 1 and 2: higher recurrence of events under metoprolol. J. Am. Coll. Cardiol. 60 (20), 2092-2099. doi: 10.1016/ j.jacc.2012.07.046

Chopra, N., Yang, T., Asghari, P., Moore, E. D., Huke, S., Akin, B., et al. (2009). Ablation of triadin causes loss of cardiac $\mathrm{Ca} 2+$ release units, impaired excitation-contraction coupling, and cardiac arrhythmias. Proc. Natl. Acad. Sci. U. S. A. 106 (18), 7636-7641. doi: 10.1073/pnas.0902919106

Coppini, R., Ferrantini, C., Mugelli, A., Poggesi, C., and Cerbai, E. (2018). Altered $\mathrm{Ca}(2+)$ and $\mathrm{Na}(+)$ homeostasis in human hypertrophic cardiomyopathy: implications for arrhythmogenesis. Front. Physiol. 9, 1391. doi: 10.3389/ fphys.2018.01391

Coumel, P. (1978). Catecholaminergic-induced severe ventricular arrhythmias with adams-Stokes syndrome in children: report of four cases. Br. Heart J. 40, $28-37$.

Crotti, L., Johnson, C. N., Graf, E., De Ferrari, G. M., Cuneo, B. F., Ovadia, M., et al. (2013). Calmodulin mutations associated with recurrent cardiac arrest in infants. Circulation 127 (9), 1009-1017. doi: 10.1161/CIRCULATIONAHA.112.001216

Damiano, B. P., and Rosen, M. R. (1984). Effects of pacing on triggered activity induced by early afterdepolarizations. Circulation 69 (5), 1013-1025. doi: 10.1161/ 01.cir.69.5.1013

Davidenko, J. M., Pertsov, A. V., Salomonsz, R., Baxter, W., and Jalife, J. (1992). Stationary and drifting spiral waves of excitation in isolated cardiac muscle. Nature 355 (6358), 349-351. doi: 10.1038/355349a0

De Ferrari, G. M., Viola, M. C., D'Amato, E., Antolini, R., and Forti, S. (1995). Distinct patterns of calcium transients during early and delayed afterdepolarizations induced by isoproterenol in ventricular myocytes. Circulation 91 (10), 2510-2515. doi: 10.1161/01.cir.91.10.2510

De Maziere, A. M., and Scheuermann, D. W. (1990). Structural changes in cardiac gap junctions after hypoxia and reoxygenation: a quantitative freeze-fracture analysis. Cell Tissue Res. 261 (1), 183-194. doi: 10.1007/bf00329451

Denegri, M., Avelino-Cruz, J. E., Boncompagni, S., De Simone, S. A., Auricchio, A., Villani, L., et al. (2012). Viral gene transfer rescues arrhythmogenic phenotype and ultrastructural abnormalities in adult calsequestrin-null mice with inherited arrhythmias. Circ. Res. 110 (5), 663-668. doi: 10.1161/ CIRCRESAHA.111.263939

Denegri, M., Bongianino, R., Lodola, F., Boncompagni, S., De Giusti, V. C., Avelino-Cruz, J. E., et al. (2014). Single delivery of an adeno-associated viral construct to transfer the CASQ2 gene to knock-in mice affected by catecholaminergic polymorphic ventricular tachycardia is able to cure the disease from birth to advanced age. Circulation 129 (25), 2673-2681. doi: 10.1161/CIRCULATIONAHA.113.006901

Denham, N. C., Pearman, C. M., Caldwell, J. L., Madders, G. W. P., Eisner, D. A., Trafford, A. W., et al. (2018). Calcium in the pathophysiology of atrial fibrillation and heart failure. Front. Physiol. 9, 1380. doi: 10.3389/ fphys.2018.01380

Devalla, H. D., Gelinas, R., Aburawi, E. H., Beqqali, A., Goyette, P., Freund, C., et al. (2016). TECRL, a new life-threatening inherited arrhythmia gene associated with overlapping clinical features of both LQTS and CPVT. EMBO Mol. Med. 8 (12), 1390-1408. doi: 10.15252/emmm.201505719

Dhein, S. (1998). Gap junction channels in the cardiovascular system: pharmacological and physiological modulation. Trends Pharmacol. Sci. 19 (6), 229-241. doi: 10.1016/s0165-6147(98)01192-4

di Bernardo, D., and Murray, A. (2002). Origin on the electrocardiogram of U-waves and abnormal U-wave inversion. Cardiovasc. Res. 53 (1), 202-208. doi: 10.1016/ s0008-6363(01)00439-4

Di Diego, J. M., and Antzelevitch, C. (1994). High [Ca2+]o-induced electrical heterogeneity and extrasystolic activity in isolated canine ventricular epicardium. Phase 2 reentry. Circulation 89 (4), 1839-1850. doi: 10.1161/ 01.cir.89.4.1839

Dong, M., Yan, S., Chen, Y., Niklewski, P. J., Sun, X., Chenault, K., et al. (2010). Role of the transient outward current in regulating mechanical properties of canine ventricular myocytes. J. Cardiovasc. Electrophysiol. 21 (6), 697-703. doi: 10.1111/ j.1540-8167.2009.01708.x

Duggal, P., Vesely, M. R., Wattanasirichaigoon, D., Villafane, J., Kaushik, V., and Beggs, A. H. (1998). Mutation of the gene for IsK associated with both jervell and lange-nielsen and romano-ward forms of long-QT syndrome. Circulation 97 (2), 142-146. doi: 10.1161/01.cir.97.2.142

Eisner, D. A., Choi, H. S., Diaz, M. E., O'Neill, S. C., and Trafford, A. W. (2000). Integrative analysis of calcium cycling in cardiac muscle. Circ. Res. 87 (12), 1087-1094. doi: 10.1161/01.res.87.12.1087 
Eisner, D. A., Li, Y., and O'Neill, S. C. (2006). Alternans of intracellular calcium: mechanism and significance. Heart Rhythm 3 (6), 743-745. doi: 10.1016/ j.hrthm.2005.12.020

Eisner, D. A., Caldwell, J. L., Kistamas, K., and Trafford, A. W. (2017). Calcium and excitation-contraction coupling in the heart. Circ. Res. 121 (2), 181-195. doi: $10.1161 /$ circresaha.117.310230

Eisner, D. A. (2018). Ups and downs of calcium in the heart. J. Physiol. 596 (1), 1930. doi: $10.1113 /$ jp275130

El-Sherif, N., and Turitto, G. (1999). The long QT syndrome and torsade de pointes. Pacing Clin. Electrophysiol. 22 (1 Pt 1), 91-110. doi: 10.1111/j.15408159.1999.tb00305.x

El-Sherif, N., and Turitto, G. (2011). Electrolyte disorders and arrhythmogenesis. Cardiol. J. 18 (3), 233-245.

el-Sherif, N., WB, G., RH, Z., and Hariman, R. (1985). Reentrant ventricular arrhythmias in the late myocardial infarction period. 12. spontaneous versus induced reentry and intramural versus epicardial circuits. J. Am. Coll. Cardiol. 6 (1), 124-132. doi: 10.1016/s0735-1097(85)80263-1

El-Sherif, N., Turitto, G., and Boutjdir, M. (2017). Congenital Long QT syndrome and torsade de pointes. Ann. Noninvasive Electrocardiol.: Off. J. Int. Soc. Holter Noninvasive Electrocardiol. Inc. 22 (6), e12481. doi: 10.1111/anec.12481

El-Sherif, N., Turitto, G., and Boutjdir, M. (2019). Acquired long QT syndrome and electrophysiology of torsade de pointes. Arrhythmia Electrophysiol. Rev. 8 (2), 122-130. doi: 10.15420/aer.2019.8.3

Eryol, N. K., Colak, R., Ozdogru, I., Tanriverdi, F., Unal, S., Topsakal, R., et al. (2003). Effects of calcium treatment on QT interval and QT dispersion in hypocalcemia. Am. J. Cardiol. 91 (6), 750-752. doi: 10.1016/s0002-9149(02) 03423-9

Faggioni, M., Kryshtal, D. O., and Knollmann, B. C. (2012). Calsequestrin mutations and catecholaminergic polymorphic ventricular tachycardia. Pediatr. Cardiol. 33 (6), 959-967. doi: 10.1007/s00246-012-0256-1

Ferrier, G. R., Saunders, J. H., and Mendez, C. (1973). A cellular mechanism for the generation of ventricular arrhythmias by acetylstrophanthidin. Circ. Res. 32 (5), 600-609. doi: 10.1161/01.res.32.5.600

Fink, M., and Noble, D. (2010). Pharmacodynamic effects in the cardiovascular system: the modeller's view. Basic Clin. Pharmacol. Toxicol. 106 (3), 243-249. doi: 10.1111/j.1742-7843.2009.00534.x

Firek, L., and Weingart, R. (1995). Modification of gap junction conductance by divalent cations and protons in neonatal rat heart cells. J. Mol. Cell. Cardiol. 27 (8), 1633-1643. doi: 10.1016/s0022-2828(95)90623-1

Gadsby, D. C., and Cranefield, P. F. (1977). Two levels of resting potential in cardiac Purkinje fibers. J. Gen. Physiol. 70 (6), 725-746. doi: 10.1085/ jgp.70.6.725

Garfinkel, A., Kim, Y. H., Voroshilovsky, O., Qu, Z., Kil, J. R., Lee, M. H., et al. (2000). Preventing ventricular fibrillation by flattening cardiac restitution. Proc. Natl. Acad. Sci. U. S. A. 97 (11), 6061-6066. doi: 10.1073/pnas.090492697

Garfinkel, A. (2007). Eight (or more) kinds of alternans. J. Electrocardiol. 40 (6 Suppl), S70-S74. doi: 10.1016/j.jelectrocard.2007.06.011

Garrey, W. E. (1914). The nature of fibrillary contraction of the heart.-its relation to tissue mass and form. Am. J. Physiology-Legacy Content 33 (3), 397-414. doi: 10.1152/ajplegacy.1914.33.3.397

George, C. H., Jundi, H., Thomas, N. L., Fry, D. L., and Lai, F. A. (2007). Ryanodine receptors and ventricular arrhythmias: emerging trends in mutations, mechanisms and therapies. J. Mol. Cell. Cardiol. 42 (1), 34-50. doi: 10.1016/j.yjmcc.2006.08.115

Goldhaber, J. I. (1996). Free radicals enhance $\mathrm{Na}+\mathrm{Ca} 2+$ exchange in ventricular myocytes. Am. J. Physiol. 271 (3 Pt 2), H823-H833. doi: 10.1152/ ajpheart.1996.271.3.H823

Gray, B., and Behr, E. R. (2016). New insights into the genetic basis of inherited arrhythmia syndromes. Circ. Cardiovasc. Genet. 9 (6), 569-577. doi: 10.1161/ CIRCGENETICS.116.001571

Gray, R. A., Jalife, J., Panfilov, A. V., Baxter, W. T., Cabo, C., Davidenko, J. M., et al. (1995). Mechanisms of cardiac fibrillation. Science 270 (5239), 1222-1223; author reply 4-5. doi: 10.1126/science.270.5239.1222

Greenstein, J. L., Wu, R., Po, S., Tomaselli, G. F., and Winslow, R. L. (2000). Role of the calcium-independent transient outward current I(tol) in shaping action potential morphology and duration. Circ. Res. 87 (11), 1026-1033. doi: 10.1161/ 01.res.87.11.1026
Greiser, M., Kerfant, B. G., Williams, G. S., Voigt, N., Harks, E., Dibb, K. M., et al. (2014). Tachycardia-induced silencing of subcellular $\mathrm{Ca} 2+$ signaling in atrial myocytes. J. Clin. Invest. 124 (11), 4759-4772. doi: 10.1172/ JCI70102

Greiser, M. (2017). Calcium signalling silencing in atrial fibrillation. J. Physiol. 595 (12), 4009-4017. doi: 10.1113/JP273045

Gussak, I., Antzelevitch, C., Hammill, S. C., Shen, W. K., and Bjerregaard, P. (2003). Cardiac Repolarization - Bridging Basic and Clinical Science. Contemporary Cardiology. (Totowa, New Jersey: Humana Press).

Haissaguerre, M., Derval, N., Sacher, F., Jesel, L., Deisenhofer, I., de Roy, L., et al. (2008). Sudden cardiac arrest associated with early repolarization. New Engl. J. Med. 358 (19), 2016-2023. doi: 10.1056/NEJMoa071968

Hayashi, M., Denjoy, I., Extramiana, F., Maltret, A., Buisson, N. R., Lupoglazoff, J. M., et al. (2009). Incidence and risk factors of arrhythmic events in catecholaminergic polymorphic ventricular tachycardia. Circulation 119 (18), 2426-2434. doi: 10.1161/ CIRCULATIONAHA.108.829267

Hegyi, B., Bers, D. M., and Bossuyt, J. (2019). CaMKII signaling in heart diseases: Emerging role in diabetic cardiomyopathy. J. Mol. Cell. Cardiol. 127, 246-259. doi: 10.1016/j.yjmcc.2019.01.001

Heijman, J., Voigt, N., Nattel, S., and Dobrev, D. (2014). Cellular and molecular electrophysiology of atrial fibrillation initiation, maintenance, and progression. Circ. Res. 114 (9), 1483-1499. doi: 10.1161/ CIRCRESAHA.114.302226

Hilliard, F. A., Steele, D. S., Laver, D., Yang, Z., Le Marchand, S. J., Chopra, N., et al. (2010). Flecainide inhibits arrhythmogenic Ca2+ waves by open state block of ryanodine receptor $\mathrm{Ca} 2+$ release channels and reduction of $\mathrm{Ca} 2+$ spark mass. J. Mol. Cell. Cardiol. 48 (2), 293-301. doi: 10.1016/ j.yjmcc.2009.10.005

Hoffman, B. F., and Rosen, M. R. (1981). Cellular mechanisms for cardiac arrhythmias. Circ. Res. 49 (1), 1-15. doi: 10.1161/01.res.49.1.1

Hopenfeld, B. (2006). Mechanism for action potential alternans: the interplay between L-type calcium current and transient outward current. Heart Rhythm 3 (3), 345-352. doi: 10.1016/j.hrthm.2005.11.016

Horvath, B., Banyasz, T., Jian, Z., Hegyi, B., Kistamas, K., Nanasi, P. P., et al. (2013). Dynamics of the late $\mathrm{Na}(+)$ current during cardiac action potential and its contribution to afterdepolarizations. J. Mol. Cell. Cardiol. 64, 59-68. doi: 10.1016/ j.yjmcc.2013.08.010

Horvath, B., Hegyi, B., Kistamas, K., Vaczi, K., Banyasz, T., Magyar, J., et al. (2015). Cytosolic calcium changes affect the incidence of early afterdepolarizations in canine ventricular myocytes. Can. J. Physiol. Pharmacol. 93 (7), 527-534. doi: 10.1139/cjpp2014-0511

Houle, T. D., Ram, M. L., and Cala, S. E. (2004). Calsequestrin mutant D307H exhibits depressed binding to its protein targets and a depressed response to calcium. Cardiovasc. Res. 64 (2), 227-233. doi: 10.1016/j.cardiores.2004.09.009

Hwang, H. S., Hasdemir, C., Laver, D., Mehra, D., Turhan, K., Faggioni, M., et al. (2011). Inhibition of cardiac Ca2 + release channels (RyR2) determines efficacy of class I antiarrhythmic drugs in catecholaminergic polymorphic ventricular tachycardia. Circ. Arrhythm. Electrophysiol. 4 (2), 128-135. doi: 10.1161/ CIRCEP.110.959916

Hwang, H. S., Baldo, M. P., Rodriguez, J. P., Faggioni, M., and Knollmann, B. C. (2019). Efficacy of flecainide in catecholaminergic polymorphic ventricular tachycardia is mutation-independent but reduced by calcium overload. Front. Physiol. 10, 992. doi: 10.3389/fphys.2019.00992

Ikeda, T., Uchida, T., Hough, D., Lee, J. J., Fishbein, M. C., Mandel, W. J., et al. (1996). Mechanism of spontaneous termination of functional reentry in isolated canine right atrium. Evidence for the presence of an excitable but nonexcited core. Circulation 94 (8), 1962-1973. doi: 10.1161/01.cir.94.8.1962

Ildarova, R., Shkolnikova, M. A., Kharlap, M., Bereznitskaya, V., and Kalinin, L. (2012). Sodium-channel blockers might contribute to the prevention of ventricular tachycardia in patients with long QT syndrome type 2: a description of 4 cases. J. Electrocardiol. 45 (3), 237-243. doi: 10.1016/ j.jelectrocard.2012.01.008

Jacobs, A., Knight, B. P., McDonald, K. T., and Burke, M. C. (2006). Verapamil decreases ventricular tachyarrhythmias in a patient with timothy syndrome (LQT8). Heart Rhythm 3 (8), 967-970. doi: 10.1016/j.hrthm.2006.04.024

Jalife, J., Delmar, M., Anumonwo, J., Berenfeld, O., and Kalifa, J. (2009). Basic mechanisms of cardiac arrhythmias. Basic Cardiac Electrophysiol. Clinician 2. 
January, C. T., and Riddle, J. M. (1989). Early afterdepolarizations: mechanism of induction and block. A role for L-type Ca2+ current. Circ. Res. 64 (5), 977-990. doi: 10.1161/01.res.64.5.977

Jensen, H. H., Brohus, M., Nyegaard, M., and Overgaard, M. T. (2018). Human calmodulin mutations. Front. Mol. Neurosci. 11, 396. doi: 10.3389/ fnmol.2018.00396

Jiang, D., Wang, R., Xiao, B., Kong, H., Hunt, D. J., Choi, P., et al. (2005). Enhanced store overload-induced $\mathrm{Ca} 2+$ release and channel sensitivity to luminal $\mathrm{Ca} 2+$ activation are common defects of RyR2 mutations linked to ventricular tachycardia and sudden death. Circ. Res. 97 (11), 1173-1181. doi: 10.1161/ 01.RES.0000192146.85173.4b

Jiang, D., Chen, W., Wang, R., Zhang, L., and Chen, S. R. (2007). Loss of luminal $\mathrm{Ca} 2+$ activation in the cardiac ryanodine receptor is associated with ventricular fibrillation and sudden death. Proc. Natl. Acad. Sci. U. S. A. 104 (46), 1830918314. doi: 10.1073/pnas.0706573104

Johnson, D. M., and Antoons, G. (2018). Arrhythmogenic mechanisms in heart failure: linking beta-adrenergic stimulation, stretch, and calcium. Front. Physiol. 9, 1453. doi: 10.3389/fphys.2018.01453

Jones, P. P., Jiang, D., Bolstad, J., Hunt, D. J., Zhang, L., Demaurex, N., et al. (2008). Endoplasmic reticulum $\mathrm{Ca} 2+$ measurements reveal that the cardiac ryanodine receptor mutations linked to cardiac arrhythmia and sudden death alter the threshold for store-overload-induced Ca2+ release. Biochem. J. 412 (1), 171-178. doi: $10.1042 / \mathrm{B} J 20071287$

Joung, B., Chen, P. S., and Lin, S. F. (2011). The role of the calcium and the voltage clocks in sinoatrial node dysfunction. Yonsei Med. J. 52 (2), 211-219. doi: 10.3349/ ymj.2011.52.2.211

Kandel, S. M., and Roth, B. J. (2015). The mechanism of reflection type reentry: a simulation study. J. Cardiovasc. Electrophysiol. 26 (12), 1370-1375. doi: 10.1111/ jce. 12815

Kang, J., Chen, X. L., Wang, H., Ji, J., Cheng, H., Incardona, J., et al. (2005). Discovery of a small molecule activator of the human ether-a-go-go-related gene (HERG) cardiac K + channel. Mol. Pharmacol. 67 (3), 827-836. doi: 10.1124/mol.104.006577

Kannankeril, P. J., Moore, J. P., Cerrone, M., Priori, S. G., Kertesz, N. J., Ro, P. S., et al. (2017). Efficacy of flecainide in the treatment of catecholaminergic polymorphic ventricular tachycardia: a randomized clinical trial. JAMA Cardiol. 2 (7), 759-766. doi: 10.1001/jamacardio.2017.1320

Karagueuzian, H. S., Pezhouman, A., Angelini, M., and Olcese, R. (2017). Enhanced late na and ca currents as effective antiarrhythmic drug targets. Front. Pharmacol. 8, 36. doi: 10.3389/fphar.2017.00036

Kashimura, T., Briston, S. J., Trafford, A. W., Napolitano, C., Priori, S. G., Eisner, D. A., et al. (2010). In the RyR2(R4496C) mouse model of CPVT, beta-adrenergic stimulation induces $\mathrm{Ca}$ waves by increasing SR Ca content and not by decreasing the threshold for Ca waves. Circ. Res. 107 (12), 1483-1489. doi: 10.1161/ CIRCRESAHA.110.227744

Kim, J. A., Lopes, C. M., Moss, A. J., McNitt, S., Barsheshet, A., Robinson, J. L., et al. (2010). Trigger-specific risk factors and response to therapy in long QT syndrome type 2. Heart Rhythm 7 (12), 1797-1805. doi: 10.1016/ j.hrthm.2010.09.011

Kirchhof, P., Benussi, S., Kotecha, D., Ahlsson, A., Atar, D. ,Casadei, B., et al. (2016). ESC Guidelines for the management of atrial fibrillation developed in collaboration with EACTS. Eur. J. Cardiothorac. Surg. 50 (5), el-e88. doi: 10.1093/ejcts/ezw313

Kistamas, K., Hegyi, B., Vaczi, K., Horvath, B., Banyasz, T., Magyar, J., et al. (2015a). Oxidative shift in tissue redox potential increases beat-to-beat variability of action potential duration. Can. J. Physiol. Pharmacol. 93 (7), 563-568. doi: 10.1139/cjpp-2014-0531

Kistamas, K., Szentandrassy, N., Hegyi, B., Vaczi, K., Ruzsnavszky, F., Horvath, B., et al. (2015b). Changes in intracellular calcium concentration influence beatto-beat variability of action potential duration in canine ventricular myocytes. J. Physiol. Pharmacol. 66 (1), 73-81.

Knollmann, B. C., Chopra, N., Hlaing, T., Akin, B., Yang, T., Ettensohn, K., et al. (2006). Casq2 deletion causes sarcoplasmic reticulum volume increase, premature $\mathrm{Ca} 2+$ release, and catecholaminergic polymorphic ventricular tachycardia. J. Clin. Invest. 116 (9), 2510-2520. doi: 10.1172/JCI29128

Kohomoto, O., Levi, A. J., and Bridge, J. H. (1994). Relation between reverse sodium-calcium exchange and sarcoplasmic reticulum calcium release in guinea pig ventricular cells. Circ. Res. 74 (3), 550-554. doi: 10.1161/ 01.res.74.3.550
Krause, U., Gravenhorst, V., Kriebel, T., Ruschewski, W., and Paul, T. (2011). A rare association of long QT syndrome and syndactyly: Timothy syndrome (LQT 8). Clin. Res. Cardiol. 100 (12), 1123-1127. doi: 10.1007/s00392-0110358-4

Lahat, H., Pras, E., Olender, T., Avidan, N., Ben-Asher, E., Man, O., et al. (2001). A missense mutation in a highly conserved region of CASQ2 is associated with autosomal recessive catecholamine-induced polymorphic ventricular tachycardia in Bedouin families from Israel. Am. J. Hum. Genet. 69 (6), 1378-1384. doi: 10.1086/324565

Laitinen, P. J., Brown, K. M., Piippo, K., Swan, H., Devaney, J. M., Brahmbhatt, B., et al. (2001). Mutations of the cardiac ryanodine receptor (RyR2) gene in familial polymorphic ventricular tachycardia. Circulation 103 (4), 485-490. doi: 10.1161/01.cir.103.4.485

Lakatta, E. G., and DiFrancesco, D. (2009). What keeps us ticking: a funny current, a calcium clock, or both? J. Mol. Cell. Cardiol. 47 (2), 157-170. doi: 10.1016/ j.yjmcc.2009.03.022

Lakatta, E. G., Maltsev, V. A., and Vinogradova, T. M. (2010). A coupled SYSTEM of intracellular $\mathrm{Ca} 2+$ clocks and surface membrane voltage clocks controls the timekeeping mechanism of the heart's pacemaker. Circ. Res. 106 (4), 659-673. doi: 10.1161/CIRCRESAHA.109.206078

Lakatta, E. G. (2010). A paradigm shift for the heart's pacemaker. Heart Rhythm 7 (4), 559-564. doi: 10.1016/j.hrthm.2009.12.013

Landstrom, A. P., Boczek, N. J., Ye, D., Miyake, C. Y., De la Uz, C. M., Allen, H. D., et al. (2016). Novel long QT syndrome-associated missense mutation, L762F, in CACNA1C-encoded L-type calcium channel imparts a slower inactivation tau and increased sustained and window current. Int. J. Cardiol. 220, 290-298. doi: 10.1016/j.ijcard.2016.06.081

Landstrom, A. P., Dobrev, D., and Wehrens, X. H. T. (2017). Calcium signaling and cardiac arrhythmias. Circ. Res. 120 (12), 1969-1993. doi: 10.1161/ CIRCRESAHA.117.310083

Lazrak, A., Peres, A., Giovannardi, S., and Peracchia, C. (1994). Ca-mediated and independent effects of arachidonic acid on gap junctions and Ca-independent effects of oleic acid and halothane. Biophys. J. 67 (3), 1052-1059. doi: 10.1016/ S0006-3495(94)80570-3

Lazzara, R. (1988). Electrophysiological mechanisms for ventricular arrhythmias. Clin. Cardiol. 11 (3 Suppl 2), II1-II4.

Lazzerini, P. E., Capecchi, P. L., and Laghi-Pasini, F. (2015). Long QT syndrome: an emerging role for inflammation and immunity. Front. Cardiovasc. Med. 2, 26. doi: $10.3389 /$ fcvm. 2015.00026

Leenhardt, A., Lucet, V., Denjoy, I., Grau, F., Ngoc, D. D., and Coumel, P. (1995). Catecholaminergic polymorphic ventricular tachycardia in children. A 7-year follow-up of 21 patients. Circulation 91 (5), 1512-1519. doi: 10.1161/ 01.cir.91.5.1512

Lehnart, S. E., Wehrens, X. H., Laitinen, P. J., Reiken, S. R., Deng, S. X., Cheng, Z., et al. (2004). Sudden death in familial polymorphic ventricular tachycardia associated with calcium release channel (ryanodine receptor) leak. Circulation 109 (25), 3208-3214. doi: 10.1161/01.CIR.0000132472.98675.EC

Li, Y., Diaz, M. E., Eisner, D. A., and O'Neill, S. (2009). The effects of membrane potential, SR Ca2+ content and RyR responsiveness on systolic Ca2+ alternans in rat ventricular myocytes. J. Physiol. 587 (Pt 6), 1283-1292. doi: 10.1113/ jphysiol.2008.164368

Limpitikul, W. B., Dick, I. E., Joshi-Mukherjee, R., Overgaard, M. T., George, A. L.Jr., and Yue, D. T. (2014). Calmodulin mutations associated with long QT syndrome prevent inactivation of cardiac L-type $\mathrm{Ca}(2+)$ currents and promote proarrhythmic behavior in ventricular myocytes. J. Mol. Cell. Cardiol. 74, 115-124. doi: 10.1016/j.yjmcc.2014.04.022

Lipp, P., and Niggli, E. (1994). Modulation of Ca2 + release in cultured neonatal rat cardiac myocytes. Insight from subcellular release patterns revealed by confocal microscopy. Circ. Res. 74 (5), 979-990. doi: 10.1161/01.res.74.5.979

Liu, D. W., and Antzelevitch, C. (1995). Characteristics of the delayed rectifier current (IKr and IKs) in canine ventricular epicardial, midmyocardial, and endocardial myocytes. a weaker IKs contributes to the longer action potential of the M cell. Circ. Res. 76 (3), 351-365. doi: 10.1161/01.res.76.3.351

Liu, N., Colombi, B., Memmi, M., Zissimopoulos, S., Rizzi, N., Negri, S., et al. (2006). Arrhythmogenesis in catecholaminergic polymorphic ventricular tachycardia: insights from a RyR2 R4496C knock-in mouse model. Circ. Res. 99 (3), 292-298. doi: 10.1161/01.RES.0000235869.50747.e1 
Liu, N., Rizzi, N., Boveri, L., and Priori, S. G. (2009). Ryanodine receptor and calsequestrin in arrhythmogenesis: what we have learnt from genetic diseases and transgenic mice. J. Mol. Cell. Cardiol. 46 (2), 149-159. doi: 10.1016/ j.yjmcc.2008.10.012

Liu, N., Ruan, Y., Denegri, M., Bachetti, T., Li, Y., Colombi, B., et al. (2011a). Calmodulin kinase II inhibition prevents arrhythmias in RyR2(R4496C+/-) mice with catecholaminergic polymorphic ventricular tachycardia. J. Mol. Cell. Cardiol. 50 (1), 214-222. doi: 10.1016/j.yjmcc.2010.10.001

Liu, N., Denegri, M., Ruan, Y., Avelino-Cruz, J. E., Perissi, A., Negri, S., et al. (2011b). Short communication: flecainide exerts an antiarrhythmic effect in a mouse model of catecholaminergic polymorphic ventricular tachycardia by increasing the threshold for triggered activity. Circ. Res. 109 (3), 291295. doi: 10.1161/CIRCRESAHA.111.247338

Liu, H., Chatel, S., Simard, C., Syam, N., Salle, L., Probst, V., et al. (2013). Molecular genetics and functional anomalies in a series of 248 Brugada cases with 11 mutations in the TRPM4 channel. PLoS One 8 (1), e54131. doi: 10.1371/journal.pone.0054131

Liu, W., Deng, J., Wang, G., Zhang, C., Luo, X., Yan, D., et al. (2014). KCNE2 modulates cardiac L-type $\mathrm{Ca}(2+)$ channel. J. Mol. Cell. Cardiol. 72, 208-218. doi: 10.1016/j.yjmcc.2014.03.013

Liu, M. B., de Lange, E., Garfinkel, A., Weiss, J. N., and Qu, Z. (2015). Delayed afterdepolarizations generate both triggers and a vulnerable substrate promoting reentry in cardiac tissue. Heart Rhythm 12 (10), 2115-2124. doi: 10.1016/j.hrthm.2015.06.019

Loughrey, C. M., Otani, N., Seidler, T., Craig, M. A., Matsuda, R., Kaneko, N., et al. (2007). K201 modulates excitation-contraction coupling and spontaneous Ca2+ release in normal adult rabbit ventricular cardiomyocytes. Cardiovasc. Res. 76 (2), 236-246. doi: 10.1016/j.cardiores.2007.06.014

Lu, Y., Mahaut-Smith, M. P., Huang, C. L., and Vandenberg, J. I. (2003). Mutant MiRP1 subunits modulate HERG $\mathrm{K}+$ channel gating: a mechanism for pro-arrhythmia in long QT syndrome type 6. J. Physiol. 551 (Pt 1), 253-262. doi: 10.1113/ jphysiol.2003.046045

Lukas, A., and Antzelevitch, C. (1996). Phase 2 reentry as a mechanism of initiation of circus movement reentry in canine epicardium exposed to simulated ischemia. Cardiovasc. Res. 32 (3), 593-603. doi: 10.1016/S00086363(96)00115-0

Lukyanenko, V., Subramanian, S., Gyorke, I., Wiesner, T. F., and Gyorke, S. (1999). The role of luminal $\mathrm{Ca} 2+$ in the generation of $\mathrm{Ca} 2+$ waves in rat ventricular myocytes. J. Physiol. 518 (Pt 1), 173-186. doi: 10.1111/j.14697793.1999.0173r.x

Magyar, J., Banyasz, T., Szentandrassy, N., Kistamas, K., Nanasi, P. P., and Satin, J. (2015). Role of gap junction channel in the development of beat-to-beat action potential repolarization variability and arrhythmias. Curr. Pharma. Des. 21 (8), 1042-1052. doi: 10.2174/1381612820666141029102443

Magyar, J., Kistamas, K., Vaczi, K., Hegyi, B., Horvath, B., Banyasz, T., et al. (2016). Concept of relative variability of cardiac action potential duration and its test under various experimental conditions. Gen. Physiol. Biophys. 35 (1), 55-62. doi: 10.4149/gpb_2015019

Mahajan, A., Shiferaw, Y., Sato, D., Baher, A., Olcese, R., Xie, L. H., et al. (2008). A rabbit ventricular action potential model replicating cardiac dynamics at rapid heart rates. Biophys. J. 94 (2), 392-410. doi: 10.1529/biophysj.106.98160

Maier, L. S., and Bers, D. M. (2007). Role of Ca2+/calmodulin-dependent protein kinase (CaMK) in excitation-contraction coupling in the heart. Cardiovasc. Res. 73 (4), 631-640. doi: 10.1016/j.cardiores.2006.11.005

Maltsev, V. A., Vinogradova, T. M., and Lakatta, E. G. (2006). The emergence of a general theory of the initiation and strength of the heartbeat. J. Pharmacol. Sci. 100 (5), 338-369. doi: 10.1254/jphs.cr0060018

Marsman, R. F., Barc, J., Beekman, L., Alders, M., Dooijes, D., van den Wijngaard, A., et al. (2014). A mutation in CALM1 encoding calmodulin in familial idiopathic ventricular fibrillation in childhood and adolescence. J. Am. Coll. Cardiol. 63 (3), 259-266. doi: 10.1016/j.jacc.2013.07.091

Maruyama, M., Joung, B., Tang, L., Shinohara, T., On, Y. K., Han, S., et al. (2010). Diastolic intracellular calcium-membrane voltage coupling gain and postshock arrhythmias: role of purkinje fibers and triggered activity. Circ. Res. 106 (2), 399-408. doi: 10.1161/CIRCRESAHA.109.211292

Mayer, A. G. (1906). Rhythmical Pulsation in Scyphomedusae (Washington DC: Carnegie Institution of Washington).
Mechmann, S., and Pott, L. (1986). Identification of Na-Ca exchange current in single cardiac myocytes. Nature 319 (6054), 597-599. doi: 10.1038/319597a0

Medeiros-Domingo, A., Kaku, T., Tester, D. J., Iturralde-Torres, P., Itty, A., Ye, B., et al. (2007). SCN4B-encoded sodium channel beta4 subunit in congenital long-QT syndrome. Circulation 116 (2), 134-142. doi: 10.1161/ CIRCULATIONAHA.106.659086

Meregalli, P. G., Wilde, A. A., and Tan, H. L. (2005). Pathophysiological mechanisms of Brugada syndrome: depolarization disorder, repolarization disorder, or more? Cardiovasc. Res. 67 (3), 367-378. doi: 10.1016/ j.cardiores.2005.03.005

Milberg, P., Ramtin, S., Monnig, G., Osada, N., Wasmer, K., Breithardt, G., et al. (2004). Comparison of the in vitro electrophysiologic and proarrhythmic effects of amiodarone and sotalol in a rabbit model of acute atrioventricular block. J. Cardiovasc. Pharmacol. 44 (3), 278-286. doi: 10.1097/ 01.fjc.0000129581.81508.78

Mines, G. R. (1913). On dynamic equilibrium in the heart. J. Physiol. 46 (4-5), 349-383. doi: 10.1113/jphysiol.1913.sp001596

Mines, G. R. (1914). On circulating excitations in heart muscle and their possible relation to tachycardia and fibrillation. Trans. $R$ Soc. Can. 8, 43-52.

Mitchell, R. D., Simmerman, H. K., and Jones, L. R. (1988). Ca2+ binding effects on protein conformation and protein interactions of canine cardiac calsequestrin. J. Biol. Chem. 263 (3), 1376-1381.

Miura, M., Ishide, N., Oda, H., Sakurai, M., Shinozaki, T., and Takishima, T. (1993). Spatial features of calcium transients during early and delayed afterdepolarizations. Am. J. Physiol. 265 (2 Pt 2), H439-H444. doi: 10.1152/ajpheart.1993.265.2.H439

Miura, M., Ishide, N., Numaguchi, H., and Takishima, T. (1995). Diversity of early afterdepolarizations in guinea pig myocytes: spatial characteristics of intracellular Ca2+ concentration. Heart Vessels 10 (5), 266-274. doi: 10.1007/BF01744906

Mohamed, U., Gollob, M. H., Gow, R. M., and Krahn, A. D. (2006). Sudden cardiac death despite an implantable cardioverter-defibrillator in a young female with catecholaminergic ventricular tachycardia. Heart Rhythm 3 (12), 1486-1489. doi: 10.1016/j.hrthm.2006.08.018

Mohler, P. J., Splawski, I., Napolitano, C., Bottelli, G., Sharpe, L., Timothy, K., et al. (2004). A cardiac arrhythmia syndrome caused by loss of ankyrin-B function. Proc. Natl. Acad. Sci. U. S. A. 101 (24), 9137-9142. doi: 10.1073/pnas.0402546101

Mohler, P. J., Schott, J. J., Gramolini, A. O., Dilly, K. W., Guatimosim, S., duBell, W. H., et al. (2003). Ankyrin-B mutation causes type 4 long-QT cardiac arrhythmia and sudden cardiac death. Nature 421 (6923), 634-639. doi: 10.1038/nature01335

Morita, H., Morita, S. T., Nagase, S., Banba, K., Nishii, N., Tani, Y., et al. (2003). Ventricular arrhythmia induced by sodium channel blocker in patients with Brugada syndrome. J. Am. Coll. Cardiol. 42 (9), 1624-1631. doi: 10.1016/ j.jacc.2003.06.004

Moss, A. J., Zareba, W., Hall, W. J., Schwartz, P. J., Crampton, R. S., Benhorin, J., et al. (2000). Effectiveness and limitations of beta-blocker therapy in congenital long-QT syndrome. Circulation 101 (6), 616-623. doi: 10.1161/ 01.cir.101.6.616

Moss, A. J., Windle, J. R., Hall, W. J., Zareba, W., Robinson, J. L., McNitt, S., et al. (2005). Safety and efficacy of flecainide in subjects with Long QT-3 syndrome (DeltaKPQ mutation): a randomized, double-blind, placebo-controlled clinical trial. Ann. Noninvasive Electrocardiol. 10 (4 Suppl), 59-66. doi: 10.1111/j.1542474X.2005.00077.x

Moss, A. J., Zareba, W., Schwarz, K. Q., Rosero, S., McNitt, S., and Robinson, J. L. (2008). Ranolazine shortens repolarization in patients with sustained inward sodium current due to type-3 long-QT syndrome. J. Cardiovasc. Electrophysiol. 19 (12), 1289-1293. doi: 10.1111/j.1540-8167.2008.01246.x

Nanasi, P. P., Magyar, J., Varro, A., and Ordog, B. (2017). Beat-to-beat variability of cardiac action potential duration: underlying mechanism and clinical implications. Can. J. Physiol. Pharmacol. 95 (10), 1230-1235. doi: 10.1139/ cjpp-2016-0597

Nattel, S., and Dobrev, D. (2016). Electrophysiological and molecular mechanisms of paroxysmal atrial fibrillation. Nat. Rev. Cardiol. 13 (10), 575-590. doi: 10.1038/ nrcardio. 2016.118

Nawathe, P. A., Kryukova, Y., Oren, R. V., Milanesi, R., Clancy, C. E., Lu, J. T., et al. (2013). An LQTS6 MiRP1 mutation suppresses pacemaker current and is associated with sinus bradycardia. J. Cardiovasc. Electrophysiol. 24 (9), 1021-1027. doi: 10.1111/ jce. 12163 
Neef, S., Dybkova, N., Sossalla, S., Ort, K. R., Fluschnik, N., Neumann, K., et al. (2010). CaMKII-dependent diastolic SR Ca2+ leak and elevated diastolic Ca2+ levels in right atrial myocardium of patients with atrial fibrillation. Circ. Res. 106 (6), 1134-1144. doi: 10.1161/CIRCRESAHA.109.203836

Nolasco, J. B., and Dahlen, R. W. (1968). A graphic method for the study of alternation in cardiac action potentials. J. Appl. Physiol. 25 (2), 191-196. doi: 10.1152/ jappl.1968.25.2.191

Nyegaard, M., Overgaard, M. T., Sondergaard, M. T., Vranas, M., Behr, E. R., Hildebrandt, L. L., et al. (2012). Mutations in calmodulin cause ventricular tachycardia and sudden cardiac death. Am. J. Hum. Genet. 91 (4), 703-712. doi: 10.1016/j.ajhg.2012.08.015

Ohgo, T., Okamura, H., Noda, T., Satomi, K., Suyama, K., Kurita, T., et al. (2007). Acute and chronic management in patients with Brugada syndrome associated with electrical storm of ventricular fibrillation. Heart Rhythm 4 (6), 695-700. doi: 10.1016/j.hrthm.2007.02.014

Oosthoek, P. W., Viragh, S., Lamers, W. H., and Moorman, A. F. (1993). Immunohistochemical delineation of the conduction system. II: The atrioventricular node and Purkinje fibers. Circ. Res. 73 (3), 482-491. doi: 10.1161/ 01.res.73.3.482

Overend, C. L., Eisner, D. A., and O'Neill, S. C. (1997). The effect of tetracaine on spontaneous $\mathrm{Ca} 2+$ release and sarcoplasmic reticulum calcium content in rat ventricular myocytes. J. Physiol. 502 (Pt 3), 471-479. doi: 10.1111/j.14697793.1997.471bj.x

Pertsov, A. M., Davidenko, J. M., Salomonsz, R., Baxter, W. T., and Jalife, J. (1993). Spiral waves of excitation underlie reentrant activity in isolated cardiac muscle. Circ. Res. 72 (3), 631-650. doi: 10.1161/01.res.72.3.631

Pflaumer, A., and Davis, A. M. (2012). Guidelines for the diagnosis and management of catecholaminergic polymorphic ventricular tachycardia. Heart Lung Circ. 21 (2), 96-100. doi: 10.1016/j.hlc.2011.10.008

Picht, E., DeSantiago, J., Blatter, L. A., and Bers, D. M. (2006). Cardiac alternans do not rely on diastolic sarcoplasmic reticulum calcium content fluctuations. Circ. Res. 99 (7), 740-748. doi: 10.1161/01.RES.0000244002.88813.91

Plaster, N. M., Tawil, R., Tristani-Firouzi, M., Canun, S., Bendahhou, S., Tsunoda, A., et al. (2001). Mutations in Kir2.1 cause the developmental and episodic electrical phenotypes of Andersen's syndrome. Cell 105 (4), 511-519. doi: 10.1016/s00928674(01)00342-7

Pogwizd, S. M., Schlotthauer, K., Li, L., Yuan, W., and Bers, D. M. (2001). Arrhythmogenesis and contractile dysfunction in heart failure: Roles of sodium-calcium exchange, inward rectifier potassium current, and residual beta-adrenergic responsiveness. Circ. Res. 88 (11), 1159-1167. doi: 10.1161/ hh1101.091193

Postma, A. V., Denjoy, I., Kamblock, J., Alders, M., Lupoglazoff, J. M., Vaksmann, G., et al. (2005). Catecholaminergic polymorphic ventricular tachycardia: RYR2 mutations, bradycardia, and follow up of the patients. J. Med. Genet. 42 (11), 863-870. doi: 10.1136/jmg.2004.028993

Pott, C., Dechering, D. G., Reinke, F., Muszynski, A., Zellerhoff, S., Bittner, A., et al. (2011). Successful treatment of catecholaminergic polymorphic ventricular tachycardia with flecainide: a case report and review of the current literature. Europace 13 (6), 897-901. doi: 10.1093/europace/euq517

Priori, S. G., and Corr, P. B. (1990). Mechanisms underlying early and delayed afterdepolarizations induced by catecholamines. Am. J. Physiol. 258 (6 Pt 2), H1796-H1805. doi: 10.1152/ajpheart.1990.258.6.H1796

Priori, S. G., Napolitano, C., Tiso, N., Memmi, M., Vignati, G., Bloise, R., et al. (2001). Mutations in the cardiac ryanodine receptor gene (hRyR2) underlie catecholaminergic polymorphic ventricular tachycardia. Circulation 103 (2), 196-200. doi: 10.1161/01.cir.103.2.196

Priori, S. G., Wilde, A. A., Horie, M., Cho, Y., Behr, E. R., Berul, C., et al. (2013). Executive summary: HRS/EHRA/APHRS expert consensus statement on the diagnosis and management of patients with inherited primary arrhythmia syndromes. Heart Rhythm 10 (12), e85-108. doi: 10.1016/j.hrthm.2013.07.021

Qi, X. Y., Yeh, Y. H., Xiao, L., Burstein, B., Maguy, A., Chartier, D., et al. (2008). Cellular signaling underlying atrial tachycardia remodeling of L-type calcium current. Circ. Res. 103 (8), 845-854. doi: 10.1161/CIRCRESAHA.108.175463

Qu, Z., and Weiss, J. N. (2015). Mechanisms of ventricular arrhythmias: from molecular fluctuations to electrical turbulence. Annu. Rev. Physiol. 77, 29-55. doi: 10.1146/annurev-physiol-021014-071622
Qu, Z., Shiferaw, Y., and Weiss, J. N. (2007). Nonlinear dynamics of cardiac excitation-contraction coupling: an iterated map study. Phys. Rev. E Stat. Nonlinear Soft Matter Phys. 75 (1 Pt 1), 011927. doi: 10.1103/PhysRevE.75.011927

Radwanski, P. B., Ho, H. T., Veeraraghavan, R., Brunello, L., Liu, B., Belevych, A. E., et al. (2016). Neuronal $\mathrm{Na}(+)$ channels are integral components of pro-arrhythmic $\mathrm{Na}$ $(+) / \mathrm{Ca}(2+)$ signaling nanodomain that promotes cardiac arrhythmias during betaadrenergic stimulation. JACC Basic to Trans. Sci. 1 (4), 251-266. doi: 10.1016/ j.jacbts.2016.04.004

Reid, D. S., Tynan, M., Braidwood, L., and Fitzgerald, G. R. (1975). Bidirectional tachycardia in a child. a study using his bundle electrography. Br. Heart J. 37 (3), 339-344. doi: 10.1136/hrt.37.3.339

Reiken, S., Gaburjakova, M., Guatimosim, S., Gomez, A. M., D'Armiento, J., Burkhoff, D., et al. (2003). Protein kinase a phosphorylation of the cardiac calcium release channel (ryanodine receptor) in normal and failing hearts. Role of phosphatases and response to isoproterenol. J. Biol. Chem. 278 (1), 444-453. doi: $10.1074 /$ jbc.M207028200

Ringer, S. (1883). A further contribution regarding the influence of the different constituents of the blood on the contraction of the heart. J. Physiol. 4 (1), 29-42. doi: 10.1113/jphysiol.1883.sp000120

Rizzi, N., Liu, N., Napolitano, C., Nori, A., Turcato, F., Colombi, B., et al. (2008), Unexpected structural and functional consequences of the R33Q homozygous mutation in cardiac calsequestrin: a complex arrhythmogenic cascade in a knock in mouse model. Circ. Res. 103 (3), 298-306. doi: 10.1161/ CIRCRESAHA.108.171660

Roden, D. M. (2004). Drug-induced prolongation of the QT interval. New Engl. J. Med. 350 (10), 1013-1022. doi: 10.1056/NEJMra032426

Roden, D. M. (2006). Long QT syndrome: reduced repolarization reserve and the genetic link. J. Internal Med. 259 (1), 59-69. doi: 10.1111/j.13652796.2005.01589.x

Rosen, M. R., Gelband, H., Merker, C., and Hoffman, B. F. (1973). Mechanisms of digitalis toxicity. effects of ouabain on phase four of canine Purkinje fiber transmembrane potentials. Circulation 47 (4), 681-689. doi: 10.1161/ 01.cir.47.4.681

Rosen, M. R., Wit, A. L., and Hoffman, B. F. (1975). Electrophysiology and pharmacology of cardiac arrhythmias. IV. Cardiac antiarrhythmic and toxic effects of digitalis. Am. Heart J. 89 (3), 391-399. doi: 10.1016/0002-8703(75) 90090-3

Rosenbaum, D. S., Jackson, L. E., Smith, J. M., Garan, H., Ruskin, J. N., and Cohen, R. J. (1994). Electrical alternans and vulnerability to ventricular arrhythmias. New Engl. J. Med. 330 (4), 235-241. doi: 10.1056/ NEJM199401273300402

Rosenthal, J. E. (1988). Reflected reentry in depolarized foci with variable conduction impairment in 1 day old infarcted canine cardiac tissue. J. Am. Coll. Cardiol. 12 (2), 404-411. doi: 10.1016/0735-1097(88)90413-5

Rosero, S. Z., Zareba, W., Robinson, J. L., and Moss, A. J. (1997). Gene-Specific Therapy for Long QT Syndrome. Ann. Noninvasive Electrocardiol. 2 (3), 274-278. doi: 10.1111/j.1542-474X.1997.tb00336.x

Rosso, R., Kalman, J. M., Rogowski, O., Diamant, S., Birger, A., Biner, S., et al. (2007). Calcium channel blockers and beta-blockers versus beta-blockers alone for preventing exercise-induced arrhythmias in catecholaminergic polymorphic ventricular tachycardia. Heart Rhythm 4 (9), 1149-1154. doi: 10.1016/j.hrthm.2007.05.017

Rosso, R., Kogan, E., Belhassen, B., Rozovski, U., Scheinman, M. M., Zeltser, D., et al. (2008). J-point elevation in survivors of primary ventricular fibrillation and matched control subjects: incidence and clinical significance. J. Am. Coll. Cardiol. 52 (15), 1231-1238. doi: 10.1016/j.jacc.2008.07.010

Rozanski, G. J., and Lipsius, S. L. (1985). Electrophysiology of functional subsidiary pacemakers in canine right atrium. Am. J. Physiol. 249 (3 Pt 2), H594-H603. doi: 10.1152/ajpheart.1985.249.3.H594

Sanguinetti, M. C., Jiang, C., Curran, M. E., and Keating, M. T. (1995). A mechanistic link between an inherited and an acquired cardiac arrhythmia: HERG encodes the IKr potassium channel. Cell 81 (2), 299-307. doi: 10.1016/ 0092-8674(95) $90340-2$

Sanguinetti, M. C., Curran, M. E., Zou, A., Shen, J., Spector, P. S., Atkinson, D. L., et al. (1996). Coassembly of K(V)LQT1 and minK (IsK) proteins to form cardiac I(Ks) potassium channel. Nature 384 (6604), 80-83. doi: 10.1038/384080a0 
Sato, D., Shiferaw, Y., Garfinkel, A., Weiss, J. N., Qu, Z., and Karma, A. (2006). Spatially discordant alternans in cardiac tissue: role of calcium cycling. Circ. Res. 99 (5), 520-527. doi: 10.1161/01.RES.0000240542.03986.e7

Saunders, J. H., Ferrier, G. R., and Moe, G. K. (1973). Conduction block associated with transient depolarizations induced by acetylstrophanthidin in isolated canine Purkinje fibers. Circ. Res. 32 (5), 610-617. doi: 10.1161/01.res.32.5.610

Schotten, U., Dobrev, D., Platonov, P. G., Kottkamp, H., and Hindricks, G. (2016). Current controversies in determining the main mechanisms of atrial fibrillation. J. Internal Med. 279 (5), 428-438. doi: 10.1111/joim.12492

Schwartz, P. J., Priori, S. G., Locati, E. H., Napolitano, C., Cantu, F., Towbin, J. A., et al. (1995). Long QT syndrome patients with mutations of the SCN5A and HERG genes have differential responses to $\mathrm{Na}+$ channel blockade and to increases in heart rate. Implications for gene-specific therapy. Circulation 92 (12), 3381-3386. doi: 10.1161/01.cir.92.12.3381

Schwartz, P. J., Crotti, L., and Insolia, R. (2012). Long-QT syndrome: from genetics to management. Circ. Arrhythmia Electrophysiol. 5 (4), 868-877. doi: 10.1161/ CIRCEP.111.962019

Shah, D. P., Baez-Escudero, J. L., Weisberg, I. L., Beshai, J. F., and Burke, M. C. (2012). Ranolazine safely decreases ventricular and atrial fibrillation in timothy syndrome (LQT8). Pacing Clin. Electrophysiol. 35 (3), e62-e64. doi: 10.1111/ j.1540-8159.2010.02913.x

Shamgar, L., Ma, L., Schmitt, N., Haitin, Y., Peretz, A., Wiener, R., et al. (2006). Calmodulin is essential for cardiac IKS channel gating and assembly: impaired function in long-QT mutations. Circ. Res. 98 (8), 1055-1063. doi: 10.1161/ 01.RES.0000218979.40770.69

Shan, J., Xie, W., Betzenhauser, M., Reiken, S., Chen, B. X., Wronska, A., et al. (2012). Calcium leak through ryanodine receptors leads to atrial fibrillation in 3 mouse models of catecholaminergic polymorphic ventricular tachycardia. Circ. Res. 111 (6), 708-717. doi: 10.1161/CIRCRESAHA.112.273342

Shiferaw, Y., Watanabe, M. A., Garfinkel, A., Weiss, J. N., and Karma, A. (2003). Model of intracellular calcium cycling in ventricular myocytes. Biophys. J. 85 (6), 3666-3686. doi: 10.1016/S0006-3495(03)74784-5

Shimizu, W., Kurita, T., Matsuo, K., Suyama, K., Aihara, N., Kamakura, S., et al. (1998). Improvement of repolarization abnormalities by a K+ channel opener in the LQT1 form of congenital long-QT syndrome. Circulation 97 (16), 1581-1588. doi: 10.1161/01.cir.97.16.1581

Shimizu, W., Antzelevitch, C., Suyama, K., Kurita, T., Taguchi, A., Aihara, N., et al. (2000). Effect of sodium channel blockers on ST segment, QRS duration, and corrected QT interval in patients with Brugada syndrome. J. Cardiovasc. Electrophysiol. 11 (12), 1320-1329. doi: 10.1046/j.1540-8167.2000.01320.x

Shkryl, V., Maxwell, J., Domeier, T., and Blatter, L. (2012). Refractoriness of sarcoplasmic reticulum $\mathrm{Ca} 2+$ release determines $\mathrm{Ca} 2+$ alternans in atrial myocytes. Am. J. Physiol. Heart Circ. Physiol. 302 (11), H2310-H2320. doi: 10.1152/ajpheart.00079.2012

Sicouri, S., and Antzelevitch, C. (2018). Mechanisms underlying the actions of antidepressant and antipsychotic drugs that cause sudden cardiac arrest. Arrhythmia Electrophysiol. Rev. 7 (3), 199-209. doi: 10.15420/ aer.2018.29.2

Simard, C., Hof, T., Keddache, Z., Launay, P., and Guinamard, R. (2013). The TRPM4 non-selective cation channel contributes to the mammalian atrial action potential. J. Mol. Cell. Cardiol. 59, 11-19. doi: 10.1016/j.yjmcc.2013.01.019

Sipido, K. R., Maes, M., and Van de Werf, F. (1997). Low efficiency of Ca2+ entry through the $\mathrm{Na}(+)-\mathrm{Ca} 2+$ exchanger as trigger for $\mathrm{Ca} 2+$ release from the sarcoplasmic reticulum. a comparison between L-type Ca2+ current and reverse-mode $\mathrm{Na}(+)-\mathrm{Ca} 2+$ exchange. Circ. Res. 81 (6), 1034-1044. doi: 10.1161/ 01.res.81.6.1034

Sipido, K. R., Bito, V., Antoons, G., Volders, P. G., and Vos, M. A. (2007). Na/Ca exchange and cardiac ventricular arrhythmias. Ann. N. Y. Acad. Sci. 1099, 339-348. doi: 10.1196/annals.1387.066

Sondergaard, M. T., Tian, X., Liu, Y., Wang, R., Chazin, W. J., Chen, S. R., et al. (2015). Arrhythmogenic calmodulin mutations affect the activation and termination of cardiac ryanodine receptor-mediated Ca2+ release. J. Biol. Chem. 290 (43), 26151-26162. doi: 10.1074/jbc.M115.676627

Sondergaard, M. T., Liu, Y., Larsen, K. T., Nani, A., Tian, X., Holt, C., et al. (2017). The Arrhythmogenic Calmodulin p.Phe142Leu mutation impairs c-domain $\mathrm{ca} 2+$ binding but not calmodulin-dependent inhibition of the cardiac ryanodine receptor. J. Biol. Chem. 292 (4), 1385-1395. doi: 10.1074/ jbc.M116.766253
Song, L., Alcalai, R., Arad, M., Wolf, C. M., Toka, O., Conner, D. A., et al. (2007). Calsequestrin 2 (CASQ2) mutations increase expression of calreticulin and ryanodine receptors, causing catecholaminergic polymorphic ventricular tachycardia. J. Clin. Invest. 117 (7), 1814-1823. doi: 10.1172/JCI31080

Sood, S., Chelu, M. G., van Oort, R. J., Skapura, D., Santonastasi, M., Dobrev, D., et al. (2008). Intracellular calcium leak due to FKBP12.6 deficiency in mice facilitates the inducibility of atrial fibrillation. Heart Rhythm 5 (7), 1047-1054. doi: 10.1016/j.hrthm.2008.03.030

Splawski, I., Tristani-Firouzi, M., Lehmann, M. H., Sanguinetti, M. C., and Keating, M. T. (1997). Mutations in the hminK gene cause long QT syndrome and suppress IKs function. Nat. Genet. 17 (3), 338-340. doi: 10.1038/ng1197-338

Splawski, I., Timothy, K. W., Sharpe, L. M., Decher, N., Kumar, P., Bloise, R., et al. (2004). Ca(V)1.2 calcium channel dysfunction causes a multisystem disorder including arrhythmia and autism. Cell 119 (1), 19-31. doi: 10.1016/ j.cell.2004.09.011

Suetomi, T., Yano, M., Uchinoumi, H., Fukuda, M., Hino, A., Ono, M., et al. (2011). Mutation-linked defective interdomain interactions within ryanodine receptor cause aberrant $\mathrm{Ca}(2)(+)$ release leading to catecholaminergic polymorphic ventricular tachycardia. Circulation 124 (6), 682-694. doi: 10.1161/ CIRCULATIONAHA.111.023259

Sumitomo, N., Nakamura, T., Fukuhara, J., Nakai, T., Watanabe, I., Mugishima, H., et al. (2010). Clinical effectiveness of pulmonary vein isolation for arrhythmic events in a patient with catecholaminergic polymorphic ventricular tachycardia. Heart Vessels 25 (5), 448-452. doi: 10.1007/s00380-009-1214-6

Sung, R. J., Wu, S. N., Wu, J. S., Chang, H. D., and Luo, C. H. (2006). Electrophysiological mechanisms of ventricular arrhythmias in relation to Andersen-Tawil syndrome under conditions of reduced IK1: a simulation study. Am. J. Physiol. Heart Circ. Physiol. 291 (6), H2597-H2605. doi: 10.1152/ajpheart.00393.2006

Surawicz, B. (1998). U wave: facts, hypotheses, misconceptions, and misnomers. J. Cardiovasc.Electrophysiol.9(10),1117-1128.doi:10.1111/j.1540-8167.1998.tb00890.x

Swan, H., Piippo, K., Viitasalo, M., Heikkila, P., Paavonen, T., Kainulainen, K., et al. (1999). Arrhythmic disorder mapped to chromosome 1q42-q43 causes malignant polymorphic ventricular tachycardia in structurally normal hearts. J. Am. Coll. Cardiol. 34 (7), 2035-2042. doi: 10.1016/s0735-1097(99)00461-1

Swan, H., Laitinen, P., Kontula, K., and Toivonen, L. (2005). Calcium channel antagonism reduces exercise-induced ventricular arrhythmias in catecholaminergic polymorphic ventricular tachycardia patients with RyR2 mutations. J. Cardiovasc. Electrophysiol. 16 (2), 162-166. doi: 10.1046/j.15408167.2005.40516.x

Szabo, B., Sweidan, R., Rajagopalan, C. V., and Lazzara, R. (1994). Role of Na+:Ca2+ exchange current in $\mathrm{Cs}(+)$-induced early afterdepolarizations in Purkinje fibers. $J$. Cardiovasc. Electrophysiol. 5 (11), 933-944. doi: 10.1111/j.15408167.1994.tb01133.x

Szabo, G., Szentandrassy, N., Biro, T., Toth, B. I., Czifra, G., Magyar, J., et al. (2005). Asymmetrical distribution of ion channels in canine and human leftventricular wall: epicardium versus midmyocardium. Pflugers Archiv. 450 (5), 307-316. doi: 10.1007/s00424-005-1445-z

Szabo, L., Szentandrassy, N., Kistamas, K., Hegyi, B., Ruzsnavszky, F., Vaczi, K., et al. (2013). Effects of tacrolimus on action potential configuration and transmembrane ion currents in canine ventricular cells. NaunynSchmiedeberg's Arch. Pharmacol. 386 (3), 239-246. doi: 10.1007/s00210-0120823-2

Szentandrassy, N., Kistamas, K., Hegyi, B., Horvath, B., Ruzsnavszky, F., Vaczi, K., et al. (2015). Contribution of ion currents to beat-to-beat variability of action potential duration in canine ventricular myocytes. Pflugers Archiv. 467 (7), 1431-1443. doi: 10.1007/s00424-014-1581-4

Takamatsu, T., and Wier, W. G. (1990). Calcium waves in mammalian heart: quantification of origin, magnitude, waveform, and velocity. FASEB J. 4 (5), 1519-1525. doi: 10.1096/fasebj.4.5.2307330

Terentyev, D., Nori, A., Santoro, M., Viatchenko-Karpinski, S., Kubalova, Z., Gyorke, I., et al. (2006). Abnormal interactions of calsequestrin with the ryanodine receptor calcium release channel complex linked to exerciseinduced sudden cardiac death. Circ. Res. 98 (9), 1151-1158. doi: 10.1161/ 01.RES.0000220647.93982.08

Thiel, W. H., Chen, B., Hund, T. J., Koval, O. M., Purohit, A., Song, L. S., et al. (2008). Proarrhythmic defects in Timothy syndrome require calmodulin kinase II. Circulation 118 (22), 2225-2234. doi: 10.1161/CIRCULATIONAHA.108.788067 
Thomsen, M. B., Verduyn, S. C., Stengl, M., Beekman, J. D., de Pater, G., van Opstal, J., et al. (2004). Increased short-term variability of repolarization predicts d-sotalol-induced torsades de pointes in dogs. Circulation 110 (16), 2453-2459. doi: 10.1161/01.CIR.0000145162.64183.C8

Trafford, A. W., Sibbring, G. C., Diaz, M. E., and Eisner, D. A. (2000). The effects of low concentrations of caffeine on spontaneous Ca release in isolated rat ventricular myocytes. Cell Calcium 28 (4), 269-276. doi: 10.1054/ ceca.2000.0156

Tse, G. (2016). Mechanisms of cardiac arrhythmias. J. Arrhythmia 32 (2), 75-81. doi: 10.1016/j.joa.2015.11.003

Uchinoumi, H., Yano, M., Suetomi, T., Ono, M., Xu, X., Tateishi, H., et al. (2010). Catecholaminergic polymorphic ventricular tachycardia is caused by mutationlinked defective conformational regulation of the ryanodine receptor. Circ. Res. 106 (8), 1413-1424. doi: 10.1161/CIRCRESAHA.109.209312

van der Werf, C., Kannankeril, P. J., Sacher, F., Krahn, A. D., Viskin, S., Leenhardt, A., et al. (2011). Flecainide therapy reduces exercise-induced ventricular arrhythmias in patients with catecholaminergic polymorphic ventricular tachycardia. J. Am. Coll. Cardiol. 57 (22), 2244-2254. doi: 10.1016/j.jacc.2011.01.026

Van Hemel, N. M., Swenne, C. A., De Bakker, J. M., Defauw, J. J., and Guiraudon, G. M. (1988). Epicardial reflection as a cause of incessant ventricular bigeminy. Pacing Clin. Electrophysiol. 11 (7), 1036-1044. doi: 10.1111/j.15408159.1988.tb03949.x

Vega, A. L., Tester, D. J., Ackerman, M. J., and Makielski, J. C. (2009). Protein kinase A-dependent biophysical phenotype for V227F-KCNJ2 mutation in catecholaminergic polymorphic ventricular tachycardia. Circ. Arrhythm. Electrophysiol. 2 (5), 540-547. doi: 10.1161/CIRCEP.109.872309

Venetucci, L. A., Trafford, A. W., Diaz, M. E., O'Neill, S. C., and Eisner, D. A. (2006). Reducing ryanodine receptor open probability as a means to abolish spontaneous $\mathrm{Ca} 2+$ release and increase $\mathrm{Ca} 2+$ transient amplitude in adult ventricular myocytes. Circ. Res. 98 (10), 1299-1305. doi: 10.1161/ 01.RES.0000222000.35500.65

Venetucci, L. A., Trafford, A. W., and Eisner, D. A. (2007). Increasing ryanodine receptor open probability alone does not produce arrhythmogenic calcium waves: threshold sarcoplasmic reticulum calcium content is required. Circ. Res. 100 (1), 105-111. doi: 10.1161/01.RES.0000252828.17939.00

Venetucci, L., Denegri, M., Napolitano, C., and Priori, S. G. (2012). Inherited calcium channelopathies in the pathophysiology of arrhythmias. Nat. Rev. Cardiol. 9 (10), 561-575. doi: 10.1038/nrcardio.2012.93

Vermeulen, J. T., McGuire, M. A., Opthof, T., Coronel, R., de Bakker, J. M., Klopping, C., et al. (1994). Triggered activity and automaticity in ventricular trabeculae of failing human and rabbit hearts. Cardiovasc. Res. 28 (10), 1547-1554. doi: 10.1093/ cvr/28.10.1547

Verrier, R. L., Klingenheben, T., Malik, M., El-Sherif, N., Exner, D. V., Hohnloser, S. H., et al. (2011). Microvolt T-wave alternans physiological basis, methods of measurement, and clinical utility-consensus guideline by international society for holter and noninvasive electrocardiology. J. Am. Coll. Cardiol. 58 (13), 1309-1324. doi: 10.1016/j.jacc.2011.06.029

Viatchenko-Karpinski, S., Terentyev, D., Gyorke, I., Terentyeva, R., Volpe, P., Priori, S. G., et al. (2004). Abnormal calcium signaling and sudden cardiac death associated with mutation of calsequestrin. Circ. Res. 94 (4), 471-477. doi: 10.1161/01.RES.0000115944.10681.EB

Vinogradova, T. M., Lyashkov, A. E., Zhu, W., Ruknudin, A. M., Sirenko, S., Yang, D., et al. (2006). High basal protein kinase a-dependent phosphorylation drives rhythmic internal Ca2+ store oscillations and spontaneous beating of cardiac pacemaker cells. Circ. Res. 98 (4), 505-514. doi: 10.1161/01.RES.0000204575.94040.d1

Voigt, N., Li, N., Wang, Q., Wang, W., Trafford, A. W., Abu-Taha, I., et al. (2012). Enhanced sarcoplasmic reticulum $\mathrm{Ca} 2+$ leak and increased $\mathrm{Na}+\mathrm{Ca} 2+$ exchanger function underlie delayed afterdepolarizations in patients with chronic atrial fibrillation. Circulation 125 (17), 2059-2070. doi: 10.1161/ CIRCULATIONAHA.111.067306

Volders, P. G., Kulcsar, A., Vos, M. A., Sipido, K. R., Wellens, H. J., Lazzara, R., et al. (1997). Similarities between early and delayed afterdepolarizations induced by isoproterenol in canine ventricular myocytes. Cardiovasc. Res. 34 (2), 348-359. doi: 10.1016/s0008-6363(96)00270-2

Volders, P. G., Vos, M. A., Szabo, B., Sipido, K. R., de Groot, S. H., Gorgels, A. P., et al. (2000). Progress in the understanding of cardiac early afterdepolarizations and torsades de pointes: time to revise current concepts. Cardiovasc. Res. 46 (3), 376-392. doi: 10.1016/s0008-6363(00)00022-5
Vukmir, R. B., and Stein, K. L. (1991). Torsades de pointes therapy with phenytoin. Ann. Emerg. Med. 20 (2), 198-200. doi: 10.1016/s0196-0644(05) 81223-5

Wang, Q., Shen, J., Splawski, I., Atkinson, D., Li, Z., Robinson, J. L., et al. (1995). SCN5A mutations associated with an inherited cardiac arrhythmia, long QT syndrome. Cell 80 (5), 805-811. doi: 10.1016/0092-8674(95)90359-3

Wang, S., Trumble, W. R., Liao, H., Wesson, C. R., Dunker, A. K., and Kang, C. H. (1998). Crystal structure of calsequestrin from rabbit skeletal muscle sarcoplasmic reticulum. Nat. Struct. Biol. 5 (6), 476-483. doi: 10.1038/nsb0698-476

Watanabe, H., Chopra, N., Laver, D., Hwang, H. S., Davies, S. S., Roach, D. E., et al. (2009). Flecainide prevents catecholaminergic polymorphic ventricular tachycardia in mice and humans. Nat. Med. 15 (4), 380-383. doi: 10.1038/nm.1942

Wegener, F. T., Ehrlich, J. R., and Hohnloser, S. H. (2008). Amiodarone-associated macroscopic T-wave alternans and torsade de pointes unmasking the inherited long QT syndrome. Europace 10 (1), 112-113. doi: 10.1093/europace/eum252

Weiss, J. N., Chen, P. S., Qu, Z., Karagueuzian, H. S., and Garfinkel, A. (2000). Ventricular fibrillation: how do we stop the waves from breaking? Circ. Res. 87 (12), 1103-1107. doi: 10.1161/01.res.87.12.1103

Weiss, J. N., Karma, A., Shiferaw, Y., Chen, P. S., Garfinkel, A., and Qu, Z. (2006). From pulsus to pulseless: the saga of cardiac alternans. Circ. Res. 98 (10), 12441253. doi: 10.1161/01.RES.0000224540.97431.f0

Weiss, J. N., Garfinkel, A., Karagueuzian, H. S., Nguyen, T. P., Olcese, R., Chen, P. S., et al. (2015). Perspective: a dynamics-based classification of ventricular arrhythmias. J. Mol. Cell. Cardiol. 82, 136-152. doi: 10.1016/j.yjmcc.2015.02.017

Wier, W. G., Cannell, M. B., Berlin, J. R., Marban, E., and Lederer, W. J. (1987). Cellular and subcellular heterogeneity of $[\mathrm{Ca} 2+] \mathrm{i}$ in single heart cells revealed by fura-2. Science 235 (4786), 325-328. doi: 10.1126/science.3798114

Wilders, R., and Verkerk, A. O. (2018). Long QT syndrome and sinus bradycardiaa mini review. Front. Cardiovasc. Med. 5, 106. doi: 10.3389/fcvm.2018.00106

Wit, A. L., and Cranefield, P. F. (1977). Triggered and automatic activity in the canine coronary sinus. Circ. Res. 41 (4), 434-445. doi: 10.1161/01.res.41.4.434

Wit, A. L., Hoffman, B. F., and Cranefield, P. F. (1972). Slow conduction and reentry in the ventricular conducting system. I. return extrasystole in canine purkinje fibers. Circ. Res. 30 (1), 1-10. doi: 10.1161/01.res.30.1.1

Wren, L. M., Jimenez-Jaimez, J., Al-Ghamdi, S., Al-Aama, J. Y., Bdeir, A., AlHassnan, Z. N., et al. (2019). Genetic mosaicism in calmodulinopathy. Circ. Genom. Precis. Med. 12 (9), 375-385. doi: 10.1161/CIRCGEN.119.002581

Wu, T. J., Lin, S. F., Weiss, J. N., Ting, C. T., and Chen, P. S. (2002). Two types of ventricular fibrillation in isolated rabbit hearts: importance of excitability and action potential duration restitution. Circulation 106 (14), 1859-1866. doi: 10.1161/ 01.cir.0000031334.49170.fb

Wu, G., Ai, T., Kim, J. J., Mohapatra, B., Xi, Y., Li, Z., et al. (2008). alpha-1-syntrophin mutation and the long-QT syndrome: a disease of sodium channel disruption. Circ. Arrhythmia Electrophysiol. 1 (3), 193-201. doi: 10.1161/CIRCEP.108.769224

Xie, L. H., Sato, D., Garfinkel, A., Qu, Z., and Weiss, J. N. (2008). Intracellular Ca alternans: coordinated regulation by sarcoplasmic reticulum release, uptake, and leak. Biophys. J. 95 (6), 3100-3110. doi: 10.1529/biophysj.108.130955

Xie, L. H., Chen, F., Karagueuzian, H. S., and Weiss, J. N. (2009). Oxidative-stressinduced afterdepolarizations and calmodulin kinase II signaling. Circ. Res. 104 (1), 79-86. doi: 10.1161/CIRCRESAHA.108.183475

Yamamoto, T., Yano, M., Xu, X., Uchinoumi, H., Tateishi, H., Mochizuki, M., et al. (2008). Identification of target domains of the cardiac ryanodine receptor to correct channel disorder in failing hearts. Circulation 117 (6), 762-772. doi: 10.1161/ CIRCULATIONAHA.107.718957

Yan, G. X., and Antzelevitch, C. (1999). Cellular basis for the Brugada syndrome and other mechanisms of arrhythmogenesis associated with ST-segment elevation. Circulation 100 (15), 1660-1666. doi: 10.1161/ 01.cir.100.15.1660

Yang, Y., Yang, Y., Liang, B., Liu, J., Li, J., Grunnet, M., et al. (2010). Identification of a Kir3.4 mutation in congenital long QT syndrome. Am. J. Hum. Genet. 86 (6), 872-880. doi: 10.1016/j.ajhg.2010.04.017

Yang, T., Chun, Y. W., Stroud, D. M., Mosley, J. D., Knollmann, B. C., Hong, C., et al. (2014). Screening for acute IKr block is insufficient to detect torsades de pointes liability: role of late sodium current. Circulation 130 (3), 224-234. doi: 10.1161/ CIRCULATIONAHA.113.007765

Yano, M., Yamamoto, T., Kobayashi, S., and Matsuzaki, M. (2009). Role of ryanodine receptor as a $\mathrm{Ca}(2)(+)$ regulatory center in normal and failing hearts. J. Cardiol. 53 (1), 1-7. doi: 10.1016/j.jjcc.2008.10.008 
Yarotskyy, V., Gao, G., Du, L., Ganapathi, S. B., Peterson, B. Z., and Elmslie, K. S. (2010). Roscovitine binds to novel L-channel (CaV1.2) sites that separately affect activation and inactivation. J. Biol. Chem. 285 (1), 43-53. doi: 10.1074/ jbc.M109.076448

Yazawa, M., Hsueh, B., Jia, X., Pasca, A. M., Bernstein, J. A., Hallmayer, J., et al. (2011). using induced pluripotent stem cells to investigate cardiac phenotypes in Timothy syndrome. Nature 471 (7337), 230-234. doi: 10.1038/nature09855

Zaza, A., Belardinelli, L., and Shryock, J. C. (2008). Pathophysiology and pharmacology of the cardiac "late sodium current." Pharmacol. Ther. 119 (3), 326-339. doi: 10.1016/j.pharmthera.2008.06.001

Zhou, Q., Xiao, J., Jiang, D., Wang, R., Vembaiyan, K., Wang, A., et al. (2011). Carvedilol and its new analogs suppress arrhythmogenic store overloadinduced Ca2+ release. Nat. Med. 17 (8), 1003-1009. doi: 10.1038/nm.2406

Zhu, Z. I., and Clancy, C. E. (2007). L-type Ca2+ channel mutations and T-wave alternans: a model study. Am. J. Physiol. Heart Circulatory Physiol. 293 (6), H3480-H3489. doi: 10.1152/ajpheart.00476.2007
Zygmunt, A. C., Eddlestone, G. T., Thomas, G. P., Nesterenko, V. V., and Antzelevitch, C. (2001). Larger late sodium conductance in M cells contributes to electrical heterogeneity in canine ventricle. Am. J. Physiol. Heart Circulatory Physiol. 281 (2), H689-H697. doi: 10.1152/ajpheart.2001.281.2.H689

Conflict of Interest: The authors declare that the research was conducted in the absence of any commercial or financial relationships that could be construed as a potential conflict of interest.

Copyright (c) 2020 Kistamás, Veress, Horváth, Bányász, Nánási and Eisner. This is an open-access article distributed under the terms of the Creative Commons Attribution License (CC BY). The use, distribution or reproduction in other forums is permitted, provided the original author(s) and the copyright owner(s) are credited and that the original publication in this journal is cited, in accordance with accepted academic practice. No use, distribution or reproduction is permitted which does not comply with these terms. 